\begin{abstract}
UNIVERSIDADE DE BRASÍLIA
FACULDADE GAMA / FACULDADE DE TECNOLOGIA PROGRAMA DE PÓS-GRADUAÇÃO EM INTEGRIDADE DE MATERIAIS DA ENGENHARIA
\end{abstract}

\title{
TERMOELASTICIDADE: UM ESTUDO VIA MÉTODO DOS ELEMENTOS DE CONTORNO, TERMOGRAFIA E CORRELAÇÃO DIGITAL DE IMAGENS
}

MATHEUS B. A. M. OBERG

ORIENTADORA: Prof ${ }^{a}$. Dra. Carla Tatiana Mota Anflor

DISSERTAÇÃO DE MESTRADO EM INTEGRIDADE DE MATERIAIS DA ENGENHARIA

PUBLICAÇÃO: $031 \mathrm{~A} / 2016$

BRASÍLIA/DF: 03 - 2016 


\section{UNIVERSIDADE DE BRASÍLIA \\ FACULDADE GAMA / FACULDADE DE TECNOLOGIA PROGRAMA DE PÓS-GRADUAÇÃO EM INTEGRIDADE DE MATERIAIS DA ENGENHARIA}

MATHEUS B. A. M. OBERG

TERMOELASTICIDADE: UM ESTUDO VIA MÉTODO DOS ELEMENTOS DE CONTORNO, TERMOGRAFIA E CORRELAÇÃO DIGITAL DE IMAGENS

DISSERTAÇÃO DE MESTRADO SUBMETIDA AO PROGRAMA DE PÓSGRADUAÇÃO EM INTEGRIDADE DE MATERIAIS DA ENGENHARIA DA FACULDADE GAMA E FACULDADE DE TECNOLOGIA DA UNIVERSIDADE DE BRASÍLIA, COMO PARTE DOS REQUISITOS NECESSÁRIOS PARA A OBTENÇÃO DO GRAU DE MESTRE EM INTEGRIDADE DE MATERIAIS DA ENGENHARIA. 


\section{UNIVERSIDADE DE BRASÍLIA \\ FACULDADE GAMA / FACULDADE DE TECNOLOGIA PROGRAMA DE PÓS-GRADUAÇÃO EM INTEGRIDADE DE MATERIAIS DA ENGENHARIA}

\section{TERMOELASTICIDADE: UM ESTUDO VIA MÉTODO DOS ELEMENTOS DE CONTORNO, TERMOGRAFIA E CORRELAÇÃO DIGITAL DE IMAGENS}

\section{MATHEUS B. A. M. OBERG}

DISSERTAÇÃO DE MESTRADO SUBMETIDA AO PROGRAMA DE PÓS-GRADUAÇÃO EM INTEGRIDADE DE MATERIAIS DA ENGENHARIA DA FACULDADE GAMA E FACULDADE DE TECNOLOGIA DA UNIVERSIDADE DE BRASÍLIA, COMO PARTE DOS REQUISITOS NECESSÁRIOS PARA A OBTENÇÃO DO GRAU DE MESTRE EM INTEGRIDADE DE MATERIAIS DA ENGENHARIA.

APROVADA POR:

Prof $^{a}$. Dra. Carla Tatiana Mota Anflor

(Orientadora)

Prof. Dr. Éder de Lima Albuquerque

(Examinador Interno)

Prof. Dr. Francisco Evangelista Júnior

(Examinador Externo) 


\section{FICHA CATALOGRÁFICA}

MATHEUS BARBOSA ANDRADE MOSER OBERG

TERMOELASTICIDADE: UM ESTUDO VIA MÉTODO DOS ELEMENTOS DE CONTORNO, TERMOGRAFIA E CORRELAÇÃO DIGITAL DE IMAGENS, [Distrito Federal] 2016.

$\mathrm{N}^{\mathrm{o}}$.p. 210 x $297 \mathrm{~mm}$ (FGA/FT/UnB, Mestre, Integridade de Materiais da Engenharia, ANO).

Dissertação de Mestrado - Universidade de Brasília. Faculdade UnB Gama. Programa de Pós-Graduação em Integridade de Materiais da Engenharia.

1. MÉTODO DOS ELEMENTOS DE CONTORNO

2. CORRELAÇÃO DIGITAL DE IMAGENS

3. IMAGENS TÉRMICAS

I. FGA/FT/UnB II. Título (série)

\section{REFERÊNCIA BIBLIOGRÁFICA}

OBERG, M. B. A. M. (2016). TERMOELASTICIDADE: UM ESTUDO VIA MÉTODO DOS ELEMENTOS DE CONTORNO, TERMOGRAFIA E CORRELAÇÃO DIGITAL DE IMAGENS. Dissertação de Mestrado em Integridade de Materiais da Integridade da Engenharia, Publicação 031A./ANO, Faculdade UnB Gama/FT/Universidade de Brasília, DF, 130.p.

\section{CESSÃO DE DIREITOS}

AUTOR: MATHEUS BARBOSA ANDRADE MOSER OBERG

TÍTULO: TERMOELASTICIDADE: UM ESTUDO VIA MÉTODO DOS ELEMENTOS DE CONTORNO, TERMOGRAFIA E CORRELAÇÃO DIGITAL DE IMAGENS

GRAU: Mestre ANO: 2016

É concedida à Universidade de Brasília permissão para reproduzir cópias desta dissertação de mestrado e para emprestar ou vender tais cópias somente para propósitos acadêmicos e científicos. $\mathrm{O}$ autor reserva outros direitos de publicação e nenhuma parte desta dissertação de mestrado pode ser reproduzida sem a autorização por escrito do autor.

MATHEUS BARBOSA ANDRADE MOSER OBERG

SHIS QI 21 CONJUNTO 8 CASA 5

CEP 71655280 Brasília, DF - Brasil.

Matheus.oberg@gmail.com 
Dedico este trabalho a todos com quem tive a oportunidade e o prazer de conviver durante a sua produção. 


\section{AGRADECIMENTOS}

Aos meus pais, Fausto e Miriam, por sempre me apoiarem em todas as minhas decisões. E também por toda paciência durante a bagunça que foi a produção deste trabalho. Muito obrigado, pai, por sempre me ajudar com meus projetos, por mais estranhos que pareçam. E muito obrigado, mãe, por toda compreensão e liberdade que me permitiram trabalhar no meu ritmo e horários malucos.

À minha namorada, Susu, por toda a ajuda que sempre me presta e, principalmente, por toda a paciência na reta final de produção do trabalho na qual tive que me dedicar em tempo praticamente integral às tarefas do mestrado. Tenho certeza que não conseguiria alcançar tudo que alcancei sem seu carinho e cuidado.

À minha orientadora, Profa. Dra. Carla Tatiana Mota Anflor, por mais uma vez, me apoiar na jornada do mundo acadêmico. Muito obrigado mesmo por todas as orientações e conversas que tem ajudado muito a iluminar o caminho que escolhi seguir. Muito obrigado por toda liberdade, dedicação e incentivo. Sempre será um grande exemplo para mim.

A todos os integrantes do GMEC, em especial ao Prof. Dr. Jhon Nero Vaz Goulart, Adrian, Niécio, Rolan e Tiago, que junto com a "Profe" Carla, contribuem sempre para o clima de união do grupo. Bom demais poder contar com vocês.

Fica registrado também um segundo agradecimento ao meu colega Rolan pela ajuda em todos os testes e experimentos com o CDI. Sua ajuda foi fundamental para a parte experimental deste trabalho.

Ao meu amigo, desde o ensino fundamental, Lucas Severo que me ensinou tudo que eu precisava saber de python para lidar com a comunicação do computador com o Arduino em apenas uma noite.

Ao meu colega Pedro Henrique, por ter me ensinado sobre o universo que é o controle com Arduino e pela força na hora de selecionar e montar os componentes do circuito da marcadora CNC.

À toda a comunidade do fórum oficial do Arduino, por partilharem sempre suas dúvidas e soluções. Um agradecimento especial aos membros do fórum PaulS, Grumpy_Mike e Robin2, cujos guias e códigos gentilmente cedidos foram cruciais para o meu entendimento do controle de motores de passos e servos via USB.

E a todos mais que de alguma forma contribuíram para a execução deste trabalho. Muito obrigado mesmo a todos vocês! 


\section{RESUMO}

Este trabalho apresenta um estudo numérico e experimental sobre termoelasticidade em regime permanente utilizando o método dos elementos de contorno (MEC) e técnicas de metrologia óptica. Na formulação termoelástica do MEC, o efeito das contribuições decorrentes do fenômeno termoelástico surge, naturalmente, na forma de uma integral de domínio. Visando preservar a característica principal do MEC, esta integral de domínio foi convertida a uma integral equivalente sobre o contorno utilizando o método da integração radial (MIR). Esta técnica de conversão, que consiste em uma abordagem puramente matemática, tem como requisito que o campo de temperaturas seja definido por meio de uma função matemática. Em grande parte dos problemas de engenharia, entretanto, esta informação é adquirida por meio de uma distribuição de valores pontuais de temperaturas. Desta forma, para aplicação do MIR, faz-se necessária a utilização de uma técnica de regressão para aproximação deste campo de temperaturas por uma função matemática que o descreva. Com o objetivo de avaliar a influência do tipo de regressão utilizada, foram elaborados uma montagem e um procedimento experimental para aquisição simultânea dos campos de temperaturas e de deslocamentos consequente. O campo de temperaturas é avaliado por meio de imagens térmicas, enquanto o campo de deslocamentos resultante é adquirido por correlação digital de imagens (CDI). Para assegurar a qualidade da análise por CDI, foi desenvolvido um equipamento de marcação CNC capaz de reproduzir de pontos, de distribuição gerada computacionalmente, sobre a superfície dos corpos de prova via impressão. A partir disto, foi construído um modelo numérico, reproduzindo as condições observadas experimentalmente, para análise via MEC com MIR. O campo de temperaturas foi aproximado por funções polinomiais de ordens bi quadrática, bi cúbica e bi quártica a fim de avaliar-se a sensibilidade do problema ao tipo de aproximação realizada. Por fim, comparando-se os campos de deslocamentos obtidos numericamente aos resultados experimentais observou-se uma boa concordância entre os resultados, independente do grau do polinômio utilizado na regressão.

Palavras-Chave: Método dos elementos de contorno; Correlação digital de imagens; Imagens térmicas. 


\begin{abstract}
This work presents a numerical and experimental study on steady-state thermoelasticity using the boundary elements method (BEM), digital image correlation (DIC) and thermal images. In the BEM formulation for thermoelasticity, the effect of the thermoelastic loads, naturally, rises as a domain integral. In order to preserve BEM's boundary only main characteristic this domain integral is converted into a boundary integral equivalent by the radial integration method (RIM). This technique, which consists in a purely mathematical approach, requires the temperature fields to be described as a function. However, in many engineering situations, this information is provided as a distribution of individual temperature values. In such situations, to successfully apply the MIR, it is necessary to use a regression technique to approach the temperature field by a mathematical function. In pursuance of evaluating the influence of the kind of regression applied, an experimental assembly was developed to acquire, simultaneously, the temperature field and the consequent displacement field field. The acquisition is performed by thermal images, while the resultant displacement field is obtained through DIC. To assure the quality of the DIC analysis, a CNC marking equipment was designed specifically to mark computer generated speckle patterns on the surfaces to be measured. After that, a numerical model was developed to reproduce the experimentally observed conditions for the BEM with RIM analysis. The experimental temperature field was approximated by three different kind of polynomial expressions: bi quadratic, bi cubic and bi quartic. In the end, the comparison between the numerical and the experimental displacement results showed good agreement regardless the type of polynomial regression used.
\end{abstract}

Keywords: Boundary element methods, Digital image correlation, thermal images. 


\section{LISTA DE FIGURAS}

3.1 - Domínio $\Omega$ e seu contorno $\Gamma$.

3.2 - Relações entre os sistemas cartesiano e polar de coordenadas.

3.3 - Contornos diferenciais polar ( $d S$ ) e real ( $d \Gamma$ ).

3.4 - Domínio circular $\Omega_{\gamma}$ com centro no ponto interno $\mathrm{p}$.

3.5 - Exemplo de discretização do contorno $\Gamma$ do domínio $\Omega$ em $\mathrm{N}_{\mathrm{e}}$ elementos de contorno quadráticos descontínuos.

3.6 - Exemplo de elemento de contorno quadrático descontínuo.

3.7 - Elemento quadrático descontínuo mapeado no espaço normalizado $\eta$.

3.8 - Interpretação gráfica das funções de forma conforme parábolas descritas.

4.1 - Exemplo de padrão de pontos sobre uma superfície.

4.2 - Efeito da amostragem e quantização em comparação a imagem contínua captada pelos sensores.

4.3 - Organização de pixels em malha.

4.4 - Exemplo de mapeamento aplicado à superfície preparada.

4.5 - Análise de uma RDI antes e após aplicada deformação.

5.1 - Estratégia para criação de padrões de superfície utilizada em Mazzoleni et al. (2015) [42].

5.2 - Estratégia proposta para geração de padrão de superfície para CDI.

5.3 - Sequência de criação de sub-regiões.

5.4 - Processo de posicionamento dos pontos circulares.

5.5 - Região limite para posicionamento dos centros dos pontos.

5.6 - Diagrama de funcionamento da rotina para criação dos padrões de pontos.

5.7 - Exemplo de rota de marcação gerada pelo programa de criação de padrões de pontos.

5.8 - Desenho esquemático do dispositivo marcador.

5.9 - Ciclo de trabalho do dispositivo marcador.

5.10 - Dispositivo de marcação montado no carro de impressão de uma impressora HP 840c.

5.11 - Detalhe da montagem do dispositivo de marcação no carro de impressão de uma impressora HP 840c.

5.12 - Montagem completa do equipamento de marcação de pontos CNC. 
5.13 - Vistas frontal (a) e lateral (b) da estrutura de travamentos em treliça adotada para aumentar a rigidez do conjunto.

5.14 - Placa Arduino Uno R3 e seus principais componentes.

5.15 - Esquema de um circuito de resistor pull-down.

5.16 - Estrutura do pacote de informações enviados ao Arduino.

5.17 - Diagrama esquemático da rotina desenvolvida para controle da marcação dos padrões de pontos.

6.1 - Esquema da montagem da placa de alumínio permitindo a aquisição simultânea das imagens térmicas e das imagens necessárias para análise por CDI.

6.2 - Encaixe entre a peça usinada para intermediar o contato entre a base do corpo de prova e a resistência utilizada.

6.3 - Circuito de alimentação da resistência de cartucho.

6.4 - Procedimento de marcação dos corpos de prova.

6.5 - Padrão de pontos resultante do processo de marcação.

6.6 - Montagem experimental antes da colocação do corpo de prova.

6.7 - Montagem experimental do ponto de vista da câmera térmica.

6.8 - Montagem experimental do ponto de vista do sistema de CDI.

6.9 - Imagem térmica do campo de temperatura em regime permanente.

6.10 - Distribuição de pontos físicos gerados pelo sistema de CDI.

6.11 - Campo experimental de deslocamentos na direção $\mathrm{X}_{1}$.

6.12 - Campo experimental de deslocamentos na direção $\mathrm{X}_{2}$.

6.13 - Campo experimental de deslocamentos resultantes.

6.14 - Determinação do ponto de ancoragem do corpo de prova.

7.1 - Modelo elaborado para reprodução das condições observadas experimentalmente.

7.2 - Distribuição dos valores pontuais de temperatura utilizados para a regressão polinomial.

7.3 - Superfície descrita pelo polinômio bi quadrático resultante do procedimento de regressão.

7.4 - Superfície descrita pelo polinômio bi cúbico resultante do procedimento de regressão.

7.5 - Superfície descrita pelo polinômio bi quártico resultante do procedimento de regressão. 
7.6 - Posicionamento das linhas para avaliação dos resultados numéricos. Dimensões em $\mathrm{mm}$.

7.7 - Deslocamentos numéricos $x$ experimentais na direção $x_{1}$ sobre as 3 linhas horizontais traçadas na figura 7.6. Dimensões em mm.

7.8 - Deslocamentos numéricos $x$ experimentais na direção $x_{2}$ sobre as 3 linhas horizontais traçadas na figura 7.6. Dimensões em $\mathrm{mm}$. 


\section{LISTA DE TABELAS}

7.1 - Coeficientes do polinômio: regressão bi quadrática. Intervalo de confiança: 95\%. 7.2 - Coeficientes do polinômio: regressão bi cúbica. Intervalo de confiança: 95\%. 7.3 - Coeficientes do polinômio: regressão bi quártica. Intervalo de confiança: 95\%. 7.4 - Erros máximos do deslocamento calculado na direção $x_{1}$ em cada linha para cada tipo de aproximação polinomial utilizada para aproximar o campo de temperaturas.

7.5 - Erros RMS do deslocamento calculado na direção $\mathrm{X}_{1}$ em cada linha para cada tipo de aproximação polinomial utilizada para aproximar o campo de temperaturas. 7.6 - Erros máximos do deslocamento calculado na direção $x_{2}$ em cada linha para cada tipo de aproximação polinomial utilizada para aproximar o campo de temperaturas.

7.7 - Erros RMS do deslocamento calculado na direção $x_{2}$ em cada linha para cada tipo de aproximação polinomial utilizada para aproximar o campo de temperaturas. 
LISTA DE ABREVIATURAS E SIGLAS

CCD

"Coupled charged device"

CDI

Correlação digital de imagens

$\mathrm{CNC}$

Comando numérico computadorizado

EIC

Equações integrais de contorno

EVR

Elemento de volume representativo

MEC

Método dos elementos de contorno

MEF

Método dos elementos finitos

MIR

Método da integração radial

MRD

Método da reciprocidade dual

MRM

Método das reciprocidades múltiplas

RDI

Região de interesse 


\section{LISTA DE SÍMBOLOS}

\section{Letras Latinas}

C

E

G

$J$

$\mathrm{k}$

$\mathrm{n}_{\mathrm{j}}$

$\mathrm{N}_{\mathrm{e}}$

p

q

$r$

$\mathrm{T}_{\mathrm{ij}}$

$t_{j}$

$U_{\mathrm{ij}}$

$\mathrm{u}_{\mathrm{j}}$

$x_{j}^{p}$

\section{Letras Gregas}

$\Gamma$

$\Delta$

$\varepsilon_{\mathrm{ij}}$

$\theta$

V

$\sigma_{i j}$

$\Phi_{j}^{\text {con }}$

$\Phi_{j}^{\text {des }}$

$\Omega$

$\delta$
Fator de forma utilizado na formulação do MEC

Módulo de elasticidade

Módulo de cisalhamento

Matriz Jacobiana utilizada na transformação $\left[\mathrm{x}_{1}, \mathrm{x}_{2}\right] \rightarrow \eta$

Coeficiente de expansão térmica linear

Versor normal

Número de elementos utilizados na discretização

Denota ponto fonte

Denota ponto campo

Distância entre o ponto fonte e o ponto campo

Solução fundamental para forças de superfície

Vetor de forças de superfícies

Solução fundamental para deslocamento

Vetor de deslocamentos lineares

Coordenadas do ponto fonte
Contorno do problema

Delta de dirac

Tensor de deformações

Temperatura

Coeficiente de Poisson

Tensor de tensões

Fatores de forma para elementos contínuos

Fatores de forma para elementos descontínuos

Domínio do problema

Delta de Kronecker 
1 INTRODUÇÃO

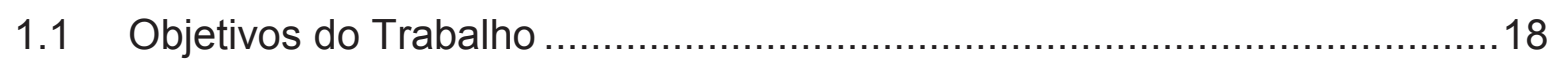

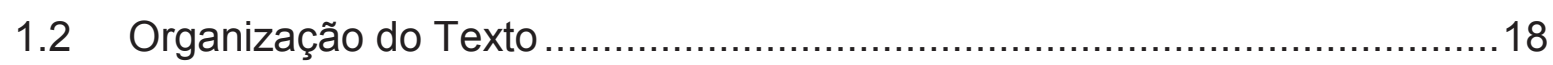

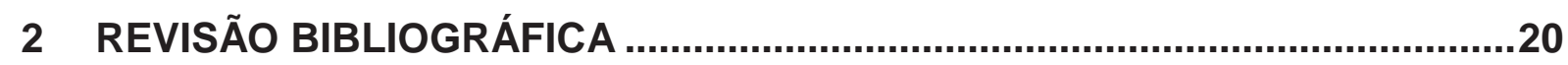

2.1 O Problema Térmoelástico com Elementos de Contorno …........................20

2.2 Conversão de Integrais de Domínio para o Contorno ...................................21

2.3 Análise Experimental com CDI e Imagens Térmicas ….............................23

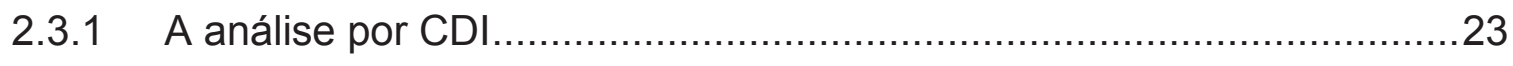

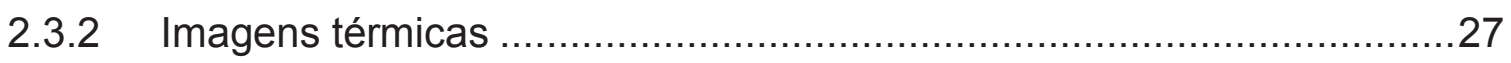

3 MÉTODO DOS ELEMENTOS DE CONTORNO EM TERMOELASTICIDADE..28

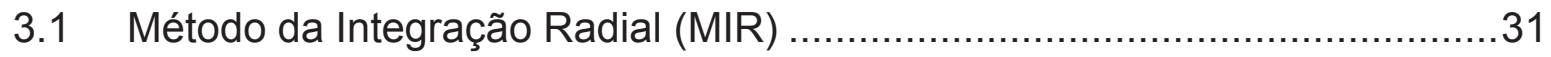

3.1.1 MIR aplicado à formulação integral para termoelasticidade ..................38

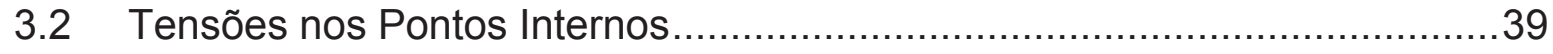

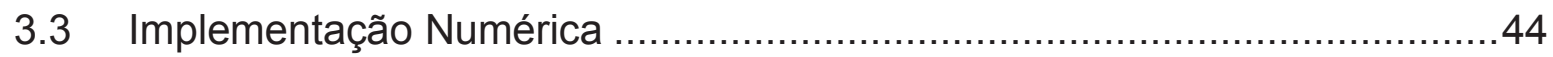

4 ANÁLISE POR CORRELAÇÃO DIGITAL DE IMAGENS .................................50

5 GERAÇÃO E APLICAÇÃO DE PADRÕES DE SUPERFÍCIE PARA CDI ........58

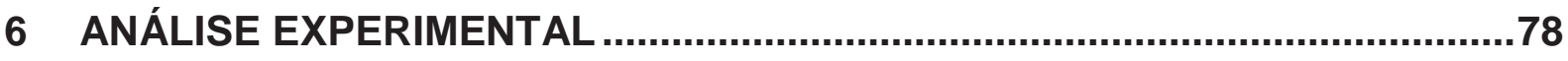

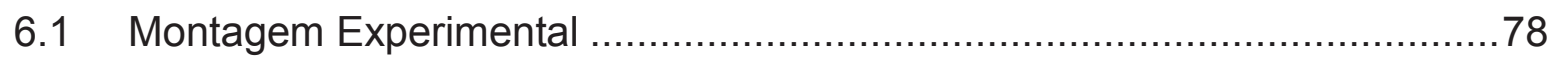

6.1.1 Materiais e equipamentos utilizados ..............................................

6.1.2 Construção do sistema de aquecimento .............................................80

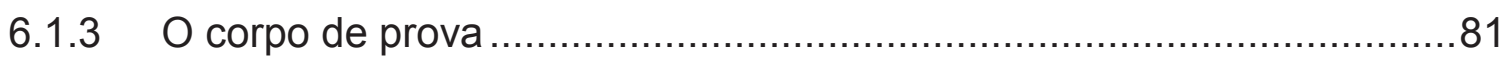

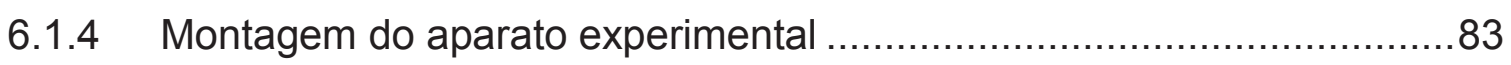

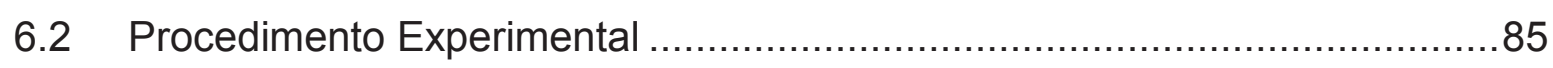

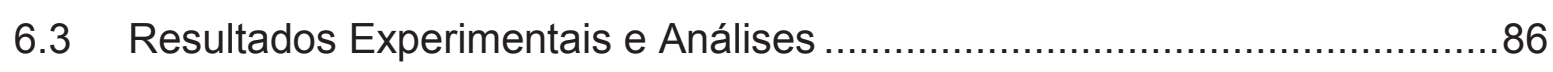

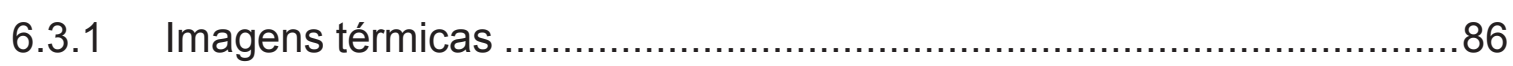

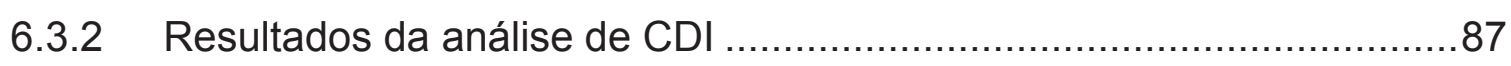

7 VERIFICAÇÃO DA METODOLOGIA NUMÉRICA...........................................

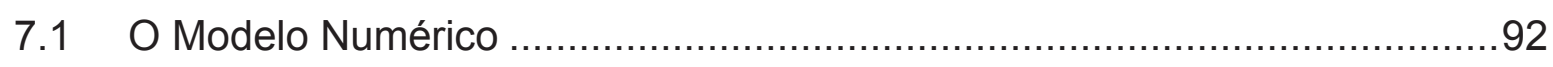

7.2 A Função que Aproxima o Campo de Temperaturas ………………….......93

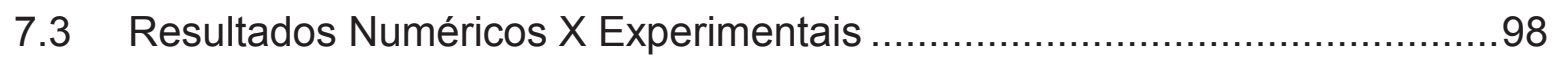

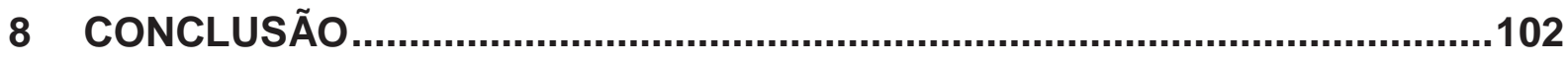

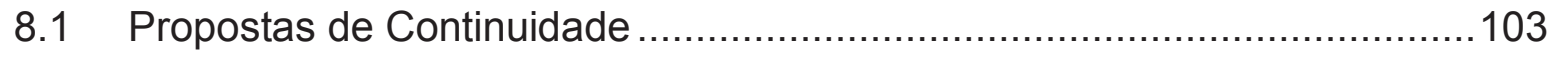

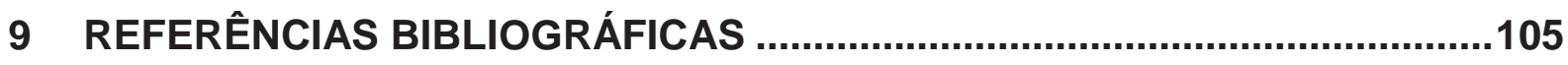





\section{INTRODUÇÃO}

O acelerado avanço tecnológico atual reflete-se no constante aumento da complexidade dos projetos de engenharia. Para viabilizar projetos cada vez mais eficientes e competitivos faz-se necessária a utilização de ferramentas computacionais adequadas. Problemas reais de engenharia geralmente envolvem complexos sistemas de esforços e solicitações. As ferramentas de modelagem computacional devem ser capazes de contabilizar todas as principais contribuições envolvidas a fim de manter uma maior fidelidade com o problema original. Essa fidelidade tem direta relação com a segurança e confiabilidade dos projetos.

Atualmente, uma grande quantidade de equipamentos, máquinas e até mesmo estruturas possuem componentes que trabalham submetidos a gradientes de temperatura que dão origem a tensões de natureza termoelástica. São exemplos: turbinas aeronáuticas, motores de combustão interna, discos de freio em protótipos de competição, usinas nucleares, ou mesmo estruturas metálicas expostas a um incêndio acidental, entre muitos outros. As tensões termoelásticas estão relacionadas a uma série de outros fenômenos de grande relevância para o meio da engenharia tais como a falha por fadiga e surgimento e a propagação de trincas além de outros fenômenos que comprometem a integridade estrutural de componentes. Falhas de projeto envolvendo esses fenômenos são historicamente relacionadas a acidentes com consequências catastróficas.

Diante da demanda atual por ferramentas de projeto eficientes e seguras, nos últimos anos, diferentes métodos computacionais têm sido desenvolvidos visando suprir soluções para os mais diversos tipos de problemas. Para o problema de termoelasticidade, dentre inúmeros métodos existentes, destacam-se, com maior utilização, o Método do Elementos Finitos (MEF) e o Método dos Elementos de Contorno (MEC).

O MEC caracteriza-se como um método para solução de problemas lineares regidos por equações diferenciais cuja formulação baseia-se na avaliação de integrais no contorno do domínio. Devido a este fato, a discretização do problema restringe-se exclusivamente ao contorno do domínio, no caso de um problema bidimensional, ou à sua superfície no caso tridimensional. Evita-se assim a necessidade de um domínio completamente discretizado, como no MEF. Essa menor discretização necessária, 
associada a técnicas de aceleração como o fast multipole, colabora para um aumento da eficiência computacional do método. Ainda em decorrência desta característica, as matrizes de solução encontradas no MEC são consideravelmente mais compactas que as encontradas no MEF, porém não simétricas e cheias. Apesar do MEC ser mais comumente aplicado na resolução de problemas lineares, existem formulações especiais para problemas não lineares, como o de plasticidade, o que amplia ainda mais o seu campo de aplicação.

O MEC vem sendo desenvolvido ao longo das três últimas décadas de maneira a abranger um leque cada vez maior de análises complexas com eficiência e precisão. Dada a sua importância para a engenharia, a solução do problema termoelástico com - MEC vem sendo tema de diversos trabalhos desde os anos iniciais de seu desenvolvimento. Neste sentido Sládek e Sládek (1983 e 1984) [1] e [2] exibe um estudo detalhado dividido em três partes sobre a formulação do MEC para termoelasticidade. Neste trabalho, as Equações Integrais de Contorno (EIC) são descritas em detalhes tanto para a teoria termoelástica acoplada mais geral quanto desacoplada com simplificações. Em Aliabadi (2002) [3], além das duas classificações utilizadas em Sládek e Sládek (1983 e 1984) [1] e [2], é ainda exibida uma terceira obtida de novas simplificações da teoria desacoplada. Nesta considera-se que que as cargas são colocadas de maneira bem lenta e que os processos difusivos estão completos, atingindo-se assim a condição de regime permanente.

Os efeitos térmicos causados por um campo de temperaturas imposto ao domínio, assim como outras forças de corpo atuantes no domínio como um todo, surgem naturalmente no problema na forma de integrais de domínio. Essas integrais podem ser diretamente avaliadas a partir de um esquema de integração por células, no qual é, porém, necessária uma discretização do interior do domínio. Isto aumenta consideravelmente o trabalho computacional necessário uma vez que essas quantidades discretizadas no interior do volume são avaliadas numericamente. Deste modo, a presença destas integrais de volume contraria a principal vantagem da utilização do MEC e relação a técnicas de domínio como o MEF. Diante deste fato ao longo do tempo foram desenvolvidas técnicas e estratégias para conversão dessas integrais de domínio para equivalentes sobre o contorno, preservando a efetividade do MEC.

Atualmente existem diversas técnicas consolidadas para conversão de integrais de domínio em integrais de contorno, que variam em aplicabilidade e complexidade 
conforme o caso a ser tratado. Dentre os métodos disponíveis, como mais utilizados, destacam-se: O emprego de integrais particulares, o método do vetor de Galerkin, o método da reciprocidade dual (MRD) e o método das reciprocidades múltiplas (MRM). Cada um desses métodos possui pontos fortes e fracos que determinam qual situação é mais adequada para suas aplicações.

Em Gao (2002) [4] é apresentada em detalhe uma técnica alternativa para a transformação de integrais de domínio em integrais de contorno. O Método da Integração Radial (MIR), como conhecido, utiliza tratamento puramente matemático capaz de converter qualquer tipo de integral de domínio para o contorno sem a necessidade de soluções particulares para o problema. Tal característica, associada à simplicidade de sua formulação, promove uma grande versatilidade na sua aplicação. Diferentemente do MRD, o MIR tem como limitação a necessidade de uma função que descreva a distribuição da força de corpo. Esta limitação pode ser contornada com relativa facilidade por meio da utilização de técnicas de regressão para aproximar essas distribuições de forças de corpo por funções polinomiais por exemplo. Diante disso, o MIR tem ganhado força recentemente figurando em diversos trabalhos a exemplo de Yang e Gao (2010) [5] e Yang et al. (2011) [6].

Em Gao (2003) [7] esta técnica é aplicada para a modelagem de problemas termoelásticos em regime permanente. Neste trabalho, a eficiência da formulação exclusiva ao contorno obtida é verificada através da comparação de seu desempenho computacional em relação a uma formulação equivalente que utiliza o método da integração por células. Além disso, o método é verificado com base em modelos analíticos conhecidos. Na etapa de verificação exibida neste trabalho são analisadas apenas campos de temperaturas já definidos por funções e cujos deslocamentos resultantes possuem solução analítica conhecida.

Em grande parte dos problemas de engenharia o campo de temperaturas é, entretanto, fornecido na forma de uma distribuição de temperaturas pontuais sobre a superfície do domínio em análise. Desta forma, faz-se necessária a utilização de uma ferramenta de regressão para obtenção de uma função cuja superfície descrita aproxime o campo formado pela distribuição de valores pontuais de temperaturas antes da utilização desta informação na formulação de termoelasticidade obtida com o MIR. Este procedimento de aproximação da distribuição de valores individuais por uma função acaba por introduzir uma nova possível fonte de erro à análise numérica proposta que deve, portanto, ser verificada. 
Sendo assim, este trabalho tem por objetivo principal a avaliação da metodologia de análise numérica para problemas termoelásticos utilizando a formulação do MEC com o MIR considerando uma distribuição de temperaturas inicialmente não definida por uma função. Para possibilitar esta avaliação, foram elaborados uma montagem e um procedimento experimental que possibilitam a aquisição simultânea do campo de temperaturas atuante sobre um corpo de prova aquecido e o seu consequente campo de deslocamentos. O campo de temperaturas resultante do aquecimento do corpo de prova é registrado via imagens térmicas enquanto o deslocamento no corpo de prova, provocado pelo aquecimento, é adquirido por meio de uma análise de correlação digital de imagens (CDI). A estratégia de aquisição simultânea dos dados utilizando imagens térmicas e CDI é utilizada também em Silva e Ravichandran (2011) [8] e em Bodelot et al. (2009) [9].

A análise por CDI é uma técnica de metrologia ótica capaz de fornecer informações acerca dos campos de deslocamentos e de deformações em superfícies com base no processamento digital de imagens da superfície em análise antes e após a aplicação do carregamento que resulta em sua deformação. Esta análise requer que a superfície a ser medida seja marcada com um padrão de pontos utilizados como referência para seu mapeamento. Conforme mostram diversos estudos, a exemplo de Pan et al. (2009) [10], Lecompte et al. (2006) [11] e Lecompte et al. (2006) [12], a qualidade do padrão de pontos marcados sobre a superfície tem influência considerável nos resultados da análise. As técnicas mais comuns utilizadas para produção destes padrões são a pintura direta com tinta spray ou utilizando aspersão de tinta com aerógrafo. Essas duas técnicas baseiam-se no comportamento aleatório resultante da interação das partículas de tinta com o fluxo de ar para geração das distribuições aleatórias de pontos sobre a superfície. Porém este mesmo comportamento aleatório inviabiliza o controle preciso de parâmetros importantes do padrão produzido tais quais o diâmetro resultante dos pontos e a sua distribuição efetiva sobre a superfície. Embora a geração computacional de padrões de pontos com parâmetros otimizados para análises por CDI seja tema de diversos trabalhos atuais, poucos abordam os aspectos práticos envolvidos na sua reprodução sobre a superfície a ser medida. Diante disso, neste trabalho é também proposta uma metodologia para geração computacional e reprodução dos padrões gerados computacionalmente sobre a superfícies a serem medidas. Neste sentido foi utilizado 
um equipamento de marcação de pontos do tipo comando numérico computadorizado $(\mathrm{CNC})$, desenvolvido especialmente para esta tarefa.

\subsection{Objetivos do Trabalho}

Diante do apresentado, este trabalho tem por objetivo a verificação experimental da formulação para termoelasticidade do MEC obtida por meio da aplicação do MIR para casos nos quais o campo de temperaturas sobre o domínio em análise é definido por um conjunto de valores pontuais de temperaturas. Neste sentido, este trabalho também como um de seus objetivos fundamentais a elaboração de uma metodologia experimental para avaliação do fenômeno termoelástico utilizando, para tal, a CDI e imagens térmicas de forma simultânea. Para que estes objetivos principais fossem alcançados de maneira adequada, alguns objetivos secundários também tiveram de ser cumpridos. São eles: A Elaboração de uma estratégia adequada para geração e aplicação de padrões de pontos em uma superfície para ensaios por CDI; E a avaliação da utilização de métodos de regressão polinomial para aproximação da distribuição pontual de valores de temperatura por uma função.

\subsection{Organização do Texto}

Os capítulos seguintes desta dissertação encontram-se organizados da seguinte maneira:

O Capítulo 2 apresenta a revisão bibliográfica que cita e apresenta, de maneira breve, os trabalhos utilizados como base produção desta dissertação, bem como os conceitos importantes abrangidos.

No capítulo 3 é descrita a formulação do MEC utilizada, demonstrando a aplicação do MIR para o problema de termoelasticidade. Além da formulação para o contorno e do próprio MIR, é apresentada também a formulação para cálculo das 
tensões nos pontos internos utilizando o MIR e um resumo acerca da implementação computacional do método.

O capítulo 4 contém uma explicação do funcionamento da análise por CDI, contando um pouco da história de seu desenvolvimento, do equipamento envolvido e das etapas que compõem a análise como um todo.

No capítulo 5 é apresentada a metodologia desenvolvida para solucionar os problemas de geração computacional de padrões de pontos para análises por CDI e da aplicação dos padrões gerados sobre as superfícies a serem medidas.

O capítulo 6 trata, em detalhes, da montagem e do procedimento experimental elaborados assim como dos resultados obtidos por meio destes.

No capítulo 7 é apresentada a metodologia utilizada para verificação do método numérico sob investigação. Neste capítulo é também abordado o procedimento para obtenção de funções que descrevam o campo de temperaturas com base na imagem térmica.

Por fim, os capítulos 8 e 9 contêm, nessa ordem, a conclusão deste trabalho e a listagem das referências bibliográficas empregada em seu desenvolvimento.

Ao fim do texto do trabalho seguem também, como apêndices, códigos computacionais desenvolvidos e detalhes do procedimento matemático utilizado no capítulo 7 para adequação das funções que descrevem os campos de temperaturas. 


\section{REVISÃO BIBLIOGRÁFICA}

\subsection{O Problema Termoelástico com Elementos de Contorno}

Como já comentado na introdução, o termoelástico foi provavelmente um dos primeiros problemas a serem adicionados ao repertório de soluções do MEC dada a sua importância para o meio da engenharia. Como descrito em Aliabadi (2002) [3], Katsikadelis (2002) [13] e Banerjee (1981) [14], o problema termoelástico pode ser dividido em três tipos principais: termoelasticidade acoplada, termoelasticidade desacoplada transiente e termoelasticidade em regime permanente.

A primeira destas formulações corresponde a uma versão completa, na qual são considerados os efeitos de geração de temperatura devido à tensão aplicada e efeitos temporais. A segunda formulação nasce de uma simplificação da primeira, desconsiderando os efeitos de geração de temperatura decorrente da aplicação de carga, uma vez que os efeitos deste fenômeno são desprezíveis para grande parte dos problemas de engenharia. Por fim, a formulação para termoelasticidade em regime permanente surge de uma nova simplificação da formulação para termoelasticidade desacoplada transiente. Agora deixam de ser considerados os termos transientes, isto é, com dependência temporal. Esta formulação simplificada se aplica para modelagem dos problemas termoelásticos nos quais o domínio sob análise já atingiu uma condição estável de temperatura de trabalho.

Em um trabalho dividido em três partes, Sládek e Sládek (1983 e 1984) [1] e [2] apresenta um trabalho completo acerca do desenvolvimento da formulação integral de contorno para os três tipos de problemas comentados, apresentando uma análise mais geral em Sládek e Sládek (1983) [1] e voltada para o problema desacoplado em Sládek e Sládek (1984) [2]. Os trabalhos de Cheng et al. (2001) [15] e Gao (2003) [7] focam-se na análise do problema termoelástico em regime permanente. A partir do desenvolvimento apresentado em ambos, nota-se que o termo responsável pelo efeito termoelástico surge naturalmente na formulação do MEC na forma de uma integral de domínio. A presença deste tipo de integral inviabiliza, a princípio, a principal característica do MEC que é a resolução do problema exclusivamente sobre o contorno. 


\subsection{Conversão de Integrais de Domínio para o Contorno}

A ação de cargas de domínio sobre um corpo, bastante comum a problemas de engenharia, surge naturalmente na formulação do MEC na forma de integrais de domínio. A presença desse tipo de integrais inviabiliza a principal característica do MEC que é a solução restrita ao contorno, tornando-o menos atrativo que outros métodos como o MEF. Diante disso, o estudo e desenvolvimento de técnicas para tratamento e conversão de integrais de domínio ao contorno, visando preservar os benefícios do MEC, tem origem quase que imediatamente após o surgimento do método. Um dos trabalhos que marcam o início do esforço pela busca de técnicas que tornem essa conversão possível é o de Cruse (1975) [16], no qual são apresentadas soluções para o problema de domínios submetidos a forças centrífugas.

Uma outra possível abordagem, proposta em Danson (1981) [16], baseia-se na utilização do Vetor de Galerkin e no teorema de Gauss-Green. Em seu trabalho são abordadas aplicações do método para forças de corpo gravitacionais e centrífugas, bem como uma possível abordagem para termoelasticidade. Este método é capaz de fornecer resultados precisos, porém sua aplicação limita-se a casos nos quais as funções das forças de corpo atuantes apresentam caráter linear ou mesmo constante.

Buscando um método mais abrangente para tratamento do problema da força de corpo arbitrária, Nardini e Brebbia (1982) [18] desenvolveram o Método da Reciprocidade Dual (MRD). Esta técnica baseia-se na aproximação de quantidades dos efeitos das forças de corpo por series finitas de funções de base, em geral, radiais. Essa transformação se dá a partir das soluções particulares do problema derivadas utilizando a função de base especificada. Este método é capaz de resolver uma elevada quantidade de problemas distintos e vem sendo ostensivamente utilizado em diversos trabalhos. Uma das vantagens do MRD é a possibilidade de impor-se valores de temperaturas pontuais distribuídos sobre o domínio, sem a necessidade de definir uma função de distribuição. Apesar disso, ainda apresenta alguns pontos negativos, como a dependência de soluções particulares. Além disso, funções de base radial, geralmente, utilizadas para as aproximações não são únicas e não há uma que adeque de maneira correta a todos os tipos de problemas. Uma aplicação do MRD para termoelasticidade é exibida em Cheng et al. (2001) [15], em meio a outras. 
O Método da Reciprocidade Múltipla (MRM), proposto em Nowak e Brebbia (1989) [19] surge como uma evolução da ideia do MRD. Este método teve a função original solucionar problemas envolvendo as equações de Helmholtz e Poisson, sendo posteriormente modificado em Neves e Brebbia (1991) [20] para solucionar as equações de Navier para elasticidade. Uma aplicação do BEM com o MRM na modelagem do problema termoelástico de um disco circular sujeitos a diferentes variações radiais de temperatura é apresentado em Neves e Brebbia (1992) [21]. Este método baseia-se na aproximação do integrando por uma sequência de soluções fundamentais de ordem superior permitindo sucessivas aplicações do teorema da reciprocidade. Esta sequência tem como limite uma formulação exclusivamente no contorno. O MRM demanda a definição do valor de uma constante associada à solução fundamental do deslocamento que tem impacto direto na solução do problema. A suposição de diferentes valores desta constante promove variações consideráveis no resultado final.

A utilização de integrais particulares também é uma opção que tem como maior atrativo a grande eficiência computacional, uma vez que se trata da transferência de integrais de domínio para o contorno de forma analítica. Entretanto a obtenção de expressões analíticas para o caso de elementos curvos quadráticos é uma tarefa de elevada complexidade, o que acaba limitando seu uso a elementos constantes e lineares.

Uma técnica alternativa para conversão de integrais de domínio em equivalentes sobre o contorno é apresentada em Gao (2002) [4]. Nomeada de MIR, esta técnica, baseia-se em uma transformação puramente matemática deduzida com base, principalmente em relações geométricas entre o domínio e o contorno. Desta forma esta técnica capaz de converter integrais de domínio dos mais variados tipos em equivalentes sobre o contorno com elevada precisão. Este método apresenta como principal limitação a necessidade de que as forças de corpo atuantes sobre o corpo sejam descritas na forma de uma função. É possível utilizar ferramentas de regressão para contornar este problema, aproximando forças de corpo conhecidas por distribuições pontuais. Entretanto, essa aproximação deve ser avaliada criteriosamente, já que pode resultar em uma possível fonte de erro para a análise.

Em Gao (2003) [7], o MIR é aplicado para a conversão do termo de domínio presente na formulação termoelástica do MEC para problemas em regime permanente. A sua eficiência computacional é verificada pela comparação de 
desempenho computacional entre o MEC com formulação para termoelasticidade baseada no MIR a uma formulação equivalente empregando a técnica de integração por células para solução com a integral de domínio.

Este método vem sendo empregado em diversos trabalhos recentes a exemplo de Yang e Gao (2010) [5], no qual o RIM é aplicado para a solução do problema termoelástico em regime transiente. E também em Yang et al. (2011) [6], onde o MIR é aplicado para resolução do problema de condução de calor em um domínio composto por diferentes coeficientes de condutibilidade.

\subsection{Análise Experimental com CDI e Imagens Térmicas}

A análise experimental apresentada neste trabalho se baseia em duas técnicas de metrologia óptica: Análise por CDI e por Análises térmicas. Estas duas técnicas já vêm sendo utilizadas em conjunto em trabalhos recentes para avaliação de fenômenos termoelástico, a exemplo de Silva e Ravichandran (2011) [8] e Bodelot et al. (2009) [9]. Em Silva e Ravichandran (2011) [8] é apresentada uma análise experimental do efeito termoelástico utilizando imagens infravermelhas e CDI porém utilizando um único equipamento capaz de realizar ambas as aquisições. Em uma abordagem mais próxima à empregada neste trabalho, Bodelot et al. (2009) [9], propôs uma montagem experimental para análise de um problema termoelástico utilizando uma câmera térmica separada do sistema de CDI. As leituras dos campos térmicos e de deslocamentos são realizadas na mesma superfície empregando, para tal, um "espelho filtro", também conhecido como espelho dicroico que permite a passagem de comprimentos de onda infravermelhos enquanto promove a reflexão dos demais. Sendo assim, posicionando este espelho de forma angulada entre a superfície da peça e a câmera térmica e posicionando o equipamento de correlação digital paralelo ao espelho é possível realizar ambas as medições simultaneamente.

\subsubsection{A análise por CDI}

A técnica de CDI é uma técnica de análise de deformação superficial baseada no processamento de imagens digitais da superfície em questão tomadas antes e após 
a sua deformação. Este método teve seu desenvolvimento inicial na década de 80 na Universidade da Carolina do Sul, Estados Unidos. O trabalho de Peters e Ranson (1982) [25] surge como uma alternativa à análise por interferometria, porém capaz de avaliar o campo de deslocamentos sobre uma superfície de forma mais direta por meio da avaliação do deslocamento de um padrão de pontos sobre ela marcado. No ano seguinte, Sutton et al. (1983) [26] apresenta uma evolução das ideias propostas em Peters e Ranson (1982) [25], consolidando a teoria apresentada anteriormente e apresentando uma rotina que descreve o funcionamento da análise por CDI. Neste trabalho é elaborada uma rotina automatizada para análises por CDI capaz de análises de deslocamentos a níveis sub-pixelares utilizando um procedimento de interpolação bi linear. Aplicações desta rotina para mecânica experimental são exibidas em Chu et al. (1985) [27]. Esforços em técnicas para análises sub-pixelares de deslocamento, como o apresentado em Scherier et al. (2000) [28] e Souza et al. (2012) [29], tem contribuído para um aumento considerável da precisão dos campos de deslocamentos obtidos via CDI.

Com o passar dos anos a técnica do CDI evoluiu sob diferentes nomenclaturas, porém sempre utilizando os mesmos princípios. Em Zhang et al. (1999) [30] uma abordagem equivalente à CDI é utilizada, com o nome de correlação digital de pontos, visando a determinação de propriedades mecânicas para espumas plásticas de poliuretano. Este mesmo nome é utilizado em Zhou e Goodson (2001) [31], no qual é proposta uma versão do mesmo método mais eficiente do ponto de vista computacional. Em Bay (1995) [32], é apresentada uma modificação do método de CDI voltado para análises biomédicas em ossos trabeculares. Neste trabalho, ao invés de uma superfície marcada, a análise de correlação é realizada com base nas irregularidades naturais observadas na superfície desse tipo de osso. Nos trabalhos de Chen et al. (1993) [33] e Gaudette et al. (2001) [34] é utilizado o nome de interferometria de pontos assistida por computador. Em Chen et al. (1993) [33] é discutida uma metodologia alternativa mais eficiente à CDI tradicional, empregando uma análise de correlação baseada em transformadas de Fourier. Já em Gaudette et al. (2001) [34], é exibida uma aplicação desta metodologia para medição da deformação da superfície cardíaca de coelhos. Apesar de diferirem entre si em alguns aspectos, as técnicas de análise de deformação exibidas nestes artigos seguem o mesmo princípio da CDI e tiveram considerável relevância em seu desenvolvimento. 
O artigo de Pan et al. (2009) [35] apresenta uma revisão detalhada da análise por CDI, reunindo e explicando os principais conceitos e procedimentos envolvidos. Juntando-se as informações contidas neste artigo às técnicas de processamento de imagem, explicadas em Gonzales e Woods (2002) [36], é possível um entendimento relativamente completo da metodologia empregada nas análises de CDI bidimensionais. De acordo com Pan et al. (2009) [35], a análise por CDI possui três etapas fundamentais: O preparo do corpo de prova; a aquisição das imagens; e o processamento das imagens adquiridas

O preparo do corpo de prova consiste na marcação do padrão de pontos a ser utilizado como referência para o procedimento de correlação. Neste assunto, por meio da análise comparativa entre diversos padrões de pontos sobre a superfície, Pan et al. (2009) [10] constatou que o padrão de pontos introduz um erro de natureza aleatória ao problema. Na mesma linha, Lecompte et al. (2007) [37] realizou um estudo acerca da influência do tamanho dos pontos nos resultados das análises por CDI. Nota-se de seus resultados que tanto erros aleatórios quanto sistemáticos podem surgir caso os pontos sejam muito pequenos ou muito grandes. Em Lecompte (2006) [11], é realizada uma análise numérica do erro associado tanto ao tamanho dos pontos utilizados no padrão quanto da área percentual que a sua distribuição ocupa sobre a superfície. Em seus resultados são apresentados intervalos tidos como ideais tanto para dimensionamento dos pontos e quanto para a porcentagem de área por estes ocupada. Este estudo, entretanto, restringe-se apenas ao caso de sub-regiões medindo $15 \times 15$ pixels. Desta forma, Lecompte (2006) [12] o complementa ao expandir a análise a subdivisões de outras dimensões. Diante da falta de um parâmetro definitivo para avaliação da qualidade do padrão de pontos, este continua sendo um tema recorrente em trabalhos atuais. Em Gu (2015) [38], por exemplo, é apresentada uma metodologia de avaliação numérica de dois modelos de padrões de pontos gerados computacionalmente. Porém por se tratar de uma análise puramente numérica, não são levados em consideração os aspectos práticos da aplicação do padrão de pontos sobre a superfície.

Neste sentido, Barranger et al. (2010) [39] exibe uma análise experimental comparativa sobre a influência do padrão de pontos, comparando três tipos de métodos para criação dos padrões, e do tipo de equipamento utilizado. Os métodos de aplicação de pontos utilizados foram a pintura com tinta em spray preta sobre fundo branco, pintura com tinta spray branca sobre fundo preto e uma técnica que usa a 
dispersão de partículas poliamida de $150 \mu \mathrm{m}$. Ambos os padrões pintados obtiveram resultados similares, enquanto a última técnica apresentou deslocamentos abaixo do esperado.

Na mesma linha, o trabalho de Crammond et al. (2013) [40] avaliou duas das mais utilizadas técnicas para geração e aplicação de padrões de pontos sobre superfícies a serem analisadas via CDI: Pintura com tinta em spray e pintura com aerógrafo. Seus resultados exibiram melhores resultados associados à pintura com aerógrafo, dada a melhor distribuição de pontos sobre a superfície. Porém, como constatado em Crammond et al. (2013) [40], tanto a técnica de pintura com tinta spray quanto a pintura com aerógrafo proporcionam pouco controle acerca de importantes propriedades do padrão como o tamanho dos pontos e sua distribuição sobre a superfície. Isto se deve ao comportamento aleatório resultante da interação das partículas de tinta com o jato de ar.

Visando contornar isso, Ghorbani et al. (2015) [41], utilizou pintura em spray auxiliada por um molde vazado com uma distribuição relativamente homogênea de pontos. Por se tratar de uma análise de uma parede de alvenaria de grandes dimensões, o molde vazado utilizado replicava pontos proporcionalmente maiores, o que acaba por facilitar a sua confecção. Para corpos de prova, entretanto, a produção do molde vazado pode se tornar, por si só, uma tarefa tão demorada quanto a marcação individual de cada ponto que compõe o padrão em questão.

Em vista disso, Mazzoleni et al. (2015) [42] propõe uma metodologia para aplicação de padrões de pontos gerados computacionalmente sobre as superfícies a serem medidas. Neste trabalho, utiliza-se um equipamento para marcação do tipo toner-termo-mecânico desenvolvido especialmente para esta tarefa. Além de possibilitar a impressão precisa de padrões gerados por computador, este método ainda dispõe da possibilidade de impressão de pontos de diversos tamanhos, aumentando sua versatilidade. Apesar de apresentar resultados comprovando sua eficácia, poucos detalhes de seu funcionamento são comentados.

Realizada a marcação do corpo de prova e adquiridas as imagens antes e após ocorrida a deformação, o passo final consiste no processamento digital das imagens e cálculo do campo de deslocamentos efetivo. Nesta etapa, o primeiro passo consiste na divisão da superfície marcada em diversas sub-regiões de mesmo tamanho. Como mostrado em Pan et al. (2008) [43], o tamanho dessas sub-regiões também influencia o resultado final da análise. Cada sub-região criada gera um ponto físico em seu 
centro, para os quais os deslocamentos são, de fato, calculados. A partir dos resultados de Pan et al. (2008) [43], nota-se que sub-regiões maiores, apesar de conferirem maior unicidade às sub-regiões e beneficiar para o processo de correlação, também diminuem a quantidade de pontos físicos e aumenta a distância entre esses. Isto acaba aumentando o erro relacionado ao processo de interpolação que estende essa análise a pontos não coincidentes com os pontos físicos. Desta forma, faz-se necessária a análise de trade-off ${ }^{1}$ para determinação do tamanho mínimo de subregião capaz de fornecer um resultado de correlação preciso para o sistema de CDI.

Após esta etapa, o próximo passo é a própria análise de correlação que consiste em identificar, nas imagens pós deformação, as sub-regiões obtidas no passo anterior. Comparando-se este posicionamento à imagem anterior ao deslocamento, finalmente calcula-se o deslocamento efetivo nos pontos físicos. A partir do deslocamento nesses pontos, o campo de deslocamento pode ser interpolado ao restante da superfície por meio de técnicas de interpolação, como as exibidas em Scherier et al (2000) [28], Souza et al. (2012) [29] e Sato (2009) [44].

\subsubsection{Imagens térmicas}

A técnica de imagens térmicas, assim como a CDI, tem por principal vantagem a obtenção de um campo de temperaturas atuante sobre toda a superfície mensurada. De maneira semelhante ao proposto neste trabalho, esta técnica foi utilizada por Dondero et al. (2011) [45] e Oberg (2013) [46] para verificação de metodologias baseadas no MEC. No caso do primeiro trabalho citado, as imagens térmicas são empregadas para verificação da condição de Elemento de Volume Representativo (EVR) para condutividade térmica efetiva, obtida numericamente para o caso de um material micro-poroso. Em Oberg (2013) [46] essa metodologia de análise é estendida para determinação da condição de EVR para casos de materiais de composição heterogênea. Com base nas informações contidas em ambos esses trabalhos foi possível a elaboração do procedimento experimental para aquisição adequada dos campos de temperaturas atuantes sobre a superfície de interesse do corpo de prova.

\footnotetext{
${ }^{1}$ Trade-off : expressão que define uma situação em que há conflito de escolhas.
} 


\section{MÉTODO DOS ELEMENTOS DE CONTORNO EM TERMOELASTICIDADE}

A formulação termoelástica em regime permanente pode ser utilizada para descrever uma grande variedade de problemas na engenharia. Sendo assim, sua formulação integral de contorno é presença recorrente em diversos trabalhos, podendo ser encontrada em detalhes em livros como Aliabadi (2002) [3], Banerjee (1981) [14] e Katsikadelis (2002) [13]. Partindo da consideração de um corpo homogêneo, como o ilustrado na figura 3.1, com relações constitutivas isotrópicas lineares, o fenômeno termoelástico em regime permanente é regido pelas equações de equilíbrio e de Laplace:

$$
\begin{gathered}
\sigma_{\mathrm{ij}, \mathrm{j}}(\mathrm{x})+\mathrm{b}_{\mathrm{i}}(\mathrm{x}) \quad \forall \mathrm{x} \in \Omega \\
\nabla^{2} \theta(\mathrm{x})=0 \quad \forall \mathrm{x} \in \Omega
\end{gathered}
$$

Onde $\theta$ representa o campo de temperatura agindo sobre o domínio.

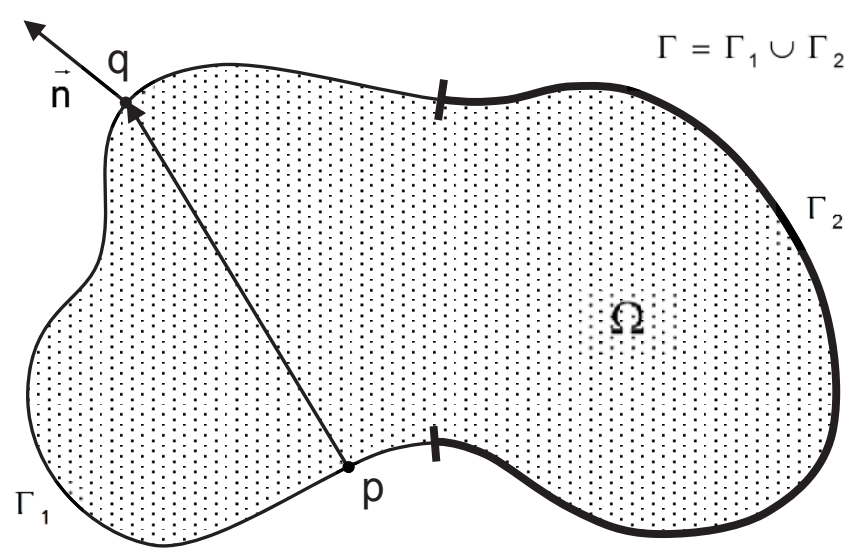

Figura 3.1 - Domínio $\Omega$ e seu contorno $\Gamma$.

Seguindo o desenvolvimento apresentado em Gao (2003) [7], um corpo submetido a uma carga térmica distribuída sofre uma expansão volumétrica pura além da deformação causada por seus carregamentos mecânicos. Deste modo, para casos assim, a relação entre tensão $(\sigma)$ e deformação $(\varepsilon)$ passa a ser descrita pela equação: 


$$
\varepsilon_{\mathrm{ij}}=\frac{1}{2 \mathrm{G}}\left\{\sigma_{\mathrm{ij}}-\frac{v}{1+v} \delta_{\mathrm{ij}} \sigma_{\mathrm{kk}}\right\}+\delta_{\mathrm{ij}} \mathrm{k} \theta
$$

Nesta equação, G corresponde ao módulo de cisalhamento, enquanto $V$ é o coeficiente de Poisson e k é o coeficiente de expansão térmica do material. Invertendo-se a relação descrita na equação (3.3), tem-se:

$$
\begin{gathered}
\sigma_{\mathrm{ij}}=2 \mathrm{G}\left\{\varepsilon_{\mathrm{ij}}+\frac{v \delta_{\mathrm{ij}} \varepsilon_{\mathrm{kk}}}{1-2 v}\right\}-\delta_{\mathrm{ij}} \tilde{\mathrm{k}} \theta \\
\mathrm{k}=\frac{2 \mathrm{G}(1+v) \mathrm{k}}{1-2 v}
\end{gathered}
$$

A equação (3.4) obtida é semelhante à equação de equilíbrio tipicamente apresentada em formulações do MEC para problemas de elasticidade com o termo de expansão térmica assumindo o papel de força de corpo. Sendo assim, seguindo o mesmo desenvolvimento, aplica-se o teorema da reciprocidade de Betti, detalhado em Aliabadi (2002) [3], resultando na relação de integrais:

$$
\int_{\Omega}\left(\sigma_{\mathrm{ij}} \varepsilon_{\mathrm{ij}}^{*}+\tilde{\mathrm{k}} \theta \varepsilon_{\mathrm{kk}}^{*}\right) \mathrm{d} \Omega=\int_{\Omega}\left(\sigma_{\mathrm{ij}}^{*} \varepsilon_{\mathrm{ij}}+\tilde{\mathrm{k}} \theta^{*} \varepsilon_{\mathrm{kk}}\right) \mathrm{d} \Omega
$$

Os valores com e sem sobrescrito representam dois estados independentes de tensão, deformação e temperatura para o domínio $\Omega$ limitado por seu contorno $\Gamma$. Continuando de acordo com Aliabadi (2002) [3], após certa manipulação matemática, a equação (3.6) pode ser reescrita como:

$$
\int_{\Omega} u_{k} \sigma_{k j, j}^{*} d \Gamma+\int_{\Omega} k \theta \varepsilon_{k k}^{*}=-\int_{\Gamma} t_{k} u_{k}^{*} d \Gamma+\int_{\Gamma} u_{k} t_{k}^{*} d \Gamma
$$

Onde u representa deslocamento. Considerando uma força pontual aplicada em um ponto X' do domínio, a tensão $\sigma_{\mathrm{kj}}^{*}$ deve ser tal que satisfaça a equação:

$$
\sigma_{\mathrm{kj}, \mathrm{j}}^{*}\left(\mathrm{X}^{\prime}, \mathrm{X}\right)+\Delta\left(\mathrm{X}^{\prime}, \mathrm{X}\right) \mathrm{e}_{\mathrm{k}}=0
$$


Sendo $e_{k}$ um vetor unitário que indica as direções da força pontual aplicada. Substituindo a equação (3.8) na equação (3.7), aplicando as propriedades da função delta de Dirac resulta em:

$$
\mathrm{u}_{\mathrm{j}}+\int_{\Gamma}\left(\mathrm{T}_{\mathrm{ij}} \mathrm{u}_{\mathrm{j}}-\mathrm{U}_{\mathrm{ij}} \mathrm{t}_{\mathrm{j}}\right) \mathrm{d} \Gamma=\int_{\Omega} \mathrm{U}_{\mathrm{ij,j}} \mathrm{k} \theta \mathrm{d} \Omega
$$

Nesta equação $U_{i j}$ e $T_{i j}$ correspondem, respectivamente às soluções fundamentais bidimensionais para deslocamento e força de superfície, descritas por:

$$
\begin{aligned}
& \mathrm{U}_{\mathrm{ij}}=\frac{1}{8 \pi(1-v) \mathrm{G}}\left[-(3-4) \delta_{\mathrm{ij}} \ln (\mathrm{r})+\mathrm{r}_{\mathrm{i}, \mathrm{r}}\right] \\
& \mathrm{T}_{\mathrm{ij}}=\frac{-1}{4 \pi \mathrm{r}(1-v)}\left\{\frac{\partial \mathrm{r}}{\partial \mathrm{n}}\left[(1-2 v) \delta_{\mathrm{ij}}+2 \mathrm{r}_{\mathrm{i}, \mathrm{r}, \mathrm{j}}\right]-(1-2 v)\left(\mathrm{r}_{;} \mathrm{n}_{\mathrm{j}}-\mathrm{r}_{j, \mathrm{i}} \mathrm{n}_{\mathrm{i}}\right)\right\}
\end{aligned}
$$

Para as quais considera-se $r$ como a distância entre os pontos de aplicação do carregamento pontual, ponto fonte, e o ponto em que seu efeito é medido, ponto campo.

A equação (3.9) tem validade apenas para pontos interiores ao domínio. Para estender a formulação ao contorno. Entretanto, a partir da aplicação das considerações apresentadas em Brebbia e Dominguez (1992) [23], é possível estender esta formulação ao contorno adicionando-se um novo termo multiplicando o primeiro termo do lado esquerdo da igualdade, $\mathrm{u}_{\mathrm{j}}$. Sendo assim, equação completa passa a ser:

$$
\mathrm{C}_{\mathrm{ij}} \mathrm{u}_{\mathrm{j}}+\int_{\Gamma}\left(\mathrm{T}_{\mathrm{ij}} \mathrm{u}_{\mathrm{j}}-\mathrm{U}_{\mathrm{ij}} \mathrm{t}_{\mathrm{j}}\right) \mathrm{d} \Gamma=\int_{\Omega} \mathrm{U}_{\mathrm{ij}, \mathrm{j}} \mathrm{k} \theta \mathrm{d} \Omega
$$

$\mathrm{Na}$ qual o termo $\mathrm{C}_{\mathrm{ij}}$ pode assumir três valores dependendo do posicionamento do ponto de fonte. Caso o ponto fonte esteja posicionado sobre um contorno suave, assume-se $\mathrm{c}_{\mathrm{ij}}=0.5 \delta_{\mathrm{ij}}$. Para os casos de pontos fontes posicionados no interior e no exterior do domínio, valem, respectivamente, $c_{i j}=\delta_{i j}$ e $c_{i j}=0$. 
A equação (3.12) se assemelha à equação integral de contorno para problemas de elasticidade com a presença de uma força de corpo. E, da mesma forma, a integral de domínio que descreve o efeito da carga térmica ainda deve ser convertida a uma integral equivalente de contorno para que seja evitada a necessidade da discretização do interior do domínio do problema. Neste momento, entra em ação o método da integração radial (MIR).

\subsection{Método da Integração Radial (MIR)}

Detalhado em Gao (2002) [4], o MIR surge como uma alternativa para conversão de integrais de domínio em integrais de contorno equivalentes. Este método vale-se de uma abordagem exclusivamente matemática, podendo ser aplicado a qualquer integral de domínio. Quando aplicado a integrais de domínio compostas por funções com variáveis conhecidas, a exemplo de um campo de temperaturas medido experimentalmente, o RIM é capaz de fornecer uma transformação precisa. Já para casos envolvendo funções com variáveis desconhecidas, como exibido em Gao (2002) [4], o RIM pode ser utilizado em conjunto com funções de base radial para aproximar os valores desconhecidos assim como realizado no MRD.

Dado o contexto bidimensional e o desenvolvimento apresentado em Gao (2002) [4], considera-se inicialmente um domínio $2 \mathrm{D}(\Omega)$ limitado por um contorno fechado $(\Gamma)$ como o exibido da figura 3.1.

Integrais de domínio que surgem diante da presença de cargas de domínio, geralmente, são da forma:

$$
\iint_{\Omega} f\left(x_{1}, x_{2}\right) d \Omega
$$

A presença dessas integrais nesta forma contraria a proposta do MEC, no qual o problema é tratado inteiramente no contorno, evitando a necessidade de discretização do domínio.

Visando a conversão destas integrais para o contorno, considera-se agora apenas um segmento infinitesimal do contorno $(\mathrm{d} \Gamma)$ e define-se um sistema de 
coordenadas polar com origem sobre o ponto fonte (p). Este procedimento é ilustrado na figura 3.2.

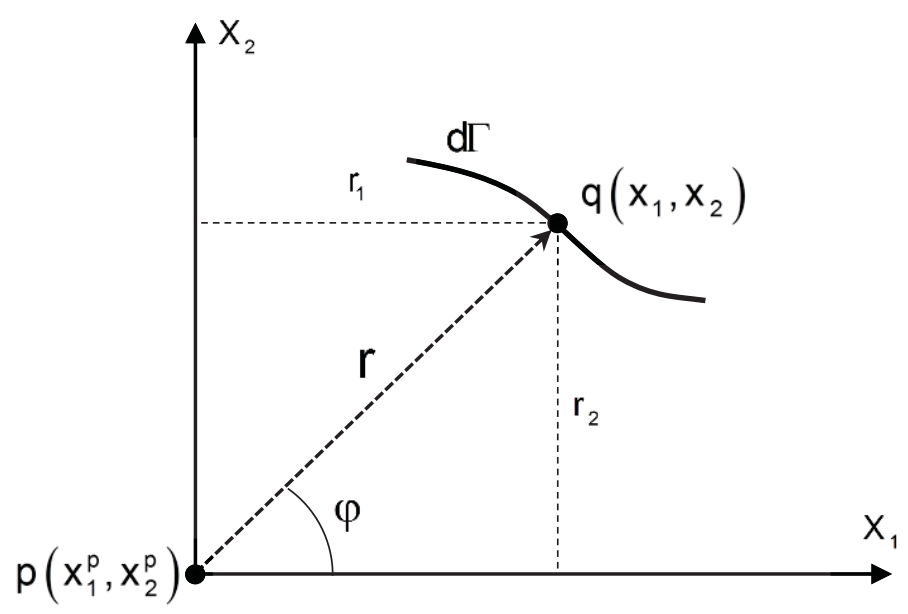

Figura 3.2 - Relações entre os sistemas cartesiano e polar de coordenadas

Na figura 3.2, ponto $p$ representa um ponto fonte do problema enquanto q a um ponto campo sobre o contorno. As componentes da distância $r, r_{1}$ e $r_{2}$, podem ser calculadas conforme as equações (3.14) e (3.15). Essas relações serão importantes mais adiante.

$$
\begin{gathered}
r_{1}=x_{1}-x_{1}^{p}=r \cdot \cos (\varphi) \\
r_{2}=x_{2}-x_{2}^{p}=r \cdot \operatorname{sen}(\varphi)
\end{gathered}
$$

O próximo passo consiste na conversão do domínio diferencial $d \Omega$ para 0 sistema de coordenadas polares. Essa transformação é regida pelo determinante Jacobiano, $J(r, \varphi)$, calculado na equação (3.16).

$$
J(r, \theta)=\left|\begin{array}{ll}
\frac{\partial x_{1}}{\partial r} & \frac{\partial x_{1}}{\partial \varphi} \\
\frac{\partial x_{2}}{\partial r} & \frac{\partial x_{2}}{\partial \varphi}
\end{array}\right|=\left|\begin{array}{cc}
\cos (\varphi) & -r \cdot \operatorname{sen}(\varphi) \\
\operatorname{sen}(\varphi) & r \cdot \cos (\varphi)
\end{array}\right|=r
$$


Desta maneira,

$$
\mathrm{d} \Omega=\mathrm{r} \cdot \mathrm{drd} \varphi
$$

Sendo assim, uma função qualquer do tipo $f\left(x_{1}, x_{2}\right)$, substituindo-se a igualdade obtida na equação (3.17) na integração descrita na equação (3.13) resulta em:

$$
\iint_{\Omega} f\left(x_{1}, x_{2}\right) d \Omega=\iint f(r, \varphi) r d r d \varphi
$$

Para tratar das integrais em $r$ e em $\theta$ de maneira separada, estabelece-se que:

$$
F(q)=\int_{0}^{r} f\left(x_{1}, x_{2}\right) r d r
$$

Desta maneira, a equação (3.18) é reescrita como:

$$
\iint f(r, \varphi) r d r d \theta=\int F(q) d \varphi
$$

No passo descrito pelas equações (3.19) e (3.20) nota-se que, para funções $f\left(x_{1}, x_{2}\right)$ fracamente singulares, isto é que possuam problemas de singularidade da ordem de 1/r, a substituição na equação (3.19) já promove a eliminação explícita da singularidade em vista da multiplicação pelo termo $r$.

Da mesma maneira que apresentado em Gao (2002) [4] para o caso tridimensional, quando o ponto campo coincide com uma posição sobre o contorno, faz-se necessária uma relação que aproxime o contorno polar (dS) do contorno real (dГ). Esta situação é evidenciada na figura 3.3. 


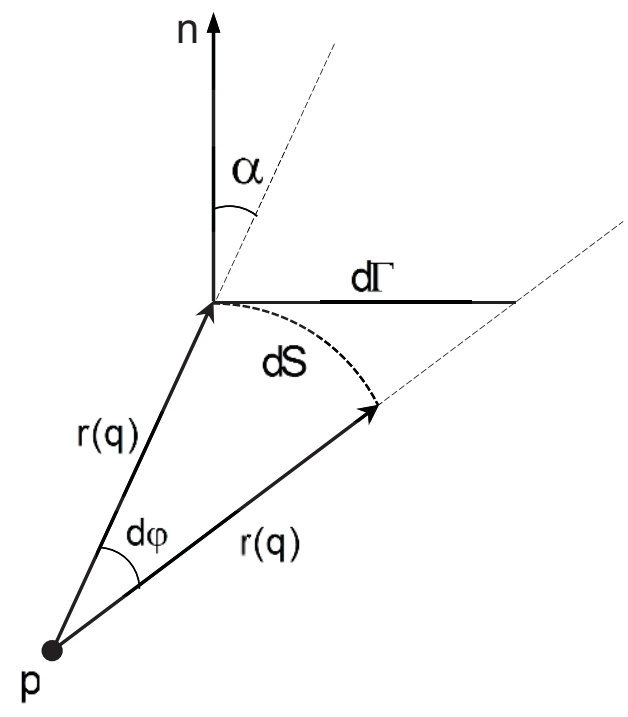

Figura 3.3 - Contornos diferenciais polar $(\mathrm{d} S)$ e real $(\mathrm{d} \Gamma)$.

Nesta figura, $\mathrm{n}$ corresponde ao vetor normal em relação ao segmento do contorno diferencial real $d \Gamma$, enquanto o ângulo $\varphi$ representa o ângulo entre esta normal e a normal ao contorno diferencial dS na direção do raio r(q). Seguindo a notação utilizada em Gao (2002) [4], o índice $q$ atribuída à distância entre os pontos fonte e campo, r(q),tem por função denotar que o ponto campo em questão está localizado sobre contorno do problema.

Assumindo-se valores infinitesimais é possível aproximar a geometria do contorno polar dS para uma reta, fazendo valer a igualdade:

$$
\mathrm{dS}=\mathrm{d} \Gamma \cdot \cos (\alpha)
$$

Das consequentes relações geométricas é possível calcular $\cos (\varphi)$ por:

$$
\cos (\alpha)=\frac{r_{i} \cdot n_{i}}{r(q)}
$$

Sabendo-se que:

$$
\frac{\partial r}{\partial n}=r_{s_{i}} \cdot n_{i}
$$


$E$ que:

$$
r_{y_{i}}=\frac{\partial r}{\partial x_{i}}=\frac{r_{i}}{r}
$$

A equação (3.22) pode ser reescrita como:

$$
\cos (\alpha)=\frac{\partial r}{\partial n}
$$

Ainda de acordo com a figura 3.3, o contorno polar diferencial dS pode ser calculado pela relação:

$$
d S=r(q) \cdot d \varphi
$$

Portanto, substituindo-se as equações (3.26) e (3.25) na equação (3.21), conclui-se que:

$$
d \varphi=\frac{1}{r(q)} \cdot \frac{\partial r}{\partial n} \cdot d \Gamma
$$

Por fim, aplicando as equações (3.27) e (3.20) na equação (3.18) resulta na expressão:

$$
\int_{\Omega} f\left(x_{1}, x_{2}\right) d \Omega=\int_{\Gamma} \frac{1}{r(q)} \cdot \frac{\partial r}{\partial n} \cdot F(q) \cdot d \Gamma
$$

Desta maneira, o par de equações (3.28) e (3.19) permite que a integração de uma função $f\left(x_{1}, x_{2}\right)$ qualquer sobre um domínio bidimensional $\Omega$ em uma integração equivalente definida exclusivamente sobre o contorno $(\Gamma)$ deste domínio. Sendo, portanto, definida como a equação fundamental do MIR para problemas bidimensionais. 
Esta formulação é válida tanto para pontos localizados sobre o contorno quanto para pontos internos ao contorno. E pode ser utilizada para elementos de contorno lineares e de ordem superior da mesma maneira que realizado convencionalmente. Sempre que possível é interessante aumentar a eficiência do método evitando a integração numérica de $F(q)$. A integração analítica desta função requer que a função $f\left(x_{1}, x_{2}\right)$ seja expressa em termos da distância r entre o ponto fonte e o ponto campo. Esta conversão pode ser realizada por meio das relações apresentadas em Gao (2002) [4] e Gao (2003) [7], nas quais:

$$
x_{i}=x_{i}^{p}+r_{i}
$$

Esta representação da coordenada $x_{i}$ como soma da coordenada $X_{i}^{p}$ à componente $r_{\mathrm{i}}$ da distância entre ambos os pontos pode ser graficamente observada na figura 3.2. Reescrevendo $r$ pela relação:

$$
r_{i}=r_{i_{i}} \cdot r
$$

Aplicando à equação (3.29):

$$
x_{i}=x_{i}^{p}+r_{p_{i}} \cdot r
$$

Esta notação mostra-se bastante conveniente ao MIR pois, quando aplicada à equação (3.19), tem-se que, $r_{, j}$ comporta-se como constante devido à construção do método. Em geral, para grande parte dos problemas com integrais de domínio envolvendo as soluções fundamentais potenciais e elásticas, a integração resultante da equação (3.19) pode ser avaliada analiticamente. Para os casos onde isso não é possível faz-se necessária a utilização de técnicas numéricas de integração, como a quadratura de Gauss por exemplo.

Considerando, agora o exemplo de um caso de problema elástico com uma força de domínio genérica regido pela equação integral: 


$$
\mathrm{C}_{\mathrm{ij}} \mathrm{u}_{\mathrm{j}}=\int_{\Gamma}\left(\mathrm{U}_{\mathrm{ij}} \mathrm{t}_{\mathrm{j}}-\mathrm{T}_{\mathrm{ij}} \mathrm{u}_{\mathrm{j}}\right) \mathrm{d} \Gamma+\int_{\Omega} \mathrm{U}_{\mathrm{ij}} \mathrm{b}_{\mathrm{j}} \mathrm{d} \Omega
$$

Olhando-se exclusivamente para a integral de domínio a ser convertida, o termo $b_{\mathrm{j}}$ corresponde à função da força de corpo distribuída pelo domínio e $U_{\mathrm{ij}}$ à solução fundamental de Kelvin para o deslocamento, apresentada na equação (3.10). Como descrito a utilização do MIR como ferramenta de conversão de integrais de domínio em equivalentes sobre o contorno, baseia-se no par de equações (3.28) e (3.19). Sendo assim, conforme a equação (3.28), busca-se a seguinte igualdade:

$$
\int_{\Omega} \bigcup_{\mathrm{ij}} \mathrm{b}_{\mathrm{j}} \mathrm{d} \Omega=\int_{\Gamma} \frac{1}{\mathrm{r}(\mathrm{q})} \cdot \frac{\partial \mathrm{r}}{\partial \mathrm{n}} \mathrm{F}(\mathrm{q}) \cdot \mathrm{d} \Gamma
$$

Com base na equação (3.13), para este caso:

$$
f\left(x_{1}, x_{2}\right)=U_{i j} b_{j}
$$

Logo, por analogia à equação(3.19), a função $F(q)$ é escrita como:

$$
F(q)=\int_{0}^{r} U_{i j} b_{j} r d r
$$

A conversão da integral de domínio em uma equivalente sobre o contorno é, por fim, completa com substituição desta função $F(q)$ na equação (3.33).

Como é possível notar, a aplicação do MIR como ferramenta de conversão requer que seja conhecida a função a ser integrada conforme as equações (3.19) e (3.35). Caso sejam conhecidos apenas valores pontuais distribuídos, é necessária a utilização de ferramentas de regressão polinomial para a obtenção de uma função, $f\left(x_{1}, x_{2}\right)$, que os represente. 
3.1.1 MIR aplicado à formulação integral para termoelasticidade

O procedimento para conversão da integral de domínio resultante na formulação integral para termoelasticidade é similar ao utilizado para o caso de um problema elástico com uma força de domínio distribuída, demonstrado como exemplo. Em um primeiro passo, isola-se a integral de domínio presente na equação (3.12) e substitui-se os valores da derivada da solução fundamental para o deslocamento e o valor de k, de acordo com a equação (3.5). Estas substituições resultam em:

$$
\int_{\Omega} U_{\mathrm{ij}, \mathrm{j}} \mathrm{k} \theta \mathrm{d} \Omega=\int_{\Omega} \frac{-(1+v) \mathrm{k}}{2 \alpha \pi(1-v) \mathrm{r}} \mathrm{r}_{\mathrm{i}} \theta \mathrm{d} \Omega
$$

Como descrito na seção anterior, o MIR baseia-se na aplicação das equações (3.28) e (3.19) à integração de domínio a ser convertida em sua equivalente de contorno. Dadas as equações (3.28) e (3.36), a aplicação do MIR para este caso visa a obtenção de uma integral de contorno equivalente da forma:

$$
\int_{\Omega} U_{\mathrm{ij}, \mathrm{j}} \mathrm{k} \theta \mathrm{d} \Omega=\int_{\Gamma} \frac{1}{\mathrm{r}(\mathrm{q})} \cdot \frac{\partial \mathrm{r}}{\partial \mathrm{n}} \cdot \mathrm{F}(\mathrm{q}) \cdot \mathrm{d} \Gamma
$$

Pela comparação das equações (3.36) e (3.13), conclui-se que:

$$
f\left(x_{1}, x_{2}\right)=\frac{-(1+v) k}{2 \alpha \pi(1-v) r} r_{,} \theta
$$

E, portanto, de acordo com a equação (3.19):

$$
F(q)=\int \frac{-(1+v) k}{2 \alpha \pi(1-v)} r_{,} \theta d r
$$

Como constatado em Gao (2003) [7], neste passo de integração o termo $r_{, j}$ age como uma constante. Desta forma, a equação (3.39) pode ser reescrita como: 


$$
F(q)=\frac{-(1+v) k}{2 \alpha \pi(1-v)} r_{, i} \bar{F}(q)
$$

Para:

$$
\overline{\mathrm{F}}(\mathrm{q})=\int_{0}^{r} \theta \mathrm{dr}
$$

O passo de integração considera agora apenas a função que descreve o campo de temperatura atuante sobre o domínio. Sendo assim, dependendo da natureza desta função, a equação (3.41) pode ser avaliada analiticamente, aumentando a eficiência computacional da análise. A substituição da equação (3.40) na equação principal (3.37), resulta, de forma mais completa, na expressão (3.42), que sumariza o procedimento de conversão da integral de domínio responsável pelos efeitos térmicos em uma integral equivalente avaliada apenas sobre o contorno.

$$
\int_{\Omega} \mathrm{U}_{\mathrm{ij}, \mathrm{j}} \mathrm{k} \theta \mathrm{d} \Omega=\int_{\Gamma} \frac{1}{\mathrm{r}(\mathrm{q})} \frac{\partial \mathrm{r}}{\partial \mathrm{n}}\left(\frac{-(1+v) \mathrm{k}}{2 \alpha \pi(1-v)} \mathrm{r}_{\mathrm{i},} \overline{\mathrm{F}}(\mathrm{q})\right) \mathrm{d} \Gamma
$$

A aplicação deste resultado na equação (3.12) resulta na equação integral de contorno para problemas termoelásticos:

$$
\mathrm{C}_{\mathrm{ij}} \mathrm{u}_{\mathrm{j}}+\int_{\Gamma}\left(\mathrm{T}_{\mathrm{ij}} \mathrm{u}_{\mathrm{j}}-\mathrm{U}_{\mathrm{ij}} \mathrm{t}_{\mathrm{j}}\right) \mathrm{d} \Gamma=\int_{\Gamma} \frac{1}{r(q)} \frac{\partial \mathrm{r}}{\partial \mathrm{n}}\left(\frac{-(1+v) \mathrm{k}}{2 \alpha \pi(1-v)} \mathrm{r}_{\mathrm{i}} \overline{\mathrm{F}}(\mathrm{q})\right) \mathrm{d} \Gamma
$$

\subsection{Tensões nos Pontos Internos}

Partindo para a análise das tensões no interior do domínio, seguindo de acordo com Gao (2003) [7], parte-se da relação entre deformação e deslocamento: 


$$
\varepsilon_{\mathrm{ij}}=\frac{\left(\mathrm{u}_{\mathrm{i}, \mathrm{j}}+\mathrm{u}_{\mathrm{j}, \mathrm{i}}\right)}{2}
$$

Com base nesta equação e também nas equações (3.4) e (3.5), a relação que descreve a relação entre tensão e deslocamento para um ponto ( $p)$, no interior do domínio, surge como:

$$
\sigma_{i j}(p)=\frac{2 G v}{1-2 v} \delta_{i j} \frac{\partial u_{m}}{\partial x_{m}^{p}}+G\left(\frac{\partial u_{i}}{\partial x_{j}^{p}}+\frac{\partial u_{j}}{\partial x_{i}^{p}}\right)-\frac{2 G(1+v) k}{1-2 v} \delta_{i j} \theta(p)
$$

Para a obtenção de uma formulação integral que descreva as tensões no interior do domínio, a equação (3.9) é derivada a fim de obter-se uma equação que descreva o gradiente do deslocamento $\mathrm{u}_{\mathrm{ij}}$.

$$
\frac{\partial u_{i}}{\partial x_{j}}=\int_{\Gamma}\left(\frac{\partial U_{i k}}{\partial x_{j}^{p}} t_{k}-\frac{\partial T_{i k}}{\partial x_{j}^{p}} u_{k}\right) d \Gamma+\frac{\partial}{\partial x_{j}^{p}} \int_{\Omega} U_{i j, j} k \theta d \Omega
$$

A derivação do conteúdo da integral de domínio resulta em uma singularidade forte. Para tratar esta singularidade, Gao (2003) [7], utiliza-se de uma aproximação que consiste em supor um pequeno domínio circular $\left(\Omega_{\gamma}\right)$, centrado sobre o ponto interno $(p)$ e com raio $\gamma$, como ilustrado na figura 3.4 .

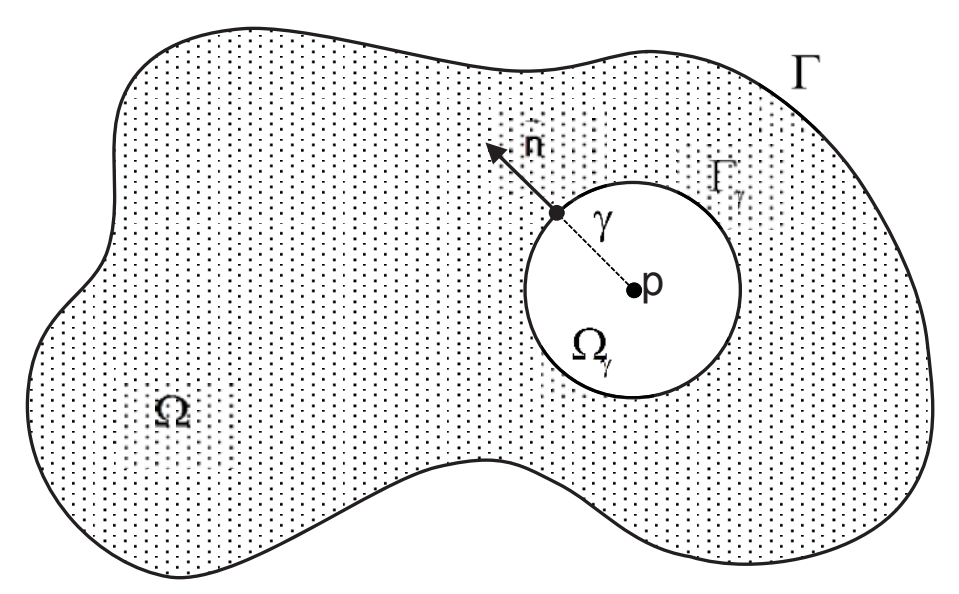

Figura 3.4 - Domínio circular $\Omega_{\gamma}$ com centro no ponto interno $\mathrm{p}$. 
Desta maneira, considerando que $\lim _{\gamma \rightarrow 0} \theta=\theta(p)$, a integral de domínio descrita na equação (3.46) pode ser escrita como a soma de dois limites:

$$
\frac{\partial}{\partial \mathbf{x}_{\mathrm{j}}^{\mathrm{p}}} \int_{\Omega} \mathrm{U}_{\mathrm{ij,j}} \mathrm{k} \theta \mathrm{d} \Omega=\lim _{\varepsilon \rightarrow 0} \int_{\Omega-\Omega_{\varepsilon}} \frac{\partial \mathrm{U}_{\mathrm{ij}, \mathrm{j}} \mathrm{k}}{\partial \mathbf{x}_{\mathrm{j}}^{\mathrm{p}}} \theta \mathrm{d} \Omega+\theta(\mathrm{p}) \lim _{\varepsilon \rightarrow 0} \int_{\Omega_{\varepsilon}} \frac{\partial \mathrm{U}_{\mathrm{ij}, \mathrm{j}} \mathrm{k}}{\partial \mathbf{x}_{\mathrm{j}}^{\mathrm{p}}} \mathrm{d} \Omega
$$

Seguindo Gao (2003) [7], aplicando-se o teorema de Gauss e a relação de continuidade no contorno $\Gamma_{\gamma}, \partial / \partial \mathrm{x}_{\mathrm{j}}^{\mathrm{p}}=-\partial / \partial \mathrm{x}_{\mathrm{j}}$, fornece:

$$
\int_{\Omega_{\gamma}} \frac{\partial \mathrm{U}_{\mathrm{ij}, \mathrm{j}} \mathrm{k}}{\partial \mathrm{x}_{\mathrm{j}}^{\mathrm{p}}} \mathrm{d} \Omega=\int_{\Gamma} \mathrm{U}_{\mathrm{ij}, \mathrm{j}} \mathrm{kn}, \mathrm{d} \Gamma
$$

Fazendo $r=\gamma, n_{j}=r_{j}$, substituindo a forma derivada da equação fundamental para os deslocamentos e considerando expressão (3.5) para k, a integral apresentada na equação (3.48) é resolvida como:

$$
\int_{\Omega_{\gamma}} \frac{\partial \mathrm{U}_{i j, j} \mathrm{k}}{\partial \mathrm{x}_{\mathrm{j}}^{\mathrm{p}}} \mathrm{d} \Omega=\frac{(1+v) \mathrm{k}}{2 \pi(1-v)} \int_{\Gamma_{\gamma}} r_{j} \mathrm{r}_{j} \mathrm{~d} \Gamma
$$

Segundo Gao (2003) [7] e de acordo com Gao e Davies (2002) [47], para um problema bidimensional, a integração no contorno $\Gamma_{\gamma}$, presente na equação (3.49), resulta em:

$$
\int_{\Gamma_{\gamma}} r_{j} r_{j} \mathrm{~d} \Gamma=\pi \mathrm{r} \delta_{i j}
$$

Desta forma, a equação (3.49) resulta em simplesmente:

$$
\int_{\Omega_{y}} \frac{\partial \mathrm{U}_{\mathrm{ij}, \mathrm{j}} \mathrm{k}}{\partial \mathrm{x}_{\mathrm{j}}^{\mathrm{p}}} \mathrm{d} \Omega=\frac{(1+v) \mathrm{k}}{2(1-v)} \delta_{\mathrm{ij}}
$$


Substituindo os resultados das equações (3.47) e (3.51) de volta na equação (3.46) e aplicando novamente as relações de continuidade $\partial / \partial x_{j}^{p}=-\partial / \partial x_{j}$, resulta na expressão:

$$
\frac{\partial \mathrm{u}_{\mathrm{i}}}{\partial \mathrm{x}_{\mathrm{j}}}=\int_{\Gamma}\left(\frac{\partial \mathrm{U}_{\mathrm{ik}}}{\partial \mathrm{x}_{\mathrm{j}}^{\mathrm{p}}} \mathrm{t}_{\mathrm{k}}-\frac{\partial \mathrm{T}_{\mathrm{ik}}}{\partial \mathrm{x}_{\mathrm{j}}^{\mathrm{p}}} \mathrm{u}_{\mathrm{k}}\right) \mathrm{d} \Gamma+\int_{\Omega} \frac{\partial \mathrm{U}_{\mathrm{ij}, \mathrm{j}}}{\partial \mathrm{x}_{\mathrm{j}}} \mathrm{k} \theta \mathrm{d} \Omega+\frac{(1+v) \mathrm{k}}{2(1-v)} \delta_{\mathrm{ij}} \theta(\mathrm{p})
$$

De acordo com Gao (2003) [7], o último termo do lado direito desta expressão corresponde a um "jump term", que surge em função da interpretação da integral de domínio singular no sentido do valor principal de Cauchy.

Sendo assim, a substituição da equação resultante (3.52) na equação (3.45) resulta em uma nova equação integral para a tensão nos pontos internos:

$$
\sigma_{i j}(p)=\int_{\Gamma} U_{i j} t_{j} d \Gamma-\int_{\Gamma} T_{i j} u_{j} d \Gamma+\int_{\Omega} \Psi_{i j} \theta d \Omega-\delta_{i j} h \theta(p)
$$

Na qual, seguindo a notação proposta por Gao (2003) [7], os termos $\Psi_{i j}$ e h são definidos pelas expressões:

$$
\begin{gathered}
\Psi_{\mathrm{ij}}=\frac{-\mathrm{G}(1+v) \mathrm{k}}{\pi(1-v) \mathrm{r}^{2}}\left(2 \mathrm{r}_{\mathrm{i}, \mathrm{j}}-\delta_{\mathrm{ij}}\right)=\frac{1}{\mathrm{r}^{2}} \phi_{\mathrm{ij}} \\
\mathrm{h}=\frac{\mathrm{G}(1+v) \mathrm{k}}{(1-v)}
\end{gathered}
$$

A integral de domínio presente na equação (3.53) adiciona uma condição de singularidade forte devido ao termo $1 / \mathrm{r}^{2}$ presente em $\Psi_{\mathrm{ij}}$. Para tratar essa singularidade, Gao (2003) [7] apresenta uma abordagem que consiste em isolá-la ao reescrever a integral em questão como a soma:

$$
\int_{\Omega} \Psi_{\mathrm{ij}} \theta \mathrm{d} \Omega=\int_{\Omega}[\theta-\theta(p)] \Psi_{\mathrm{ij}} \mathrm{d} \Omega+\theta(p) \int_{\Omega} \Psi_{\mathrm{ij}} \mathrm{d} \Omega
$$


Essa nova forma divide a integral fortemente singular em dois termos. $O$ primeiro termo do lado direito desta equação é fracamente singular e será tratado mais adiante. O segundo termo resultante permanece fortemente singular, entretanto pode ser tratado semi-numericamente utilizando-se uma abordagem similar à demonstrada na figura 3.4. Assumindo-se um domínio circular com raio $\gamma$, centrado no ponto interno $p$ e adotando-se também um sistema de coordenadas polar local $(r, \varphi)$ de mesmo centro, esta integral fortemente singular pode ser expressa como:

$$
\int_{\Omega} \Psi_{\mathrm{ij}} \theta \mathrm{d} \Omega=\int_{0}^{2 \pi}\left(\lim _{\gamma \rightarrow 0} \int_{\gamma}^{\mathrm{r}(\Gamma)} \frac{1}{\mathrm{r}^{2}} \mathrm{rdr}\right) \phi_{\mathrm{ij}} \mathrm{d} \varphi
$$

E, portanto:

$$
\int_{\Omega} \Psi_{\mathrm{ij}} \mathrm{d} \Omega=\int_{0}^{2 \pi} \ln (\mathrm{r}(\Gamma)) \phi_{\mathrm{ij}} \mathrm{d} \varphi-\lim _{\gamma \rightarrow 0} \ln (\gamma) \int_{0}^{2 \pi} \ln (\mathrm{r}) \phi_{\mathrm{ij}} \mathrm{d} \varphi
$$

Nas quais $r(\Gamma)$ representa a distância do ponto $p$ ao contorno $\Gamma$. A aplicação da relação descrita na equação (3.27) na equação (3.58) resulta na equação regularizada (3.59), que pode ser avaliada numericamente conforme a quadratura de Gauss convencional.

$$
\int_{\Omega} \Psi_{\mathrm{ij}} \mathrm{d} \Omega=\int_{\Gamma} r \ln (r) \frac{\partial \mathrm{r}}{\partial \mathrm{n}} \Psi_{\mathrm{ij}} \mathrm{d} \Gamma
$$

Voltando à equação(3.56), ainda resta converter a integral contendo termo fracamente singular em uma integral equivalente sobre o contorno. Desta vez utilizase o MIR, como feito para obtenção da equação integral de contorno, descrita na equação (3.43). Da mesma forma como apresentado na equação (3.37), o MIR busca uma integral de contorno equivalente a integral de domínio em questão da forma:

$$
\int_{\Omega}[\theta-\theta(p)] \Psi_{i j} d \Omega=\int_{\Gamma} \frac{1}{r(q)} \cdot \frac{\partial r}{\partial n} \cdot F(q) \cdot d \Gamma
$$


Por analogia com as equações (3.13) e (3.19), e seguindo a notação proposta por Gao (2003) [7], para este caso, F(q) pode ser escrito como:

$$
F(q)=\phi_{i j} \int_{0}^{r(q)} \frac{\theta-\theta(p)}{r} d r=\Psi_{i j} F(q)
$$

Com $F(q)$ dado por:

$$
F(q)=\int_{0}^{r(q)} \frac{\theta-\theta(r)}{r} d r
$$

Por fim, combinando as equações (3.61) e (3.59), e substituindo-as na equação (3.53), obtém-se a expressão integral avaliada exclusivamente no contorno para tensões em pontos internos:

$$
\sigma_{i j}(p)=\int_{\Gamma}\left(U_{i j} t_{j}-T_{i j} u_{j}\right) d \Gamma+\theta(p) \int_{\Gamma} r \ln (r) \frac{\partial r}{\partial n} \Psi_{i j} d \Gamma+\int_{\Gamma} r \frac{\partial r}{\partial n} \Psi_{i j} F(q) d \Gamma-\delta_{i j} h \theta(p)
$$

\subsection{Implementação Numérica}

A implementação da formulação obtida na equação (3.43) é similar à apresentada em Aliabadi (2002) [3] para o método dos elementos de contorno com força de corpo. Desta forma, o primeiro passo para a resolução numérica do método é a discretização do contorno do problema, $\Gamma$, em $\mathrm{N}_{\mathrm{e}}$ elementos, organizados em sequência como ilustrado na figura 3.5 .

Desta forma, fazendo:

$$
\mathrm{Th}_{\mathrm{j}}=\int_{\Gamma} \frac{1}{\mathrm{r}(\mathrm{q})} \frac{\partial \mathrm{r}}{\partial \mathrm{n}}\left(\frac{-(1+v) \mathrm{k}}{2 \alpha \pi(1-v)} \mathrm{r}_{, \mathrm{F}} \overline{\mathrm{F}}(\mathrm{q})\right) \mathrm{d} \Gamma
$$


A equação (3.43) discretizada pode ser reescrita na forma do somatório:

$$
\mathrm{C}_{\mathrm{ij}} \mathrm{u}_{\mathrm{j}}+\sum_{\mathrm{j}=1}^{\mathrm{N}_{\mathrm{e}}} \int_{\Gamma_{\mathrm{j}}} \mathrm{T}_{\mathrm{ij}} \mathrm{u}_{\mathrm{j}} \mathrm{d} \Gamma-\sum_{\mathrm{j}=1}^{\mathrm{N}_{\mathrm{e}}} \int_{\Gamma_{\mathrm{j}}} \mathrm{U}_{\mathrm{ij}} \mathrm{t}_{\mathrm{j}} \mathrm{d} \Gamma=\sum_{\mathrm{j}=1}^{\mathrm{N}_{\mathrm{e}}} T \mathrm{~h}_{\mathrm{j}}
$$

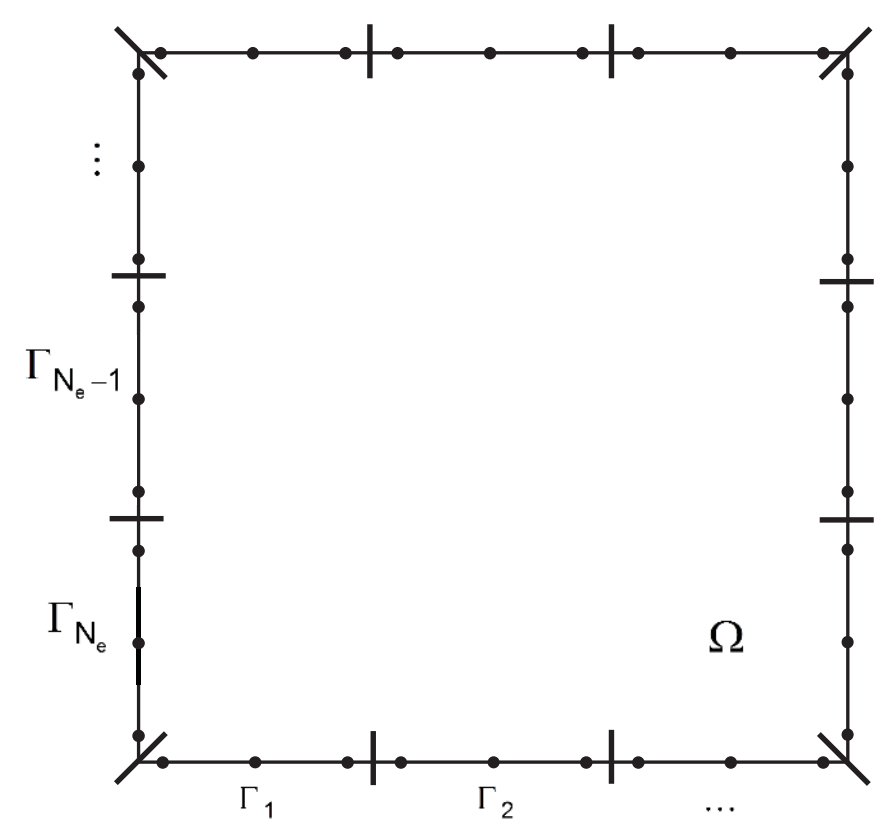

Elemento de contorno quadrático descontínuo

Figura 3.5 - Exemplo de discretização do contorno $\Gamma$ do domínio $\Omega$ em $\mathrm{N}_{\mathrm{e}}$ elementos de contorno quadráticos descontínuos.

Assim como ilustrado na figura 3.5, neste trabalho foi implementada uma discretização com elementos de contorno quadráticos descontínuos visando a obtenção de um código mais versátil para futuras outras aplicações. Como explicado em Brebbia e Dominguez (1996) [23], embora elementos constantes e lineares sejam capazes de prover soluções para diversos problemas de maneira relativamente eficiente, estes encontram limitação na hora de aproximar geometrias curvas. Neste sentido, para esses casos é indicada a utilização de elementos curvos como o elemento de contorno quadrático. Para aproximar a geometria discretizada, o elemento quadrático conta com três nós geométricos, um central e um sobre cada uma de suas extremidades, como exibido na figura 3.6. Além disso, este tipo de elemento conta também com três nós físicos sobre os quais o problema é, de fato, avaliado. Na formulação para elementos quadráticos contínuos os nós físicos localizados nas extremidades dos elementos são coincidentes com os nós 
geométricos. Já na técnica de elementos descontínuos, os nós físicos posicionados nas extremidades do elemento são deslocados em direção ao seu interior, deixando de coincidir com os nós geométricos da discretização. Este ajuste, como citado em Brebbia e Dominguez (1996) [23], consiste em uma maneira simples de se evitar o problema da definição das condições de contorno em cantos ou pontos de descontinuidade.

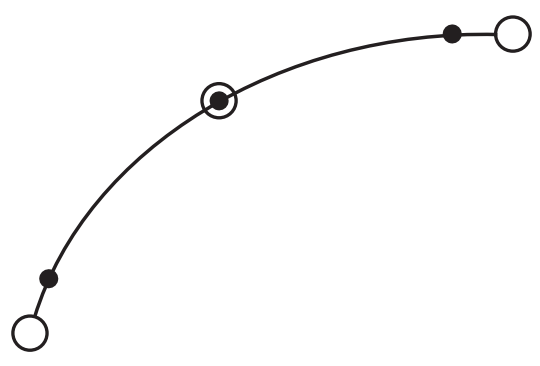

Nós geométricos

- Nós físicos

Figura 3.6 - Exemplo de elemento de contorno quadrático descontínuo.

Seguindo a notação utilizada em Buroni (2006) [24], a matriz das funções de forma para o caso de elementos quadráticos descontínuos, $\left[\Phi^{\text {des }}\right]$, é obtida a partir da modificação da matriz das funções de forma para elementos quadráticos contínuos, $\left[\Phi^{\text {con }}\right]$, por uma matriz, $[Q]$, que contém os fatores geométricos decorrentes dos deslocamentos dos nós no elemento descontínuo. Esta operação é demonstrada na equação (3.66).

$$
\left[\Phi^{\text {des }}\right]=\left[\Phi^{\text {con }}\right][Q]=\left[\begin{array}{cccccc}
\Phi_{1}^{\text {des }} & 0 & \Phi_{2}^{\text {des }} & 0 & \Phi_{3}^{\text {des }} & 0 \\
0 & \Phi_{1}^{\text {des }} & 0 & \Phi_{2}^{\text {des }} & 0 & \Phi_{3}^{\text {des }}
\end{array}\right]
$$

Considerando-se o mapeamento do elemento quadrático descontínuo em um espaço normalizado $\eta[-1 ;+1]$, ilustrado na figura 3.7 , as funções de forma para o caso de elementos quadráticos descontínuos são dadas por:

$$
\Phi_{1}^{\text {des }}=\frac{\eta(\eta-1+b)}{2+a^{2}+a b-3 a}
$$




$$
\Phi_{2}^{\text {des }}=\frac{\eta(a-b-\eta)-a+a b+1-b}{-a+a b+1-b}
$$

$$
\Phi_{3}^{\text {des }}=\frac{-\eta(a-1-\eta)}{2+b^{2}+a b-3 b}
$$

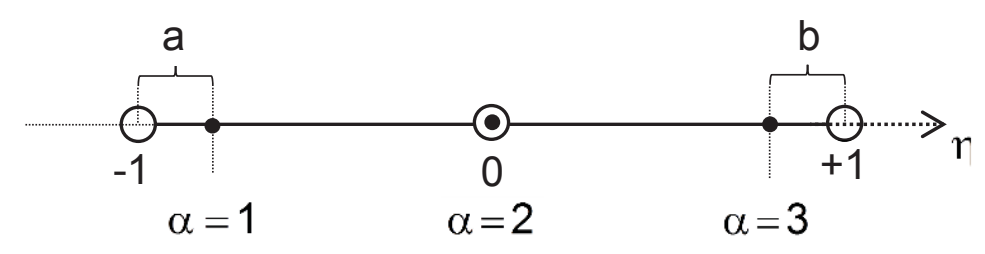

Figura 3.7 - Elemento quadrático descontínuo mapeado no espaço normalizado $\eta$.

Seguindo Dominguez (1993) [48], a força de superfície, $t_{j}$, e do deslocamento, $\mathrm{u}_{\mathrm{j}}$, atuantes sobre o elemento j podem ser escritas como:

$$
\begin{aligned}
& \mathrm{t}_{\mathrm{j}}=\sum_{\alpha=1}^{3} \Phi_{\alpha}^{\text {des }}(\eta) \mathrm{t}_{\mathrm{j}}^{\alpha}=\left[\begin{array}{lll}
\Phi_{1}^{\text {des }} & \Phi_{2}^{\text {des }} & \Phi_{3}^{\text {des }}
\end{array}\right]\left\{\begin{array}{l}
\mathrm{t}_{\mathrm{j}}^{1} \\
\mathrm{t}_{\mathrm{j}}^{2} \\
\mathrm{t}_{\mathrm{j}}^{3}
\end{array}\right\} \\
& \mathrm{u}_{\mathrm{j}}=\sum_{\alpha=1}^{3} \Phi_{\alpha}^{\text {des }}(\eta) \mathrm{u}_{\mathrm{j}}^{\alpha}=\left[\begin{array}{lll}
\Phi_{1}^{\text {des }} & \Phi_{2}^{\text {des }} & \Phi_{3}^{\text {des }}
\end{array}\right]\left\{\begin{array}{l}
\mathrm{u}_{\mathrm{j}}^{1} \\
\mathrm{u}_{\mathrm{j}}^{2} \\
\mathrm{u}_{\mathrm{j}}^{3}
\end{array}\right\}
\end{aligned}
$$

Sendo $t_{j}^{\alpha}$ e $u_{j}^{\alpha}$, as forças de superfície e o deslocamento sobre o nó físico $\alpha$ do elemento j. Substituindo as equações (3.70) e (3.71) nas integrais de contorno da equação (3.65), resulta em:

$$
\int_{\Gamma_{j}} T_{i j} u_{j} d \Gamma=\int_{\Gamma_{j}} T_{i j}\left[\begin{array}{lll}
\Phi_{1}^{d e s} & \Phi_{2}^{\text {des }} & \Phi_{3}^{\text {des }}
\end{array}\right] d \Gamma\left\{\begin{array}{l}
u_{j}^{1} \\
u_{j}^{2} \\
u_{j}^{3}
\end{array}\right\}=\left[\begin{array}{lll}
H_{1}^{i j} & H_{2}^{i j} & H_{3}^{i j}
\end{array}\right]\left\{\begin{array}{l}
u_{j}^{1} \\
u_{j}^{2} \\
u_{j}^{3}
\end{array}\right\}
$$




$$
\int_{\Gamma_{j}} U_{i j} t_{j} d \Gamma=\int_{\Gamma_{j}} U_{i j}\left[\begin{array}{lll}
\Phi_{1}^{\text {des }} & \Phi_{2}^{\text {des }} & \Phi_{3}^{\text {des }}
\end{array}\right] d \Gamma\left\{\begin{array}{l}
t_{j}^{1} \\
t_{j}^{2} \\
t_{j}^{3}
\end{array}\right\}=\left[\begin{array}{lll}
G_{1}^{j} & G_{2}^{\mathrm{jij}} & G_{3}^{\mathrm{j} j}
\end{array}\right]\left\{\begin{array}{l}
\mathrm{t}_{\mathrm{j}}^{1} \\
\mathrm{t}_{\mathrm{j}}^{2} \\
\mathrm{t}_{\mathrm{j}}^{3}
\end{array}\right\}
$$

De forma que:

$$
\begin{aligned}
& H_{k}^{i j}=\int_{\Gamma_{j}} \Phi_{k}^{d e s} T_{i j} \\
& G_{k}^{i j}=\int_{\Gamma_{j}} \Phi_{k}^{d e s} U_{i j}
\end{aligned}
$$

A avaliação destes termos exige a utilização de um Jacobiano, uma vez que os fatores de forma foram obtidos em função de $\eta$, enquanto as integrais estão expressas em função do segmento de contorno $\Gamma_{\mathrm{j}}$, definido sobre o plano cartesiano.

As coordenadas $\mathrm{x}_{1}$ e $\mathrm{x}_{2}$ dos nós geométricos podem ser definidas em termos de $\eta$ utilizando os fatores de forma para elementos contínuos, uma vez que apenas os pontos físicos são deslocados na formulação descontínua. Sendo assim, de maneira análoga ao realizado com $u_{j}$ e $t_{j}$ :

$$
\mathrm{X}_{\mathrm{j}}=\sum_{\alpha=1}^{3} \Phi_{\alpha}^{\mathrm{con}}(\eta) \mathrm{x}_{\mathrm{j}}^{\alpha}=\left[\begin{array}{lll}
\Phi_{1}^{\mathrm{con}} & \Phi_{2}^{\mathrm{con}} & \Phi_{3}^{\mathrm{con}}
\end{array}\right]\left\{\begin{array}{l}
\mathrm{x}_{\mathrm{j}}^{1} \\
\mathrm{x}_{\mathrm{j}}^{2} \\
\mathrm{x}_{\mathrm{j}}^{3}
\end{array}\right\}
$$

Definido $x_{j}$ em função de $\eta$, a transformação exigida é dada por:

$$
\mathrm{d} \Gamma=\sqrt{\left(\frac{d \mathrm{x}_{1}}{\mathrm{~d} \eta}\right)^{2}+\left(\frac{\mathrm{dx}}{\mathrm{d} \eta}\right)^{2}} \mathrm{~d} \eta=|J| \mathrm{d} \eta
$$

Desta forma, as integrais nas equações (3.74) e (3.75) são reescritas como:

$$
H_{\mathrm{k}}^{\mathrm{ij}}=\int_{\Gamma_{\mathrm{j}}} \Phi_{\mathrm{k}}^{\mathrm{des}} T_{\mathrm{ij}}=\int_{-1}^{1} \Phi_{\mathrm{k}}^{\mathrm{des}} T_{\mathrm{ij}} \mid \mathrm{J} \mathrm{d} \eta
$$




$$
\mathrm{G}_{\mathrm{k}}^{\mathrm{ij}}=\int_{\Gamma_{\mathrm{j}}} \Phi_{\mathrm{k}}^{\mathrm{des}} U_{\mathrm{ij}}=\int_{-1}^{1} \Phi_{\mathrm{k}}^{\mathrm{des}} U_{\mathrm{ij}}|\mathrm{J}| \mathrm{d} \eta
$$

Substituindo as equações (3.72) e (3.73) na equação integral de contorno (3.65) resulta na expressão:

$$
C_{i j} u_{j}+\sum_{j=1}^{N_{e}}\left[\begin{array}{lll}
H_{1}^{i j} & H_{2}^{i j} & H_{3}^{i j}
\end{array}\right]\left\{\begin{array}{l}
u_{j}^{1} \\
u_{j}^{2} \\
u_{j}^{3}
\end{array}\right\}-\sum_{j=1}^{N_{e}}\left[\begin{array}{lll}
G_{1}^{i j} & G_{2}^{i j} & G_{3}^{i j}
\end{array}\right]\left\{\begin{array}{l}
t_{j}^{1} \\
t_{j}^{2} \\
t_{j}^{3}
\end{array}\right\}=\sum_{j=1}^{N_{e}} T h_{j}
$$

O termo $\mathrm{Th}_{\mathrm{j}}$, que carrega o efeito termoelástico, é dependente apenas da distância entre o ponto fonte e os pontos campos. Sendo assim, pode ser avaliada diretamente para cada um dos elementos por meio de uma técnica de integração numérica a exemplo da quadratura de Gauss.

A equação (3.80), aplicada a todos os pontos fontes de um contorno fechado pode ser escrita na forma matricial como:

$$
[H]\{\mathrm{u}\}-[\mathrm{G}]\{\mathrm{t}\}=\{\mathrm{Th}\}
$$

Levando em conta que o vetor de contribuições devido ao efeito termoelástico é todo conhecido, a reorganização desta equação matricial, separando as condições de contorno conhecidas das forças de superfície e deslocamentos desconhecidos, dá origem a um sistema linear de equações do tipo:

$$
[A]\{X\}=\{B\}
$$

No qual $\{\mathrm{X}\}$ representa o vetor de incógnitas, $[\mathrm{A}]$ é a matriz de coeficientes do sistema e $\{B\}$ é o vetor de termos independentes.

Por fim, este sistema pode ser solucionado fazendo-se:

$$
\{\mathrm{X}\}=[\mathrm{A}]^{-1}\{\mathrm{~B}\}
$$




\section{ANÁLISE POR CORRELAÇÃO DIGITAL DE IMAGENS}

A análise por CDI é uma técnica de metrologia óptica baseada no processamento digital de imagens que possibilita a obtenção de campos de deslocamentos e de deformações em superfícies por meio da análise de imagens digitais. Estas informações são adquiridas a partir da comparação entre uma imagem do estado inicial da superfície em estudo e sucessivas imagens tomadas durante e após um ensaio mecânico que promove a sua deformação. Segundo Pan et al. (2009) [35], o início da CDI data da década de 1980 com trabalhos como Peters e Ranson (1982) [25], Sutton et al (1983) [26] e Chu et al. (1985) [27] que apresentam a base teórica para o método de análise por CDI moderno. Com os avanços tecnológicos nas áreas da eletrônica ótica e computacional, a análise por CDI, que demandava um potencial computacional grande para a época, cresceu em popularidade perante outras técnicas como as de interferometria ótica. Pan et al. (2009) [35] destaca ainda que nas décadas seguintes, a CDI figurou em diversos trabalhos, porém com diferentes nomenclaturas a exemplo de "método correlação digital de pontos" em Zhang et al. (1999) [30] e Zhou e Goodson (2001) [31], "correlação de textura" em Bay (1995) [32] e também "interferometria de pontos auxiliada por computador" em Chen et al. (1993) [33] e Gaudette et al. (1993) [34], entre outros nomes. Desde então, o método tem sido otimizado de maneira a aumentar sua precisão e reduzir sua complexidade computacional, tornando-o uma alternativa experimental cada vez mais acessível para obtenção dos campos de deslocamento e deformação sobre a superfície.

A técnica de análise por CDI atual, segundo Pan et al. (2009) [35], se baseia em três etapas principais: Preparação da superfície do corpo de prova; Obtenção das imagens da superfície antes e após aplicada a deformação; E, por fim, processamento das imagens adquiridas para determinação dos campos de deslocamentos e deformações resultantes.

$\mathrm{Na}$ primeira etapa, o preparo da superfície do corpo de prova consiste na impressão de uma distribuição randômica de escalas de cinza que sejam capazes de se deformar-se juntamente com a superfície à qual aplicada. Este efeito de escalas de cinza pode ser obtido pela impressão de uma nuvem de pequenos pontos com distribuição aleatória sobre a superfície, exemplificado na figura 4.1. Para tal podem ser utilizadas técnicas envolvendo pintura com tinta spray, entre outros. A qualidade do padrão empregado tem impacto direto nas próximas etapas da análise. 


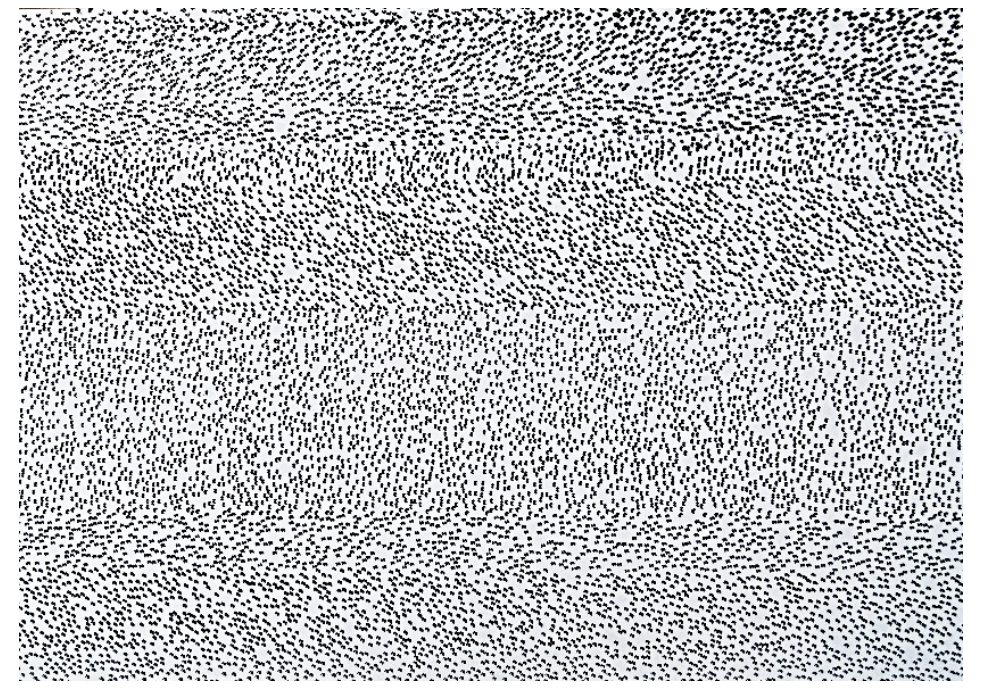

Figura 4.1 - Exemplo de padrão de pontos sobre uma superfície.

De acordo com Pan et al. (2009) [35], a obtenção das imagens em uma análise de CDI bidimensional requer a utilização de uma câmera fixa com sensores do tipo CCD (charge coupled device). Como descrito em Gonzales e Woods (2002) [36], câmeras deste tipo podem ser fabricadas com uma gama diversa de propriedades de captação e contam com inúmeros conjuntos sensores eletromagnéticos organizados em formato de uma matriz bidimensional. A leitura realizada por cada sensor é proporcional à intensidade de energia luminosa que incide na sua superfície de captação, assim como o sinal de saída produzido por estes. Por fim os circuitos analógicos e digitais da câmera se incumbem da conversão do conjunto desses sinais em um sinal de vídeo, que, posteriormente, dá origem à imagem digital.

Dada a forma como a imagem é captada pelos sensores é possível assumir esses sinais de saída como valores escalares associados a uma função bidimensional $f(x, y)$. Ainda segundo Gonzales e Woods (2002) [36], para imagens monocromáticas, como em geral utilizado em análises de CDI, os valores obtidos de $f(x, y)$ correspondem variações na escala de cinza, tendendo ao preto para valores menores de intensidade e ao branco para maiores valores. Desta maneira, o padrão impresso sobre a superfície é traduzido em sinais que variam em amplitude entre as regiões mais escuras e mais claras. A formação da imagem digital da superfície depende ainda da aplicação de dois processos: amostragem e quantização, descrito também em Sato (2009) [44]. O procedimento de amostragem consiste na discretização espacial do domínio contínuo da imagem nas dimensões x e y do problema, enquanto 
o procedimento de quantização consiste na avaliação do valores de $f(x, y)$ para os pontos obtidos no processo de quantização. Ao menor elemento resultante do processo de amostragem dá-se o nome de pixel (picture element). De acordo com Gonzales e Woods (2002) [36], o processo de amostragem se dá na prática em função do arranjo de sensores utilizados para captar a imagem. A figura 4.2, baseada também em Gonzales e woods (2002) [36] e Sato (2009) [44], ilustra a comparação entre uma imagem monocromática contínua e seu equivalente após submetida aos processos de amostragem e quantização. Nesta figura, cada espaço ilustrado representa um pixel, de modo que quanto maior a resolução do equipamento utilizado para captar uma mesma imagem, mais elementos serão utilizados no processo de amostragem, gerando uma imagem digital mais próxima da real. Além disso, a quantização em escalas de cinza empregada também tem grande influência na qualidade da imagem digitalizada. Como apresenta Gonzales e Woods (2002) [36], para uma resolução espacial constante, uma escala com uma maior quantidade de níveis de cinza produz uma imagem digital com variações de tons mais próximas, o que causa um aspecto de melhor continuidade.

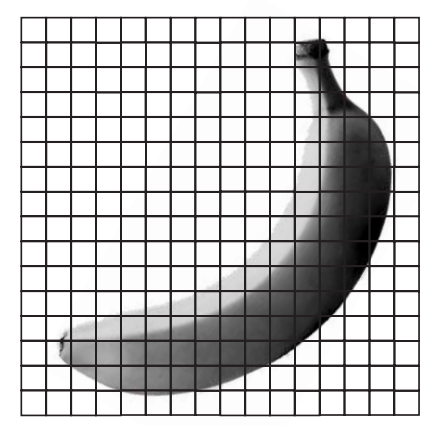

Imagem original
Quantização

Amostragem

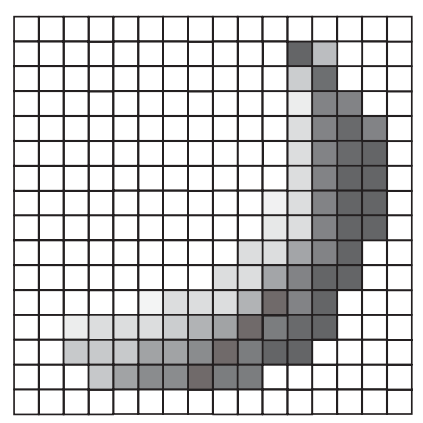

Imagem interpretada

Figura 4.2 - Efeito da amostragem e quantização em comparação a imagem contínua captada pelos sensores.

Após os processos de quantização e amostragem, tem-se apenas valores discretos de $f(x, y)$, isto é, valores discretos de escalas de cinza. Desta maneira, tornase possível escrever a distribuição de $f(x, y)$ na forma de matriz, onde sua posição no interior da matriz remete às posições dos respectivos pixels no plano $(x, y)$. Seguindo a notação apresentada em Gonzales e Woods (2009) [36], e considerando-se uma 
amostragem com $\mathrm{N}$ pixels distribuídos sobre o eixo $\mathrm{x}$ e $\mathrm{M}$ pixels sobre o eixo y, temse que a distribuição $f(x, y)$ pode ser escrita como:

$$
f\left(x_{i}, y_{j}\right)=\left[\begin{array}{cccc}
f\left(x_{0}, y_{0}\right) & f\left(x_{1}, y_{0}\right) & \cdots & f\left(x_{N-1}, y_{0}\right) \\
f\left(x_{0}, y_{1}\right) & f\left(x_{1}, y_{1}\right) & \cdots & f\left(x_{N-1}, y_{1}\right) \\
\vdots & \vdots & \ddots & \vdots \\
f\left(x_{0}, y_{M-1}\right) & f\left(x_{1}, y_{M-1}\right) & \cdots & f\left(x_{N-1}, y_{M-1}\right)
\end{array}\right]
$$

Onde $f\left(x_{0}, y_{0}\right)$ corresponde ao tom de cinza atribuído ao pixel localizado mais à esquerda e mais ao topo, seguindo a mesma convenção adotada em Gonzales e Woods (2002) [36] e Pan et al. (2009) [35]. Considerando o posicionamento dos pixels como uma malha, onde cada intersecção de duas linhas representa um pixel, tem-se uma disposição teórica em concordância com a matriz de escalas de cinza exibidas na equação (4.1). A figura 4.3, baseada em Gonzales e Woods (2002) [36] , ilustra esse posicionamento de pixels em malha.

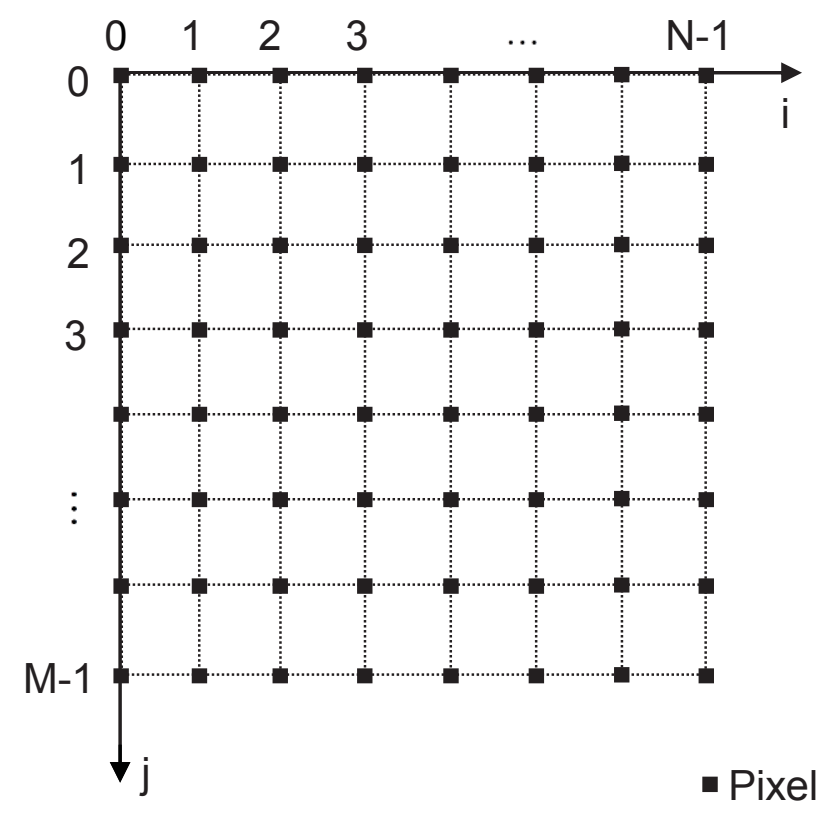

Figura 4.3 - Organização de pixels em malha.

Como salienta Sato (2009) [44], esta notação matricial de $f(x, y)$ é bastante conveniente, pois além de associar valores aos tons de cinza proporcionados pelos pixels da imagem, torna possível a aplicação de operações matriciais 
Estabelecida a representação matricial dos valores de $f(x, y)$, isto é, dos tons de cinza dos pixels presentes na superfície preparada, realiza-se um procedimento de mapeamento da imagem de referência, dividindo-a em uma série de sub-regiões denominadas regiões de interesse (RDI). No interior de cada uma dessas RDIs são estabelecidos pontos físicos para os quais serão, posteriormente, calculados os deslocamentos e deformações. O procedimento de mapeamento aplicado à superfície apresentada na figura 4.1 é ilustrado na figura 4.4, baseada em Pan et al. (2009) [35].

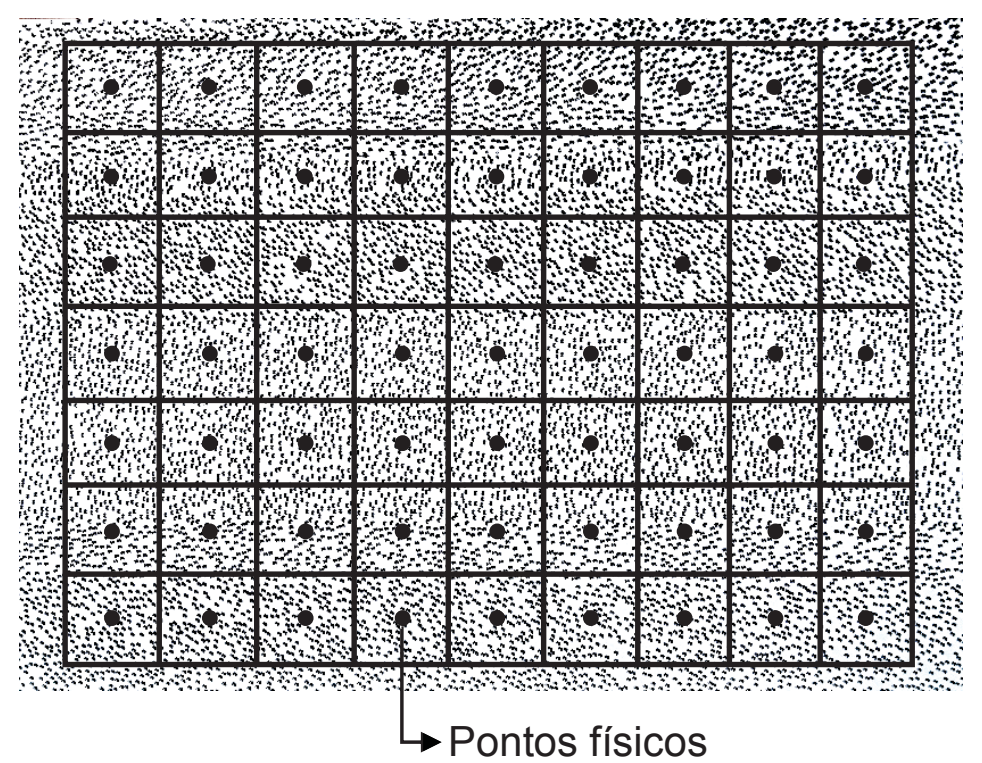

Figura 4.4 - Exemplo de mapeamento aplicado à superfície preparada.

A partir do mapeamento individual das distribuições aleatórias de pixels contidas no interior de cada RDI é possível identificar estas mesmas regiões nas imagens da superfície deformada por meio de avaliações de grau de similaridade. Ao aplicar-se uma deformação a essa superfície ocorre tanto um deslocamento dos pontos físicos do problema quanto a deformação da RDI que os envolvem. Este fenômeno é exemplificado na figura 4.5, adaptada de Pan et al. (2009) [35], na qual observa-se isoladamente uma única RDI antes e após aplicada a deformação, adotando-se um sistema de coordenadas fixo com origem sobre o ponto físico da RDI não deformada. De acordo com Pan et al. (2009) [35], o conjunto de pixels contidos no interior de uma RDI, obtida a partir de uma dispersão aleatória de pontos na superfície, forma um padrão bastante diverso de escalas de cinza, garantindo uma melhor diferenciação desta para as demais. A qualidade da distribuição de pontos 
utilizadas na superfície apresenta, portanto, um papel bastante importante na qualidade da análise por CDI, sendo inclusive o tema de diversos trabalhos recentes, como Gu (2015) [38], Mazzoleni et al. (2015) [42], Crammond et al. (2013) [40], Barranger et al. (2010) [39], Pan et al. (2009) [10] e Lecompte et al. (2007) [37]. Esses trabalhos serão abordados novamente na subseção referente à produção dos corpos de prova.

Além dos padrões de pontos, outro fator que tem grande influência na análise por CDI é o tamanho da RDI selecionada. Como explicado em Pan et al. (2008) [43], utilização de RDIs maiores implica em uma maior quantidade de pontos em seu interior, o que o confere uma maior unicidade. Por outro lado, RDIs maiores acabam, também, por gerar uma quantidade menor de pontos físicos ao problema, prejudicando a precisão da aproximação do campo de deslocamentos para pontos não coincidentes com os pontos físicos. Desta forma, faz-se necessária uma análise de "trade-off" para determinação do tamanho mínimo de RDI capaz de fornecer um resultado de correlação preciso para o sistema de CDI empregado.

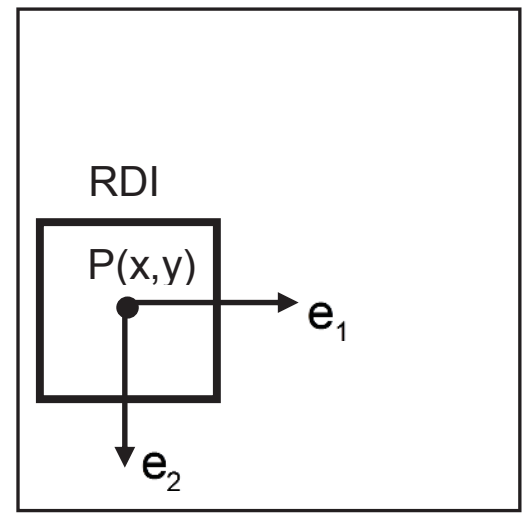

Estado de referência

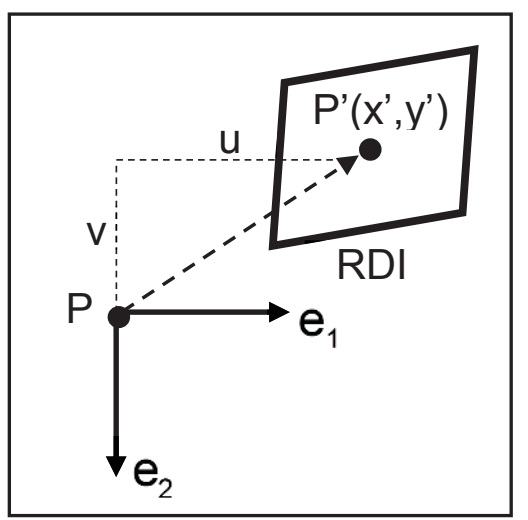

Estado deformado

Figura 4.5 - Análise de uma RDI antes e após aplicada deformação.

Como apresenta Sato (2009) [44], o deslocamento resultante sofrido pelo ponto físico $\mathrm{P}$ pode ser obtido a partir da análise das coordenadas cartesianas dos pontos $P$ e seu equivalente deformado $P$ '. Desta maneira, assumindo que $P$ tenha coordenadas $(x, y)$ enquanto $P^{\prime}$ esteja localizado em ( $\left.x^{\prime}, y^{\prime}\right)$, as componentes do vetor deslocamento apresentado, u e v, podem ser calculadas por:

$$
u=x^{\prime}-x
$$




$$
v=y^{\prime}-y
$$

Desta maneira, a análise por CDI tem por objetivo a identificação e localização nas imagens deformadas dos equivalentes deformados de cada um dos pontos físicos mapeados na imagem de referência. Como comentado, por meio das distribuições de pixels no interior de cada RDI mapeado na imagem de referência, é possível localizálos nas imagens deformadas da mesma superfície aplicando-se avaliações de grau de similaridade.

A avaliação do grau de similaridade entre as RDls originais na imagem de referência e nas imagens deformadas se dá por meio da utilização de equações de compatibilidade. Pan et al. (2009) [35] destaca dois tipos principais de métodos para avaliação do grau de similaridade entre as RDIs antes e após deformação. São eles: O critério de correlação cruzada (CC) e o critério da soma de diferenças de quadrados (SDQ). As equações (4.4) e (4.5) exibem, respectivamente, formulações normalizadas da CC e da SQD.

$$
\begin{gathered}
\mathrm{CC}_{\text {normalizada }}=\frac{\sum\left[\mathrm{f}(\mathrm{x}, \mathrm{y}) \cdot \mathrm{g}\left(\mathrm{x}^{\prime}, \mathrm{y}^{\prime}\right)\right]}{\left[\sum \mathrm{f}(\mathrm{x}, \mathrm{y})^{2}\right]^{1 / 2} \cdot\left[\sum g\left(x^{\prime}, y^{\prime}\right)^{2}\right]^{1 / 2}} \\
\mathrm{SQD}_{\text {normalizada }}=\sum\left\{\frac{\mathrm{f}(\mathrm{x}, \mathrm{y})}{\left[\sum \mathrm{f}(\mathrm{x}, \mathrm{y})^{2}\right]^{1 / 2}}-\frac{g\left(x^{\prime}, y^{\prime}\right)}{\left[\sum g\left(x^{\prime}, y^{\prime}\right)^{2}\right]^{1 / 2}}\right\}^{2}
\end{gathered}
$$

Em concordância com a notações utilizadas em Pan et al. (2009) [35] e Sato (2009) [44], nas equações (4.4) e (4.5), f(x,y) corresponde à intensidade de cinza na imagem de referência; $g\left(x^{\prime}, y^{\prime}\right)$, à intensidade de cinza na imagem com deformação.

Com o aumento da popularidade das análises por CDI, naturalmente surgiram variações alternativas destas equações sendo as mais frequentemente utilizadas apresentadas em Pan et al. (2009) [35]. Esses métodos podem ainda ser combinados entre si ou mesmo com outros métodos, a exemplo de Sousa et al. (2012), no qual o método da CC é aplicado em conjunto com uma técnica diferencial visando atingir precisão a nível de sub-pixel. 
Como aponta Pan et al. (2009) [35], a natureza discreta da imagem digital permite a avaliação direta dos deslocamentos a nível de pixel. Nesta escala, para deformações ou rotações pequenas, é possível obter-se estimativas precisas de deslocamento inicial por meio de métodos de busca simples. Em uma busca espacial simples, busca-se a determinação dos RDIs na imagem deformada por meio da avaliação dos coeficientes de correlação pixel a pixel de regiões específicas. Métodos como algoritmos de busca "coarse-fine" ou "nested search", Zhang et al. (2006) [49], podem ser aplicados para tornar esse procedimento mais eficiente.

Para estender a análise a níveis sub-pixelares, e, consequentemente, elevar a sua precisão é necessária a adoção de técnicas adicionais. Geralmente, resultados provenientes de técnicas de busca a escala de pixel agem como um conjunto de valores iniciais a serem explorados pela técnicas sub-pixelares. O algoritmo de correlação cruzada espacial, por exemplo, que é apontado por Pan et al. (2009) [35] como um dos métodos mais comumente utilizados, e que também figura em Sato (2009) [44], exige valores iniciais relativamente precisos para atingir seus requisitos de convergência. Além deste, Pan et al. (2009) [35] lista uma série de outros possíveis algoritmos para análise em nível de sub-pixel, evidenciando suas aplicabilidades, requisitos de precisão do conjunto de valores iniciais, pontos fortes e limitações entre outras características intrínsecas aos métodos.

Por fim, algumas vezes durante a análise, pontos de interesse, como uma fronteira de RDI ou mesmo o próprio ponto físico, podem coincidir com localizações entre pixels na imagem deformada. A princípio, como constata Sato (2009) [44], são conhecidos apenas informações acerca dos pixels. Para solucionar este problema e aumentar a continuidade da análise são empregadas técnicas de interpolação. A qualidade desta interpolação reside tanto na quantidade de pixels presentes quanto no grau do polinômio utilizado na aproximação. Scherier et al. (2000) [28] apresenta um estudo acerca dos erros sistemáticos provenientes da utilização de interpolações polinomiais para aproximar esses valores de intensidade. Nota-se de seus resultados que a utilização de aproximações por polinômios bicúbicos, como apresentado também em Sato (2009) [44], proporciona uma redução considerável do erro quando comparado a uma aproximação por polinômios bilineares. O mesmo é observado para polinômios biquinticos, porém de maneira menos sensível. Apesar de elevar o custo computacional da análise, Scherier (2000) [28] conclui que a utilização de polinômios de ordem elevada é necessária para uma análise robusta. 


\section{GERAÇÃO E APLICAÇÃO DE PADRÕES DE SUPERFÍCIE PARA CDI}

Dada a importância do padrão de pontos adotados para precisão das funções de correlação utilizadas pelo CDI, a análise de seus parâmetros e como estes influenciam a análise por CDI tem sido tópico recorrente em diversos trabalhos atuais. Neste sentido, Pan et al. (2009) [10] demonstrou, por comparação entre diferentes padrões, que o padrão de pontos introduz um erro de natureza aleatória ao problema. Por sua vez Lecompte et al. (2006) [11] realizou uma análise numérica acerca da dimensão dos pontos utilizados e sua densidade de distribuição. Para um contexto de uma única região de interesse, medindo $15 \times 15$ pixels, observou-se melhores resultados para padrões compostos por aproximadamente 5 pixels e cobrindo entre 40 e $70 \%$ da superfície em análise. Já em Lecompte et al. (2006) [12], apresenta-se uma tabela de tamanhos ótimos de pontos, em pixels, para diferentes tamanhos de RDI. Em uma abordagem mais experimental, Lecompte et al. (2007) [37], testou distribuições aleatórias de pontos geradas por pintura com spray. Em concordância com os resultados numéricos apresentados em Lecompte et al. (2006) [11], foram observados resultados mais precisos com distribuições de pontos contendo de 1 a 5 pixels. Além disso, foi observado também que padrões com pontos maiores (contendo de 1 a 13 pixels) provocam um erro aleatório maior, enquanto padrões compostos por pontos menores (contendo 0 a 3 pixels) provocam aumento tanto do erro aleatório quanto do sistemático.

Com o passar do tempo, muitos critérios para avaliação da qualidade dos padrões utilizados foram sendo desenvolvidos. Porém, como constatado em Crammond et al (2013) [40], estes parâmetros terminam servindo apenas como ferramentas de comparação. Diferentemente das análises numéricas, os aspectos práticos dos métodos utilizados para criação do padrão na superfície e o próprio equipamento utilizado acabam por proporcionar características únicas a cada experimento. Em seu trabalho, Crammond et al. (2013) [40] apresentou uma investigação sobre dois dos métodos mais comumente utilizados para criação de padrões de pontos em superfícies: pintura utilizando tinta em spray e, também, pintura com aerógrafo. Seus resultados experimentais demonstraram que distribuições mais uniformes, atingidas apenas com técnicas de aerógrafo, proporcionaram os melhores resultados. 
Ainda assim, a partir dos resultados apresentados Lecompte et al. (2007) [37] e de Crammond et al. (2013) [40] fica evidente que técnicas de aplicação de padrões baseadas em pintura com tinta spray e também com aerógrafo proporcionam pouco controle acerca de importantes propriedades do padrão como o tamanho dos pontos e sua distribuição na superfície. Como apontados em Crammond et al. (2013) [40], a aleatoriedade causada pela interação do fluxo de ar com as partículas de tinta resulta na impraticabilidade de utilizar tais técnicas para criação de padrões específicos com características tidas como ótimas. Para contornar tal problema, Ghorbani et al. (2015) [41] utilizou uma abordagem com tinta em spray em conjunto com um molde vazado para aplicação de um padrão mais homogeneamente distribuído de pontos sobre a superfície de uma parede de alvenaria. Esta técnica permite a criação de padrões com pontos maiores, necessários para manter uma proporção entre área e dimensões dos pontos próxima da apontada em Lecompte (2006) [11] como ótima. Apesar de efetivo, para casos menores, a exemplo deste trabalho, a criação de um molde vazado para distribuições contendo mais de 20000 pontos, cada um medindo cerca de 0,5 mm, torna-se uma tarefa complexa, exigindo trabalho meticuloso que consome bastante tempo.

Diante destes problemas, Mazzolleni et al. (2015) [42] propôs um método para aplicação de padrões de pontos gerados por computador em superfícies utilizando um toner termo-mecânico especialmente desenvolvido para esta tarefa. Este equipamento também foi desenvolvido visando atender problemas de grande escala, como em Ghorbani et al. (2015) [41] atendendo aos padrões ótimos apontados em Lecompte et al. (2006) [11] e Lecompte et al. (2006) [12]. Apesar disso, o trabalho pouco comenta sobre o equipamento em si, voltando-se mais para os resultados que este proporciona.

Diante dos problemas observados em relação aos métodos convencionais para geração e aplicação de padrões de superfície para ensaios do tipo CDI, e na pouca informação acerca dos aspectos práticos envolvendo os métodos existentes, neste trabalho é proposto um método alternativo para aplicação de padrões de pontos gerados por computador. Visando cumprir especificamente com essa função foi desenvolvido um equipamento de marcação CNC de relativo baixo custo, capaz de realizar marcações em superfícies de até 160 x 160mm. Aspectos acerca do método utilizado para gerar computacionalmente os padrões a serem marcados, da 
montagem, construção e funcionamento do equipamento elaborado, e de também todos os códigos utilizados em sua programação são discutidos.

\subsection{Geração dos Padrões de Pontos}

Mazzoleni et al. (2015) [42] propõe um método para geração de padrões aleatórios de pontos com uma distribuição pseudo-aleatória sobre a superfície a partir da perturbação de uma distribuição de pontos inicialmente organizada em um grid. Essa perturbação consiste em somar ou subtrair pequenos valores aleatórios nas coordenadas $x$ e y de cada ponto, forçando o seu deslocamento. A figura 5.1, baseada em um esquema apresentado em Mazzolleni et al. (2015) [42], ilustra esse procedimento aplicado a um pequeno grupo de pontos.

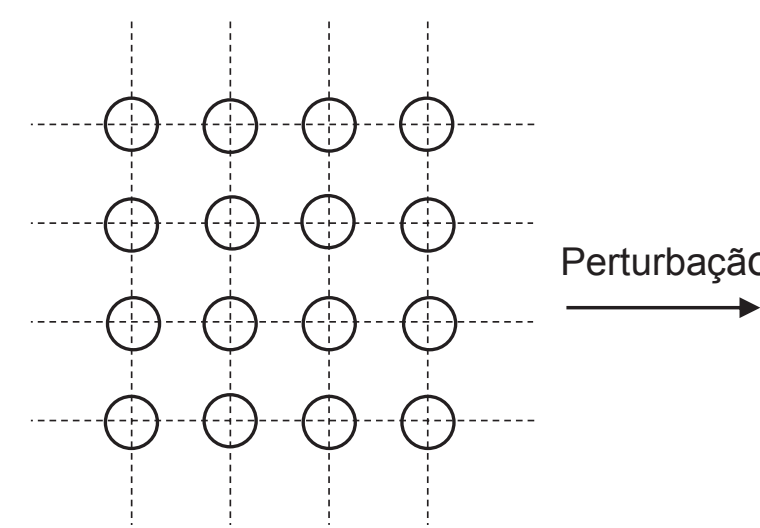

Estado inicial

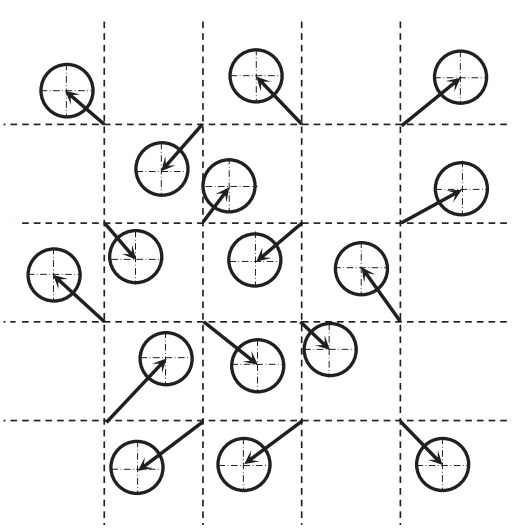

Estado final

Figura 5.1 - Estratégia para criação de padrões de superfície utilizada em Mazzolleni et al. (2015)

[42].

Em vista dos problemas observados nos métodos convencionais de geração de padrões de pontos, e inspirado em Mazzoleni et al. (2015) [42], este trabalho propõe um novo método para aplicação de padrões de pontos gerados em computador em superfícies para ensaios do tipo CDI. Este método consiste na impressão dos pontos, que compõem o padrão gerado, utilizando um equipamento de marcação por comando numérico computadorizado (CNC). 
O primeiro passo consiste na geração do padrão de pontos a ser impresso na superfície a ser medida. Diferentemente, do método apresentado em Mazzoleni et al. (2015) [42] para geração dos padrões aleatórios, neste trabalho adotou-se um método no qual o padrão final é gerado pelo agrupamento de padrões aleatórios menores. No método proposto, a superfície a ser medida é dividida em um conjunto de áreas menores. Em seguida, para cada uma dessas áreas é gerado uma distribuição aleatória de pontos respeitando o intervalo de área ocupada tido como ótimo em Lecompte et al. (2006) [11]. Ao final, as sub-regiões, contendo cada uma um padrão aleatório, são reagrupadas dando origem a um padrão único para a superfície. Este procedimento é ilustrado na figura 5.2.

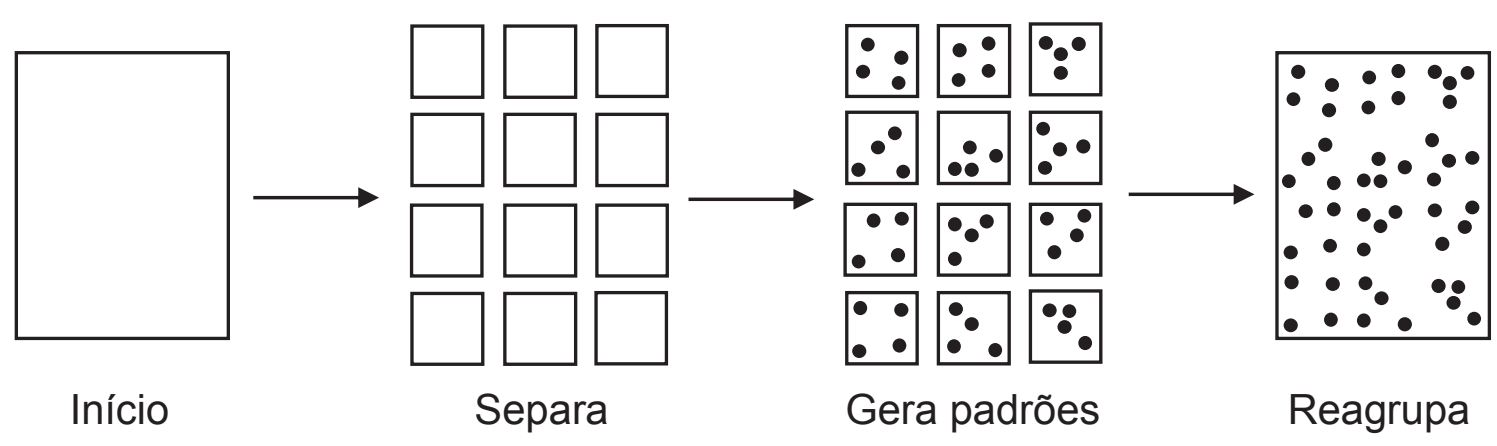

Figura 5.2 - Estratégia proposta para geração de padrão de superfície para CDI.

Na prática, visando maior eficiência, a rotina desenvolvida para a criação do padrão de pontos aleatórios cria cada uma das sub-regiões seguindo uma sequência, formando a superfície completa ao final, como exibido na figura 5.3. Após a criação de cada sub-região, já é realizada a distribuição de pontos em seu interior. Desta maneira, o processo de criação do padrão de superfície para análises por CDI se resume a um laço com duas operações principais: gerar a sub-região e gerar a distribuição aleatória de pontos em seu interior.

A distribuição de pontos para cada sub-região da superfície é gerada de maneira similar à mostrada em Oberg (2013) [46]. O algoritmo utilizado posiciona um ponto por vez na região delimitada até que a proporção de área designada a ser ocupada pelos pontos seja atingida, garantindo que não ocorra intersecção com os pontos já posicionado, como ilustrado na figura 5.4. Caso ocorra intersecção de contornos de dois ou mais círculos que representam os contornos dos pontos, o último 
ponto colocado é reposicionado. Este procedimento é repetido até que seja atingida uma posição satisfatória ou até que seja atingido um limite máximo de tentativas. Caso atingido o limite, o padrão atual é descartado e a geração um novo padrão é iniciada.

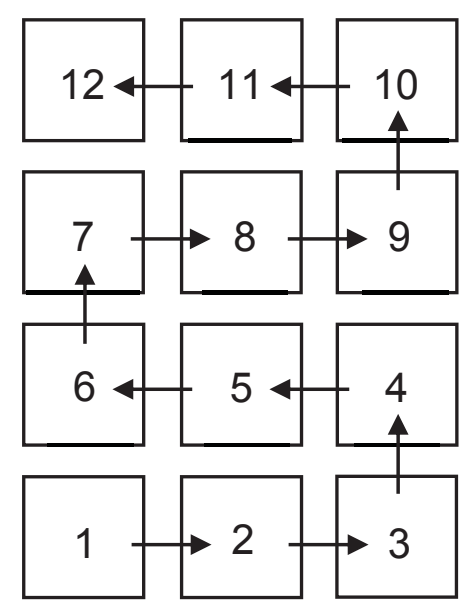

Figura 5.3 - Sequência de criação de sub-regiões.

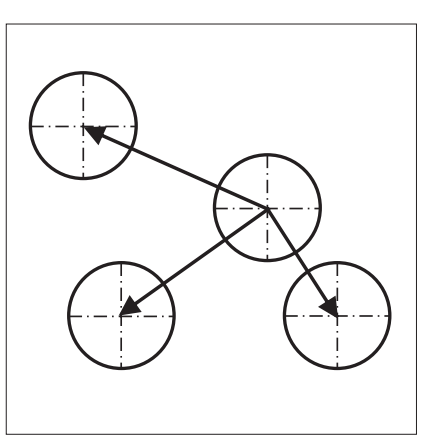

Aprova

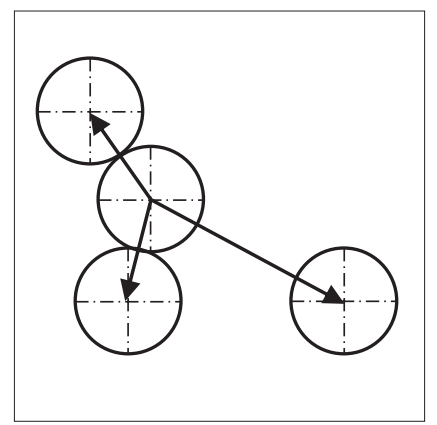

Aprova

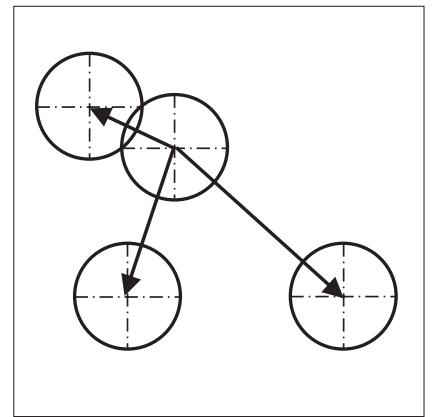

Rejeita

Figura 5.4. Processo de posicionamento dos pontos circulares.

Apesar da restrição quanto a intersecção, é permitido o posicionamento de pontos tangentes, aumentando o campo de possibilidades de posicionamento. Para manter os pontos restritos ao interior de cada região designada, evitando que partes dos pontos ultrapassem seus limites, estabelece-se uma área limite para posicionamento dos centros dos pontos, como ilustrado na figura 5.5. Esta área, definida em função do raio dos pontos gerados, garante que quando essas subregiões forem reposicionadas para reconstrução da superfície completa, pontos de 
uma região não possuam partes sobrepondo pontos de regiões vizinhas. Com isso, é garante-se que a proporção de área ocupada pelos pontos pode ser calculada respeite a equação equação (5.1). O processo completo descrito para criação do padrão de pontos a ser impresso na superfície para o ensaio por CDI é apresentado esquematicamente na figura 5.6.

$$
A_{\text {ocupada }}=\frac{n \cdot\left(\pi \cdot \frac{d^{2}}{4}\right)}{A_{\text {total }}}
$$

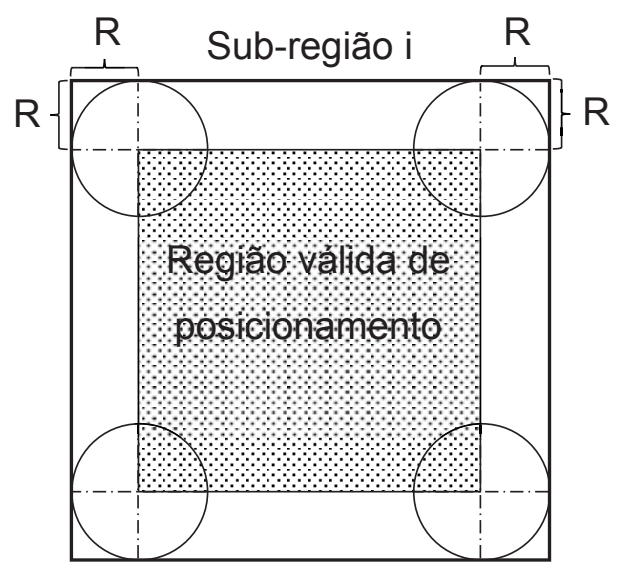

Figura 5.5 - Região limite para posicionamento dos centros dos pontos.

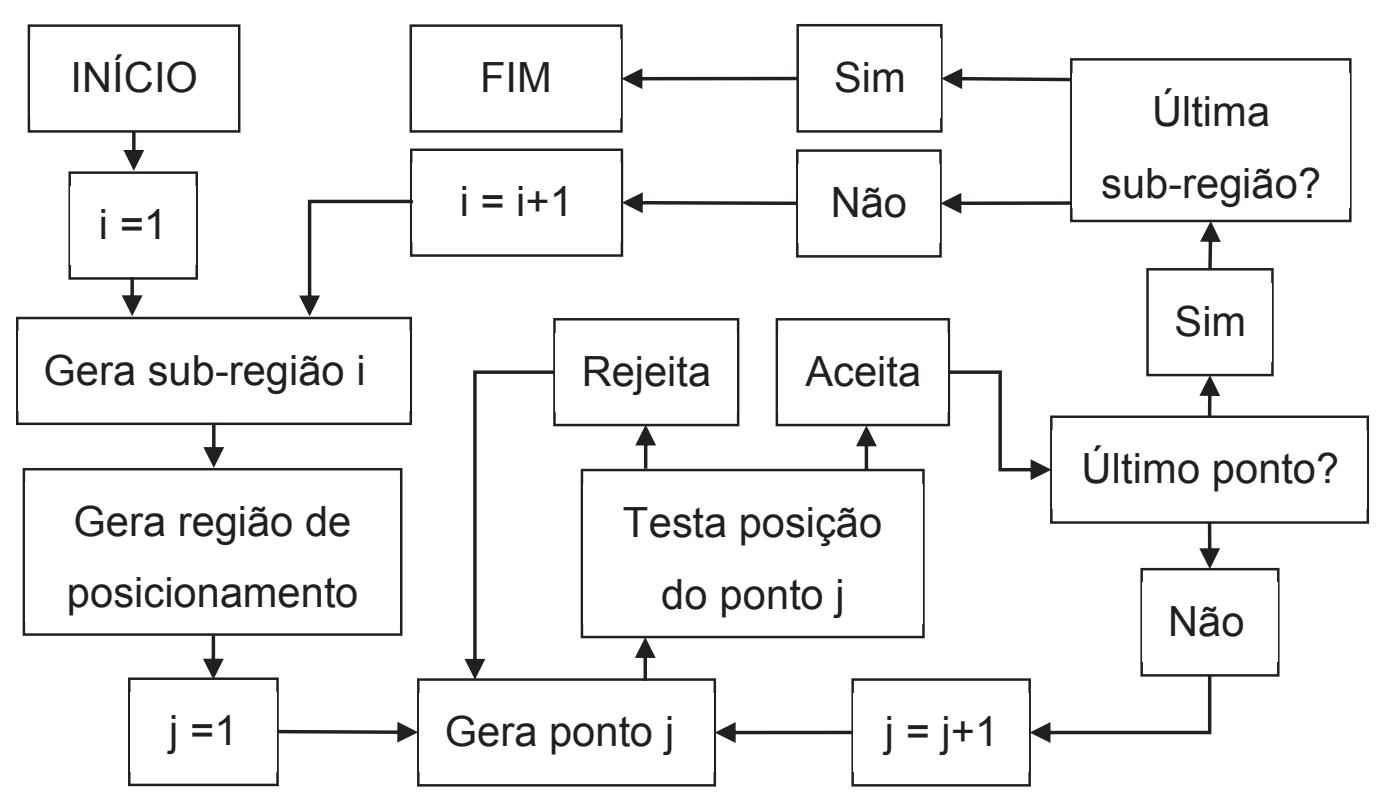

Figura 5.6 - Diagrama de funcionamento da rotina para criação dos padrões de pontos. 
As coordenadas de marcação de cada ponto são armazenadas em um par de vetores, uma para cada coordenada cartesiana do ponto, organizados de maneira a compor uma rota otimizada de marcação como exemplificado na figura 5.7. Esta rota reduz a movimentação no eixo y a apenas uma direção, reduzindo erros devido a possíveis folgas. Por fim, a rotina converte as coordenadas dos pontos em passos a serem percorridos, em cada eixo, pelos motores de passo para seguir de um ponto ao ponto seguinte, indicados pelas setas na figura 5.7. A conversão é realizada com base na distância percorrida pelo marcador ao incremento de um passo pelo motor de passo utilizado. Caso o diâmetro primitivo de ambas as engrenagens motoras de cada correia de dentada seja o mesmo, a equação de conversão utilizada será a mesma para ambos os eixos de deslocamento. Porém em caso de diâmetros primitivos distintos, é necessária uma equação para cada eixo.

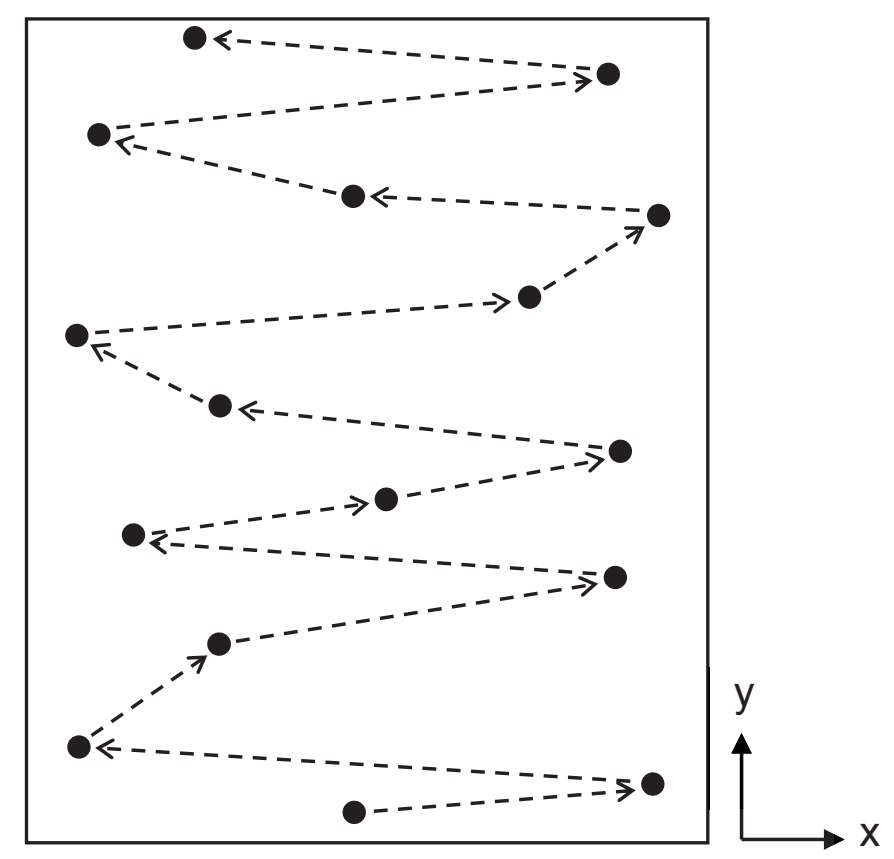

Figura 5.7 - Exemplo de rota de marcação gerada pelo programa de criação de padrões de pontos.

\subsection{O Equipamento de Marcação}

Para tornar possível a reprodução do padrão gerado por computador na superfície a ser analisada, foi desenvolvido um equipamento de marcação por 
comando numérico computacional (CNC). Este equipamento utiliza como meio de marcação uma caneta de tinta permanente com ponta fina $(1.0 \mathrm{~mm})$. Este tipo de marcador foi selecionado com base em testes prévios, a partir dos quais comprovouse a sua capacidade de produzir padrões de pontos com bom contraste, pontos bem definidos, medindo entre 0.6 e $0.7 \mathrm{~mm}$. Além disso, cada caneta testada foi capaz de produzir até 20000 pontos antes de começarem a falhar. Outros fatores que favoreceram a escolha deste tipo de instrumento de marcação foram seu baixo custo e facilidade de obtenção em papelarias, por exemplo.

Definido o tipo de marcador a ser utilizado pelo equipamento para gerar os padrões de pontos, o próximo passo do projeto consistiu no desenvolvimento do sistema automático de marcação, responsável por, de fato, marcar os pontos na superfície. Para isso, o sistema proposto deveria ser capaz de empurrar a ponta da caneta contra a superfície a ser marcada, sem danificar nenhum dos dois, e, em seguida, reerguer a caneta para que esta possa ser movimentada para a posição do ponto seguinte. Com este intuito, foi elaborado um sistema no qual o movimento de contato da caneta com a superfície a ser marcada é controlado por um servo motor com $180^{\circ}$ de amplitude de movimento. Para esta função foi selecionado o micro servo 9g SG90 TowerPro, bastante utilizado em projetos de aeromodelos em virtude de seu baixo custo e boa performance. Para retornar a caneta à sua posição original, o servo retorna à sua angulação original e uma mola empurra a caneta para cima. Para que o ponto seja marcado com nitidez na superfície é necessária uma certa pressão por parte do servo motor. Entretanto, pressão excessiva pode danificar a ponta da caneta, alterando o padrão de pontos produzidos e reduzindo a sua vida útil. Em vista disso, o dispositivo de marcação desenvolvido conta com um sistema de recuo, que assegura que apenas a pressão necessária seja aplicada à ponta da caneta. A figura 5.8 contém um desenho esquemático do dispositivo de marcação desenvolvido, evidenciando seus componentes fundamentais. O seu ciclo de funcionamento detalhado é ilustrado na figura 5.9. A fabricação de todos os elementos estruturais do dispositivo marcador foi realizada em madeira do tipo MDF visando leveza, baixo custo e facilidade de usinagem. 


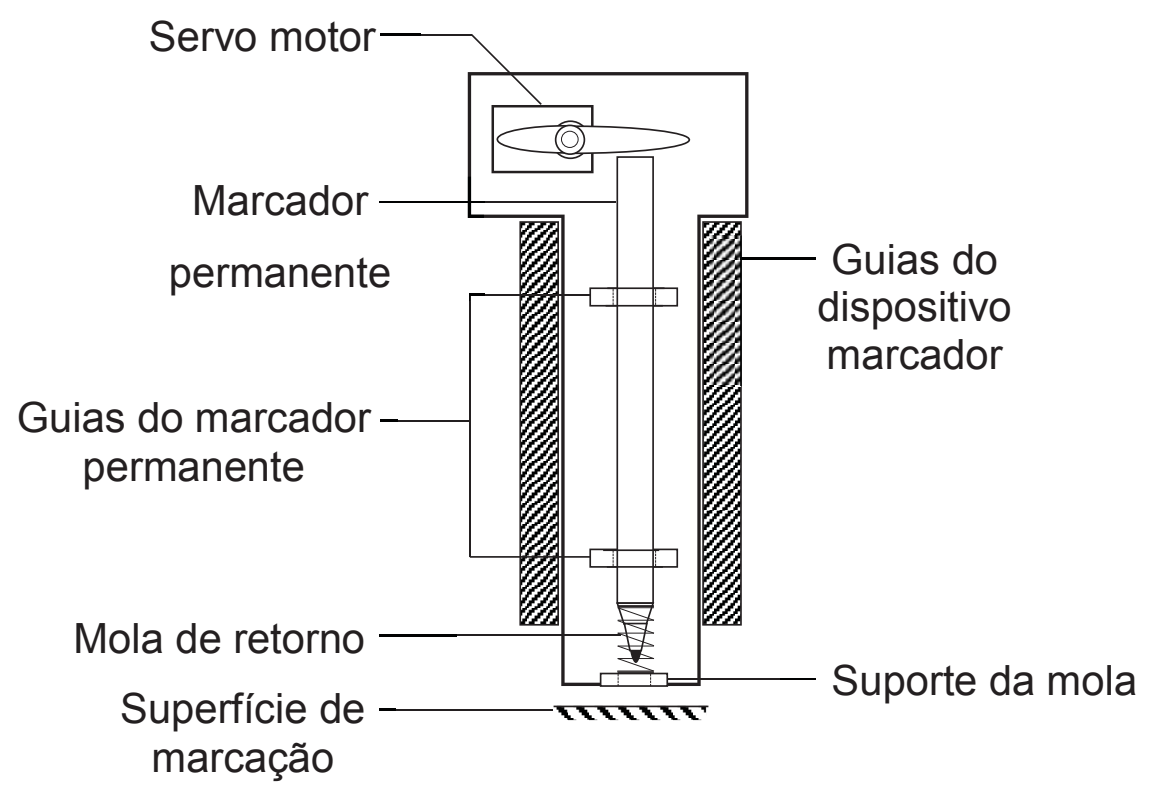

Figura 5.8 - Desenho esquemático do dispositivo marcador.

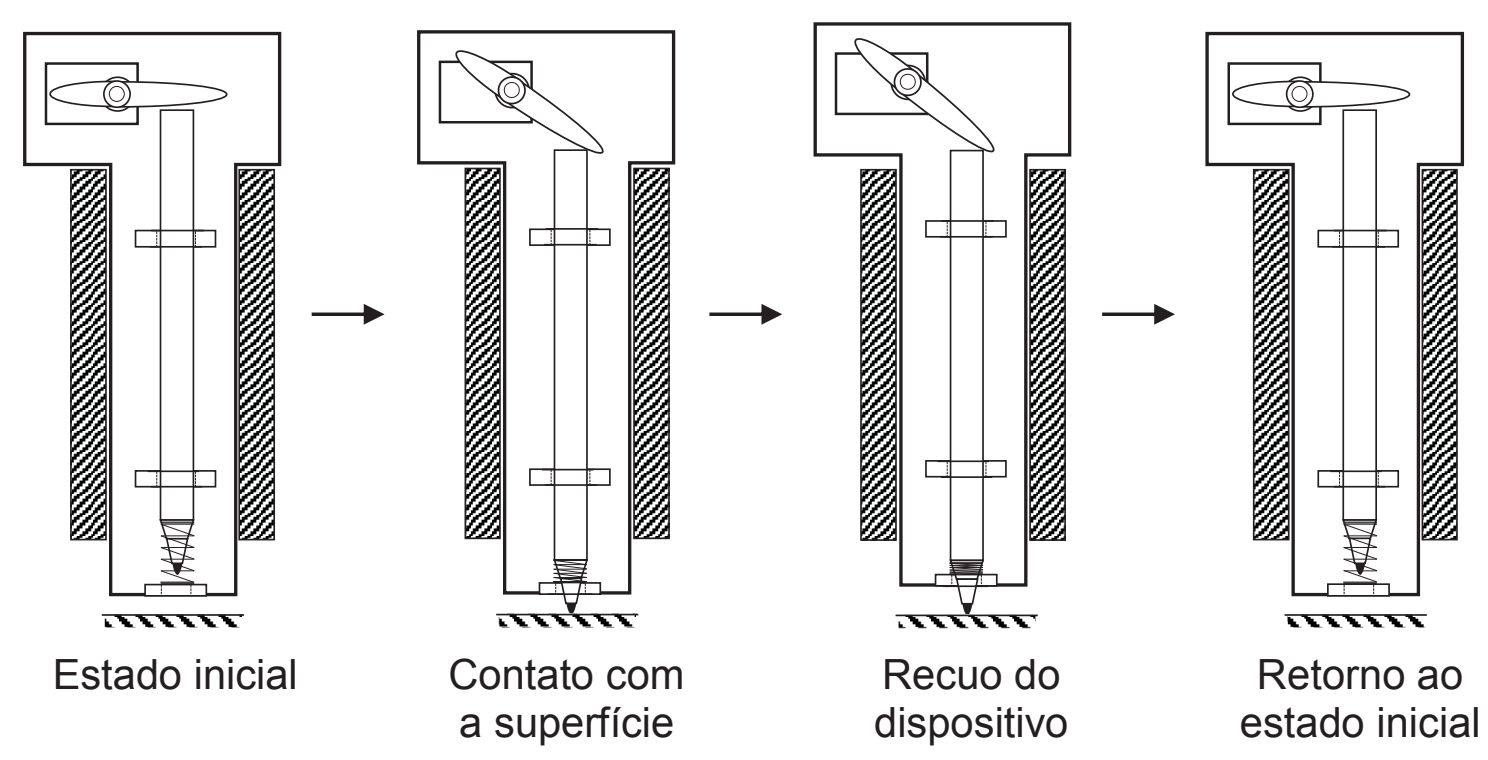

Figura 5.9 - Ciclo de trabalho do dispositivo marcador.

Definido o dispositivo de marcação, o próximo passo é o seu deslocamento para as coordenadas em que os pontos devem ser marcados. Assumindo-se a necessidade de 2 graus de liberdade no plano, o sistema de deslocamento proposto utiliza o sistema de movimentação de cartuchos de impressoras de jato de tinta com ligeiras modificações. Impressoras são atualmente um dos chamados "lixos 
eletrônicos" mais comuns. Devido a este fato, é bastante simples adquirir peças de impressoras defeituosas, sendo inclusive, muitas vezes, isento de custos. O sistema de movimentação do carro de impressão, que comporta os cartuchos da impressora, utiliza um sistema por correia dentada que confere precisão necessária para uma boa impressão. Aproveitando esta característica, esse sistema mecânico é utilizado completo, substituindo-se apenas o motor original que move a correia por um motor de passo. O dispositivo aqui desenvolvido poderia ser fabricado utilizando os componentes mecânicos responsáveis pelo deslocamento do carro de impressão de qualquer modelo de impressora jato de tinta. Nesta construção foram utilizados os modelos HP 840c e HP 1510.

Para a movimentação horizontal do dispositivo foi utilizado o sistema de movimento do carro de impressão de uma impressora HP 840c. Após a substituição de seu motor original por um motor de passo, esta teve o seu carro de impressão modificado para carregar o dispositivo de marcação ao invés dos cartuchos de tinta. A foto apresentada na figura 5.10 exibe o dispositivo de marcação desenvolvido já acoplado no sistema de movimentação da impressora HP 840c. Os detalhes do acoplamento são exibidos na figura 5.11.

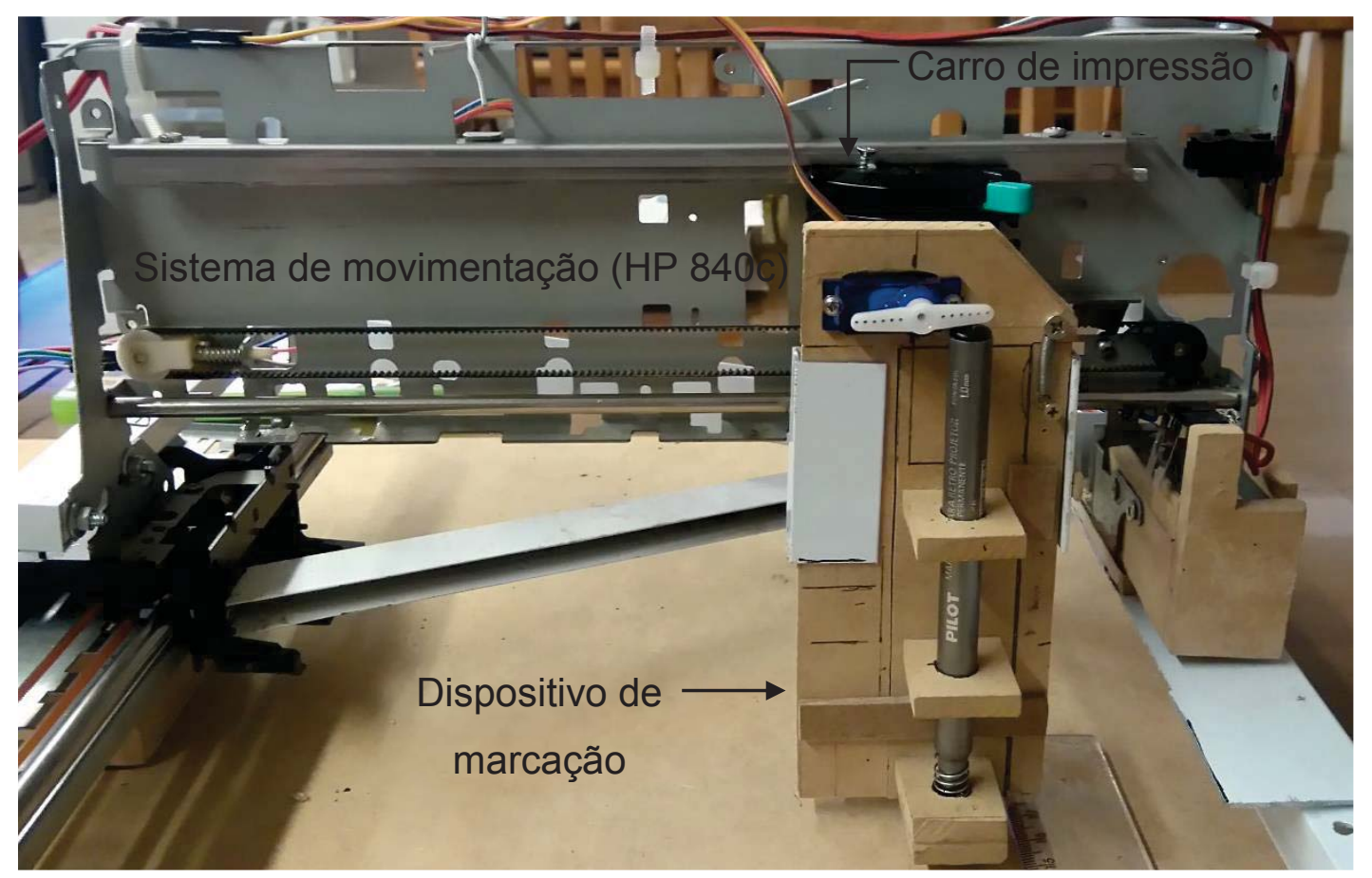

Figura 5.10 - Dispositivo de marcação montado no carro de impressão de uma impressora HP 840c. 


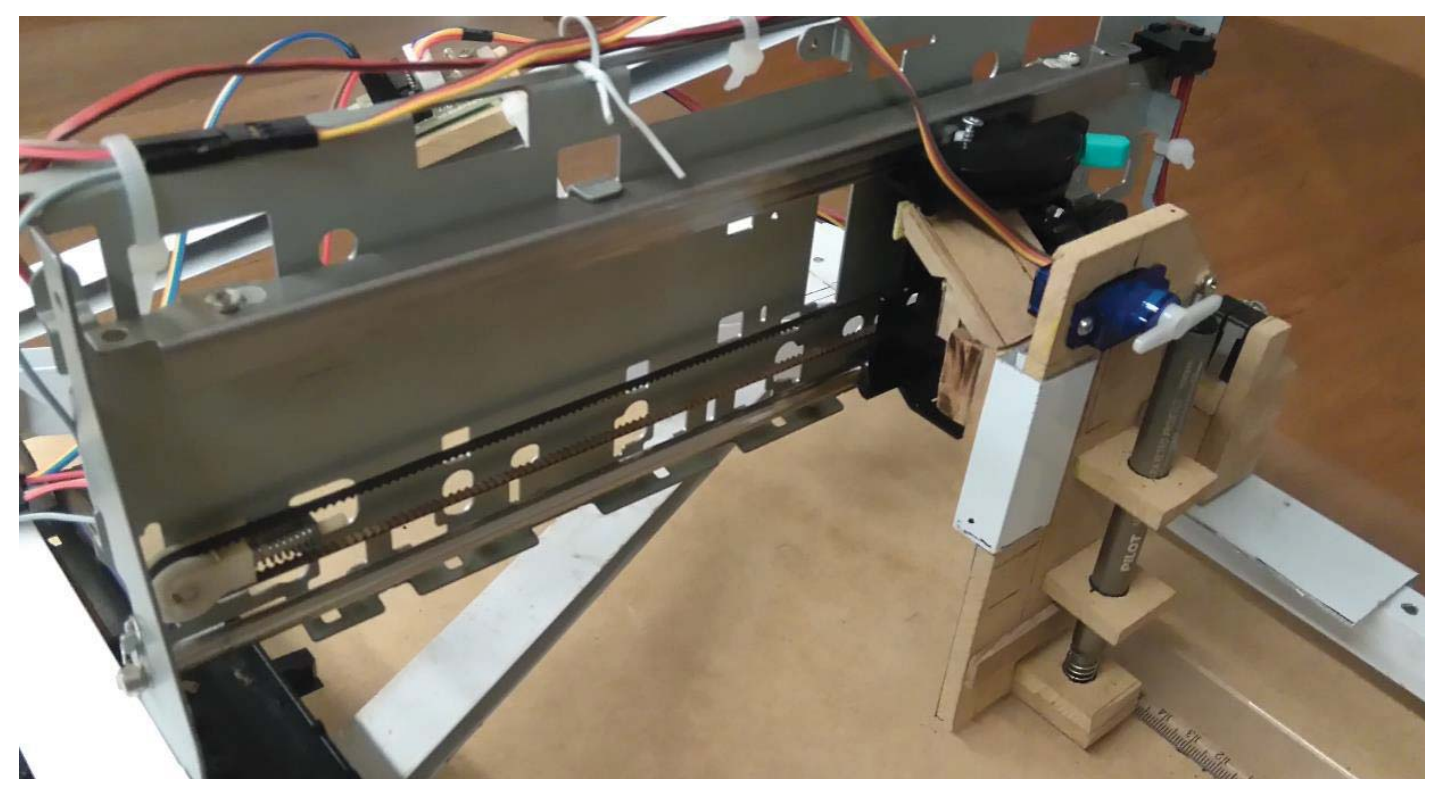

Figura 5.11 - Detalhe da montagem do dispositivo de marcação no carro de impressão de uma impressora HP 840c.

Esta montagem permite que o dispositivo de marcação se movimente lateralmente ao longo do eixo horizontal de marcação em relação ao plano da superfície a ser marcada. Para adicionar o segundo grau de liberdade em relação ao plano de marcação, utiliza-se outro sistema de movimento de carro de impressão. Desta vez utilizou-se um retirado de uma impressora HP 1315. O carro de impressão deste outro mecanismo de movimentação é montado como base para a extremidade esquerda do conjunto formado pelo dispositivo de marcação e o mecanismo de movimentação da impressora 840c. A outra extremidade é montada sobre um trilho guia paralelo ao mecanismo de movimentação proveniente da HP 1315 , desta maneira o dispositivo de marcação se mantém nivelado durante toda a movimentação. Esta montagem pode ser visualizada na figura 5.12. Para que o equipamento proposto consiga reproduzir os padrões de pontos gerados computacionalmente com fidelidade é necessário que a estrutura a ser movimentada ao longo do segundo eixo de movimentação (eixo y) seja suficientemente rígida. Caso contrário, a extremidade apoiada sobre o carro de impressão tende a se mover mais que a extremidade apoiada sobre o trilho guia, torcendo a estrutura responsável pelo primeiro eixo de movimentação (eixo x). Para evitar este problema, fez-se necessária a adição de uma estrutura de travamentos em treliça para elevação da rigidez do equipamento em movimento, exibida na figura 5.13. 


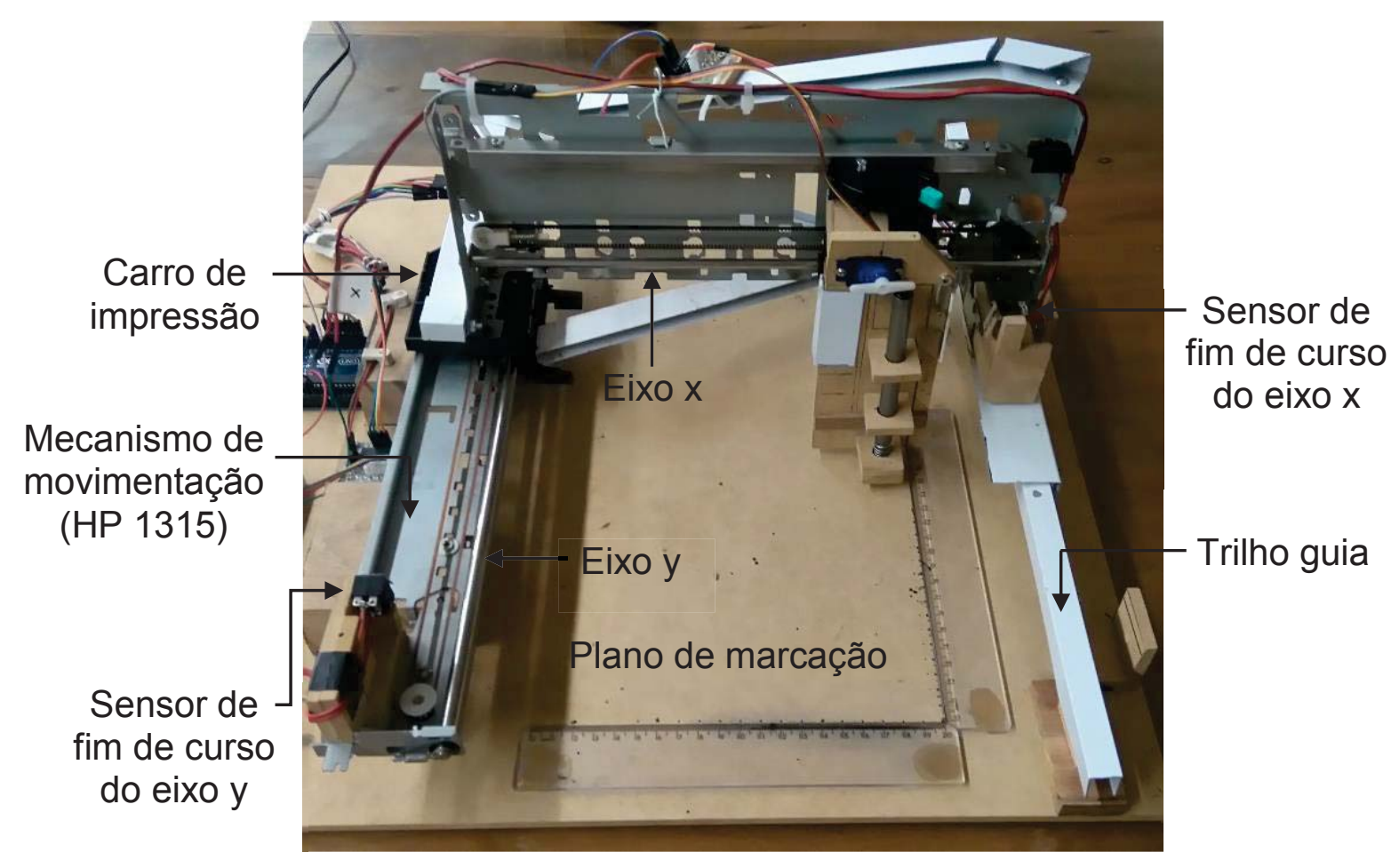

Figura 5.12 - Montagem completa do equipamento de marcação de pontos CNC.
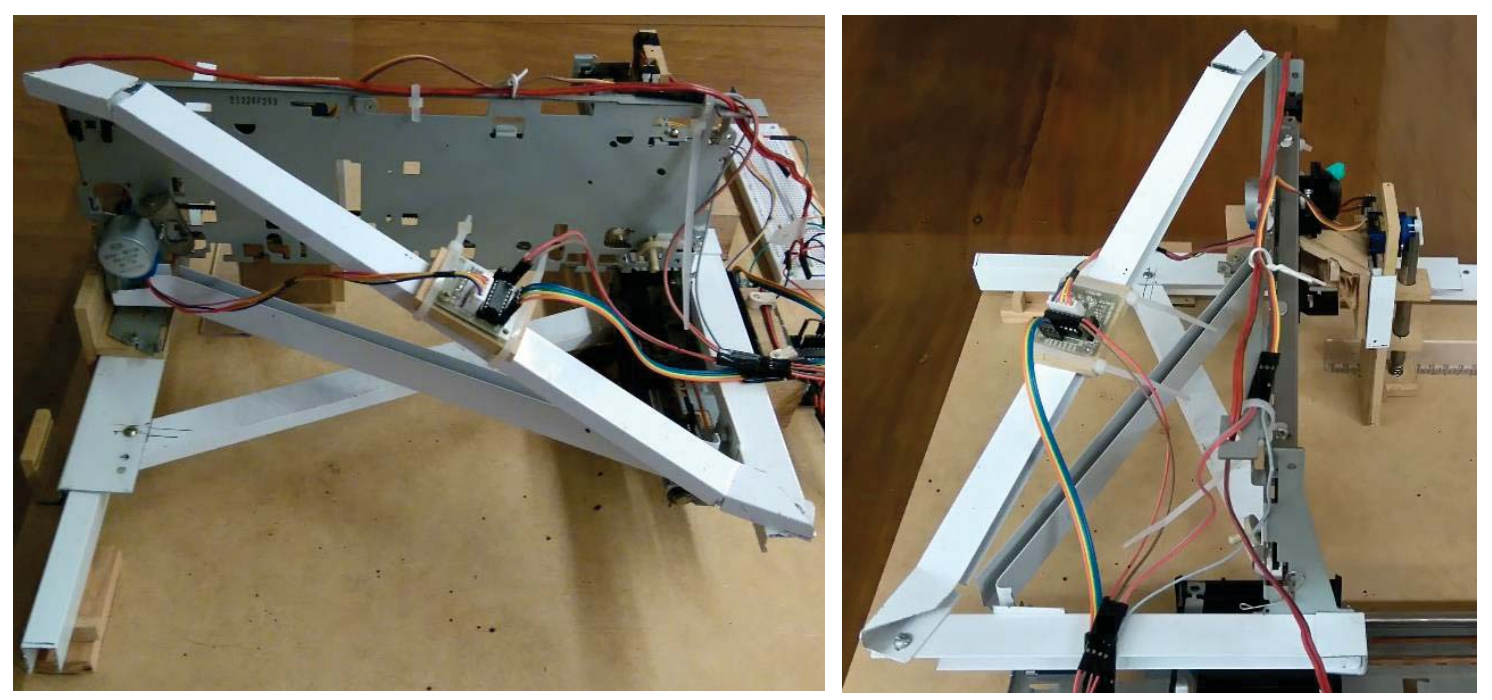

Figura 5.13 - Vistas frontal (a) e lateral (b) da estrutura de travamentos em treliça adotada para aumentar a rigidez do conjunto.

Para movimentar o marcador foram utilizados dois motores de passo 28BYJ48 de 5V, um para cada eixo. Trata-se de um motor de passo unipolar com 4 solenoides para controle da rotação, que lhe conferem um movimento angular padrão de $5,625^{\circ}$ por passo utilizando a recomendação de controle em meio passo. Esses 
motores contam ainda com uma redução interna de 1/64 que o proporciona um bom torque a uma velocidade de rotação máxima de aproximadamente 14 RPM. Esta redução acoplada também acaba por reduzir o movimento angular resultante a $0.088^{\circ}$ por passo, elevando sua resolução de posição e deixando o controle de posição mais preciso. Esses motores de passo, geralmente, são acompanhados pelo driver de controle ULN-2003, o que simplifica sua implementação em um circuito de controle. A alimentação de ambos os motores de passo e também do servo motor é realizada por meio de uma única fonte de $5 \mathrm{~V}$ e corrente máxima de 2,5A.

Para marcar uma origem, isto é, o ponto de começo da marcação, são utilizados 2 pares de sensores de fim de curso, posicionados em um dos extremos de cada eixo de movimentação, como mostrado na figura 5.11. Antes da execução de qualquer marcação, o marcador deve sempre retornar à posição desses sensores. Desta maneira, estabelece-se um padrão de origem que deve ser o mesmo do padrão gerado computacionalmente. Para permitir um ajuste desta origem, admite-se um pequeno retorno após o contato com os sensores de fim de curso. Após repetidos usos, pode ocorrer desgaste de componentes ou eventuais folga, sendo assim o comprimento do recuo após o contato com cada sensor de fim de curso serve como medida de calibração do ponto de origem da marcação. Os sensores de fim de curso nada mais são que interruptores que, como utilizados no circuito deste equipamento de impressão, enviam um sinal de Low (OV) para o Arduino enquanto não pressionados, ou High (5V) em caso contrário. Da maneira como programado este sinal de High serve de aviso para parar o motor de passo do eixo cujo sensor emitiu o sinal e impor um ligeiro recuo em seguida.

\subsection{Sistema de Controle}

O controle de todo o processo é realizado por meio de uma placa Arduino Uno R3 ligada a um computador. O Arduino é uma plataforma popular de prototipagem eletrônica open-source de baixo custo, utilizada com frequência em projetos de robótica, automação residencial, impressoras 3D e máquinas CNC em geral entre outros. A placa utilizada conta com um microcontrolador programável ATMEL ATMEGA328 de 8 bits responsável pela execução dos códigos carregados e controle 
dos componentes conectado à placa. Dentre os componentes do circuito do Arduino Uno R3 destacam-se: O oscilador a cristal, responsável pela velocidade de clock de $16 \mathrm{MHz}$; O regulador de tensão, que garante a tensão estabilizada de trabalho da placa de 5V; 14 pinos que podem ser utilizados como entradas e saídas digitais, capazes de assumir dois estados: High e Low, caracterizados pelas tensões de OV e $5 \mathrm{~V}$ respectivamente; 6 canais de conversão analógico digital que permitem a interpretação e envio de sinais de valores variáveis entre $5 \mathrm{~V}$ e 0V; Além de uma porta para comunicação serial (USB), controlada por um microcontrolador ATMEL ATMEGA16U2, responsável pela comunicação do Arduino com o computador. Este último microcontrolador também é responsável por receber os dados pela porta USB, convertê-los apropriadamente e gravá-los no ATMEGA328. Isto permite que os códigos de controle elaborados e compilados no computador sejam carregados de maneira prática e direta no Arduino. A porta USB também pode desempenhar a função de alimentação da placa, uma vez que, portas usb de computadores tem por norma uma tensão de saída de 5V. A figura 5.14 exibe uma placa Arduino Uno R3, na qual são ressaltados os componentes supracitados.

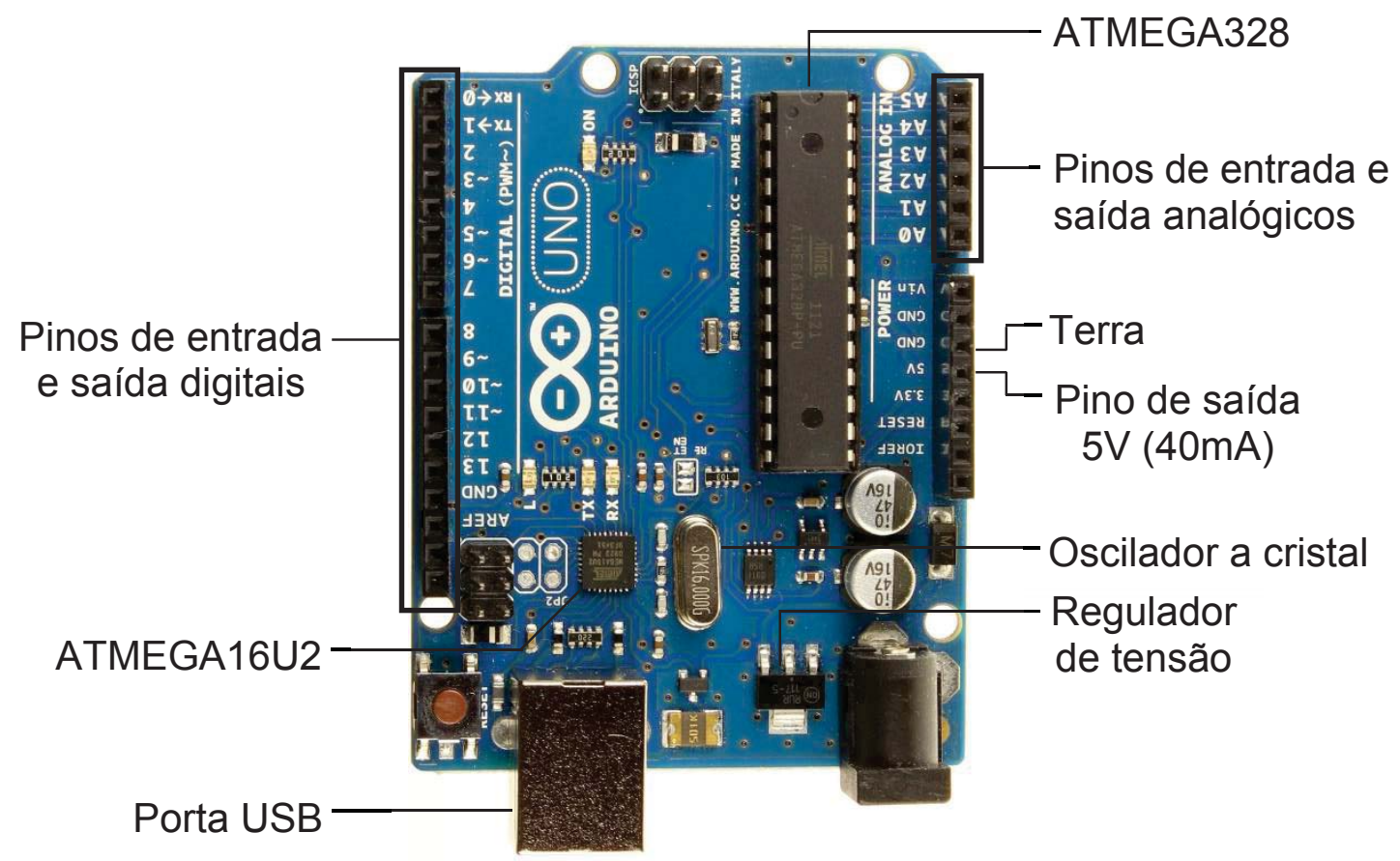

Figura 5.14 - Placa Arduino Uno R3 e seus principais componentes. 
O controle dos motores de passo 28BYJ-48 utilizados é assistido por um par drivers ULN-2003, um para cada motor. O driver é responsável pela interpretação dos sinais enviados pelo Arduino, convertendo-os em informação útil para o motor de passo. Por exemplo, a distância angular percorrida pelo eixo do motor de passo é proporcional à quantidade de sinais enviados ao driver, enquanto a frequência desses sinais dita sua velocidade de rotação. Neste caso, para cada conjunto de driver e motor de passo, o controle, são necessários quatro sinais digitais (High ou Low) distintos, um para cada solenoide do motor. O envio organizado dos sinais, ativa e desativa os solenoides em sequência fazendo o eixo rotor do motor girar, alinhandose com os solenoides energizados. Portanto, para controle de cada par composto por motor de passo e driver selecionados são necessárias quatro saídas digitais do Arduino. A sequência de pinos digitais utilizada na placa do Arduino deve ser conectada na mesma ordem no driver para que os motores funcionem adequadamente.

O servo motor, por outro lado não depende de um controlador adicional para seu funcionamento, podendo ter seu sinal obtido diretamente pelo Arduino. Entretanto, diferentemente do motor de passo, neste caso utiliza-se um único pino de saída analógico. Visto que o modelo de servo motor selecionado, Tower Pro 9g SG90, possui velocidade e torque de trabalho constantes, a única informação necessária para seu funcionamento é o valor da amplitude angular do movimento a ser executado. Embora o Arduino possua uma saída de $5 \mathrm{~V}$, os motores de passo e servo motor empregados foram alimentados por meio de uma fonte externa. O Arduino possui uma corrente máxima de trabalho de $200 \mathrm{~mA}$ somando todos os pinos em trabalho simultâneo. Correntes superiores a este valor representam sério risco à integridade do sistema. Mesmo para o caso do servo motor, onde a corrente necessária é inferior ao limite de corrente do Arduino, não convém a utilização da alimentação direto da placa. Como explica McRoberts (2015) [50], isto pode gerar ruídos nos sinais e também aquecimento excessivo dos componentes eletrônicos.

Por fim, os últimos elementos que restam ser conectados ao Arduino são os circuitos dos sensores de fim de curso, utilizados para definir uma origem para o processo de marcação. Como já comentado, estes sensores de fim de curso são interruptores mecânicos responsáveis por sinalizar ao Arduino o limite físico do curso possível para eixo de movimento. A partir desta informação é possível instituir um ponto de origem padrão para cada marcação. Estes sensores são montados em um 
circuito normalmente aberto, isto é, enquanto não for acionado, o Arduino recebe um sinal de Low (OV). Quando o interruptor do sensor de fim de curso é acionado, o circuito é fechado e o sinal enviado ao Arduino passa a ser High (5V). A troca do tipo de sinal recebido pelo Arduino indica que o final do curso de movimento para o eixo em questão foi atingido e, portanto, o movimento neste eixo deve cessar e um pequeno recuo deve ser executado, liberando novamente o interruptor. Este procedimento é executado apenas uma vez antes do início de todo procedimento de marcação. Para cumprir com esse objetivo, cada sensor de fim de curso é montado em um circuito utilizando um resistor na configuração conhecida como "Pull down", esquematizado na figura 5.15, adaptada de McRoberts (2015) [50].

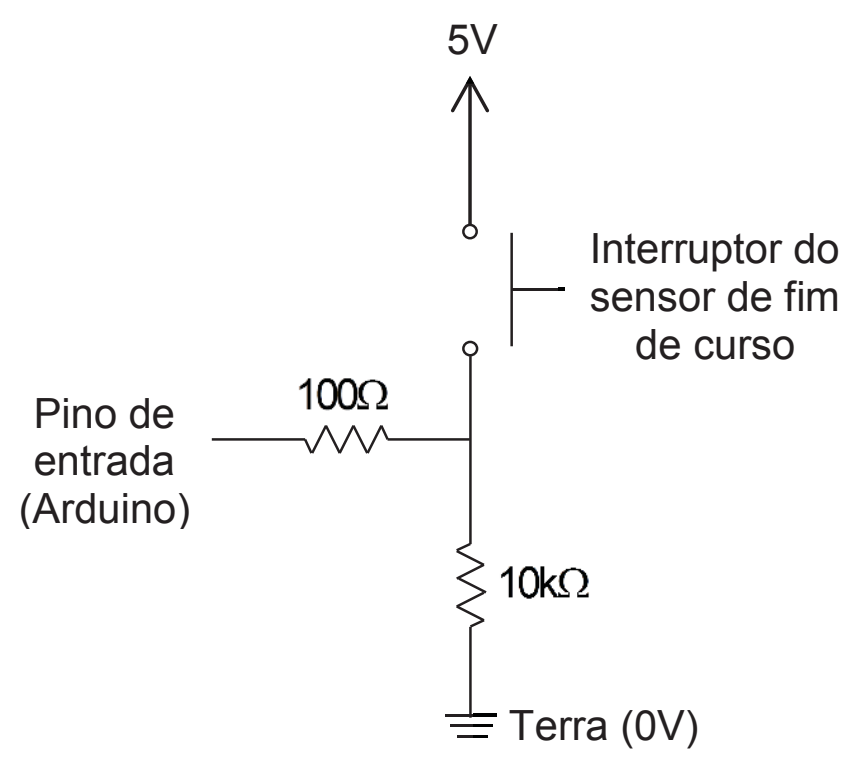

Figura 5.15 - Esquema de um circuito de resistor pull-down.

No circuito exibido, enquanto o interruptor não é pressionado, a entrada é apontada para o terra (OV). Quando o interruptor for pressionado, a corrente seguirá

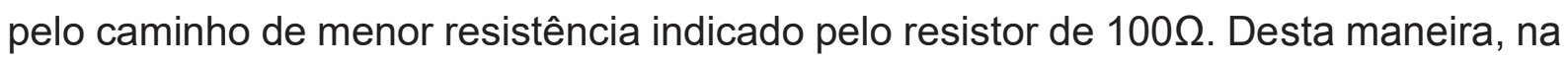
entrada passa a ser registrado um valor de 5V. Como explicado em McRoberts (2015) [50], a ausência do resistor de $10 \mathrm{~K} \Omega$ implicaria no pino de entrada do Arduíno não estar conectado a nada enquanto o interruptor não fosse acionado deixando-o suscetível a ruídos. Isto acontece pois quando definidos como pinos de entrada, os pinos digitais do Arduino são colocados em uma condição de elevada impedância, equivalente a um capacitor de 100 Megohms montado logo à frente do pino de acordo 
com a documentação oficial do Arduino. Isto faz com que o Arduino faça demandas extremamente baixas de corrente ao circuito em que é ligado para obter suas leituras. Porém isto também significa que correntes muito baixas, como correntes induzidas por campos eletromagnéticos também, são capazes de produzir valores consideráveis de tensão neste pino, provocando mudanças aleatórias de estado. $\mathrm{Na}$ condição de pino flutuante, como também é conhecida, os fios que compõem o circuito conectado ao pino agem como pequenas antenas, agravando o problema de sinal ruidoso.

Um esquema completo do circuito como montado no equipamento de marcação desenvolvido é exibido no apêndice A. A ordem dos pinos do Arduino utilizados é importante para o funcionamento correto dos componentes conectados e também do código de controle carregado.

\subsection{Rotina para Marcação de Pontos}

Para que seja possível a execução coordenada dos processos envolvidos no procedimento de marcação dos pontos é necessário um código de controle específico. O Arduino conta com um ambiente integrado de desenvolvimento, geralmente conhecido pelas siglas em inglês IDE, a partir do qual é possível escrever os códigos de controle, compilá-los e carregá-los no microprocessador ATMEGA328 via USB. A linguagem utilizada para tal consiste em um apanhado de funções de $\mathrm{C} / \mathrm{C}++$ que podem ser carregadas aos códigos por meio de uso de bibliotecas. Desta maneira, livros que tratam da linguagem C, como Backers (2013), servem como boas fontes para a programação da rotina para o Arduino.

O Arduino já possui diversas bibliotecas que permitem o controle de uma série de equipamentos como os servos e motores de passo aqui utilizados. Apesar de a sua biblioteca padrão para controle de servos se adeque bem ao modelo de servo utilizado, o mesmo não acontece para o modelo de motor de passo selecionado. $\mathrm{A}$ utilização da biblioteca original para controle do motor de passo 28BYJ-48 acaba por provocar aquecimento excessivo, indesejável em longas operações contínuas. Outro ponto negativo da biblioteca original para motores de passo é que ela se limita ao controle de um motor de passo por vez, o que inviabiliza movimentos em diagonal do marcador e, consequentemente, aumenta consideravelmente o tempo de execução 
de rotas deste tipo. A biblioteca utilizada "Accelstepper", desenvolvida por Mike McCauley e distribuída gratuitamente pela Airspayce Pty Ltd. sob termos de uma licença GPL V2, permite não só o controle simultâneo de ambos os motores de passo e um menor aquecimento, mas também outras opções como controle de aceleração e desaceleração.

Apesar de muito versátil, o Arduino Uno possui uma memória de armazenamento (SRAM) de apenas 2 Kbytes. Isto limita consideravelmente o tamanho das informações que podem ser carregadas em seu microprocessador. Isto também inviabiliza que sejam armazenados, em seu interior, grandes matrizes e vetores, como é o caso dos vetores contendo os incrementos de passo de cada eixo. Para contornar este problema, utilizou-se a capacidade de comunicação serial do Arduino, através da qual é possível tanto enviar pacotes de informações ao Arduino quanto receber respostas do mesmo. Aproveitando-se desta característica, foi elaborado um código em Python 3.5 em conjunto com a extensão para comunicação pySerial. É importante ressaltar que esta extensão é exclusivamente 32 bits, logo também foi utilizada a versão do Python 3.532 bits.

O código em Python contém os vetores de incrementos de passos para cada posição de ponto a ser marcado e é responsável por coordenar a impressão dos pontos em sequência. Isto é, estabelecida a comunicação serial, a rotina em Python envia as coordenadas para marcação do primeiro ponto ao Arduino. O Arduino, então, recebe esta informação, ordena o movimento dos motores de passo para que o marcador seja deslocado até as coordenadas recebidas. Executado o ciclo de trabalho do marcador, ilustrado na figura 5.9, o Arduino envia um pacote sinalizando "ponto marcado" ao computador via USB. O código em Python identifica este pacote de informação recebido e envia as coordenadas do ponto seguinte, dando continuidade à marcação. Este ciclo é repetido até que o padrão de pontos esteja completo.

Antes de enviar informações via comunicação serial, tanto o código Python quanto o Arduino, convertem essa informação para a forma de "string" para contornar a limitação de buffer de apenas 64 bits do Arduino. Essas informações são, então, convertidas aos formatos adequados após recebidas. Além disso, para garantir que a informação está sendo enviada e lida por completo, são utilizados marcadores de início e fim do pacote de informação. A figura 5.16 exibe um exemplo de pacote de informação enviado, na forma de "string", pelo código em Python ao Arduíno. 


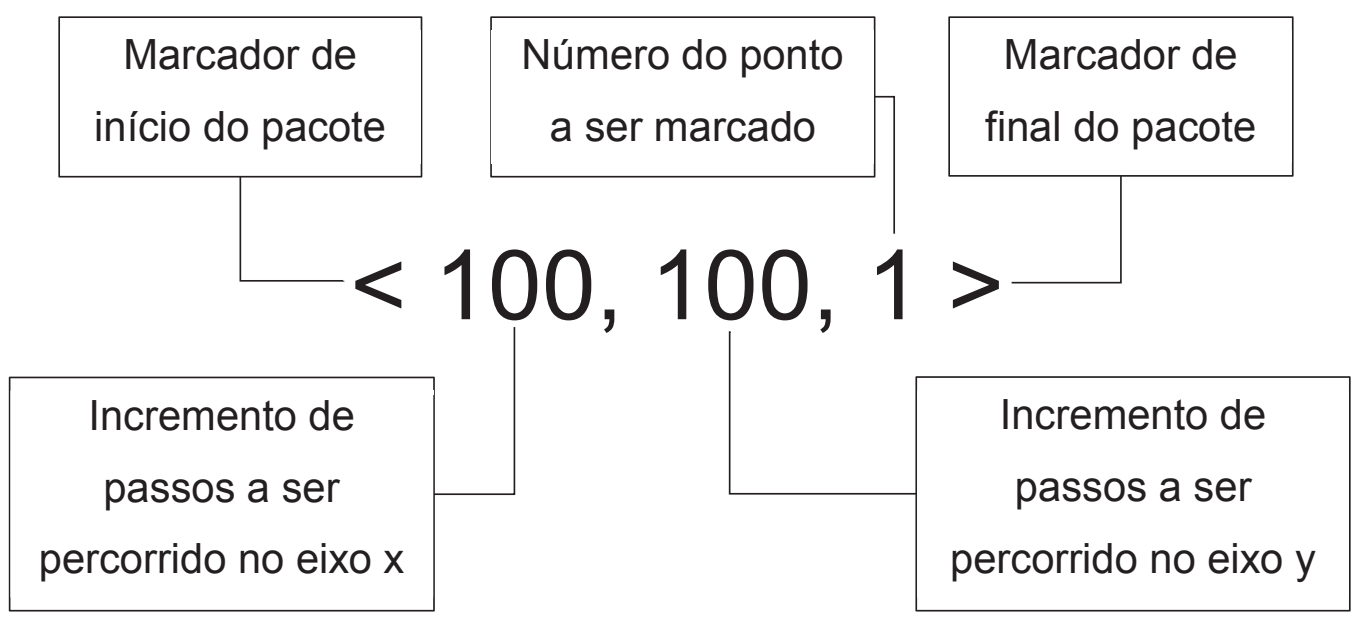

Figura 5.16 - Estrutura do pacote de informações enviados ao Arduino.

O numerador de ponto, mostrado na estrutura de um pacote de informação tem por função indicar o andamento da marcação. Caso a caneta permanente utilizada comece a falhar no meio da impressão, o conhecimento do número do ponto é útil para que a impressão possa ser pausada e retomada do mesmo ponto, ou mesmo de algum ponto anterior, remarcando pontos com pouca nitidez.

Os códigos de geração dos padrões de ponto, em Matlab, e o código para envio de controle do Arduino, em Python, são integrados. Esta integração se dá de maneira que quando gerados os vetores com os incrementos de passos no primeiro código, estes vetores são automaticamente atualizados no código Python, tornando o processo mais prático.

A figura 5.17 apresenta um diagrama do funcionamento da rotina de controle da marcação de pontos sobre a superfície a ser medida, destacando o funcionamento em conjunto da rotina em Python, responsável pelo controle, com o código carregado no Arduino, responsável pela execução. Neste esquema, inc_x e inc_y correspondem aos vetores contendo as informações acerca do incremento de passos a serem dados antes da marcação de cada ponto. O Arduino é, por padrão, programado para reiniciar automaticamente sempre que uma nova comunicação serial é iniciada. Desta forma, o código do Arduino só tem início de fato, quando o programa de controle em Python inicia a comunicação serial. Todos os códigos discutidos neste capítulo são disponibilizados completos nos apêndices ao final do trabalho. 


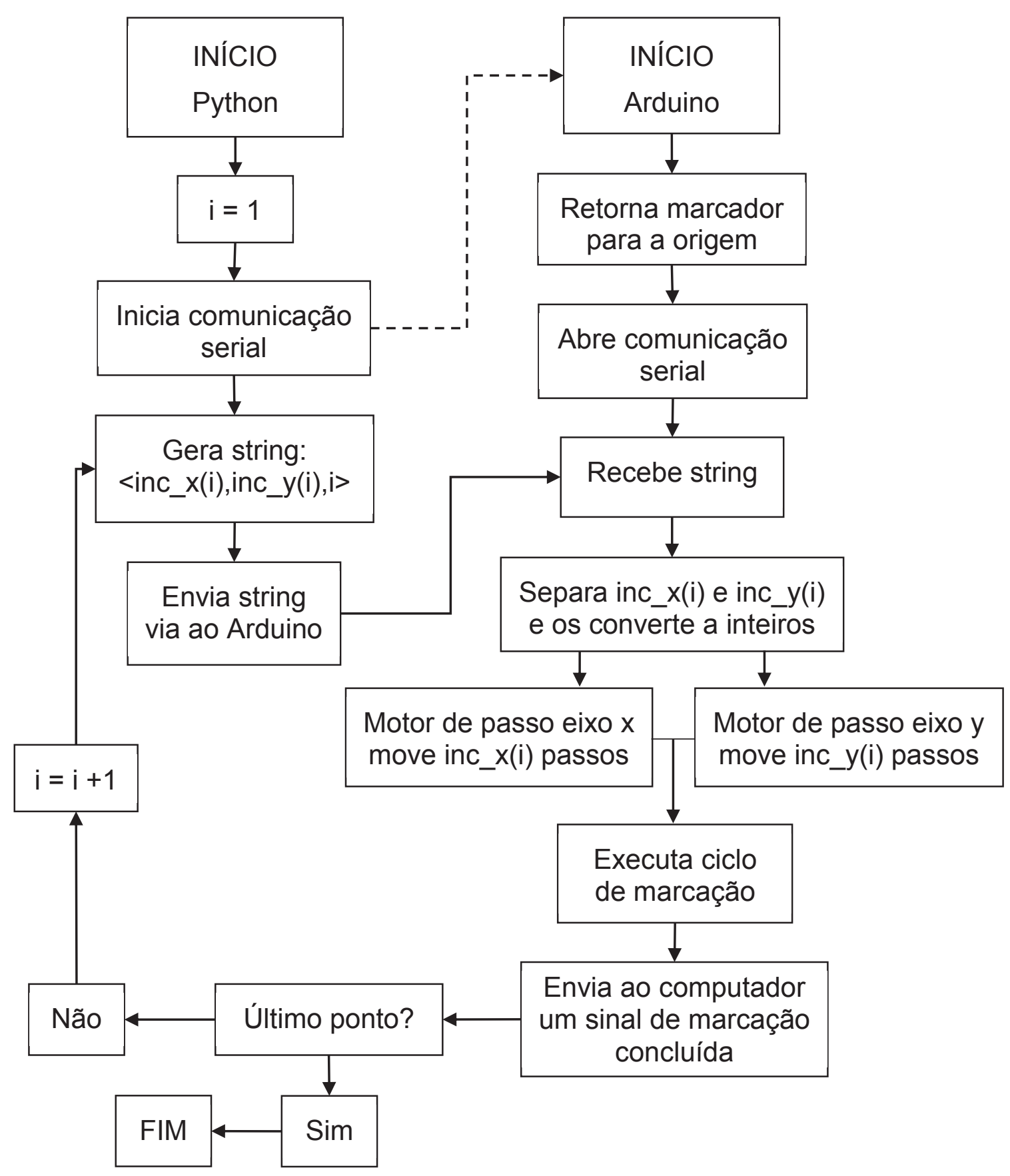

Figura 5.17- Diagrama esquemático da rotina desenvolvida para controle da marcação dos padrões de pontos. 


\section{ANÁLISE EXPERIMENTAL}

\subsection{Montagem Experimental}

Visando a avaliar a metodologia numérica apresentada para simulação de problemas termoelásticos, foi elaborado um procedimento experimental capaz de fornecer, simultaneamente, dados acerca dos campos de temperaturas atuantes e deslocamentos resultantes. Para tal são utilizadas imagens térmicas em conjunto com a técnica de CDI. A análise é realizada sobre um corpo de prova retangular, medindo 140 × 102.6 × 9.6 mm, fabricado em alumínio ASTM 6351 em vista de sua boa capacidade de dilatação térmica e conhecidas propriedades mecânicas.

O campo de temperatura atuante sobre a placa é gerado por uma resistência de cartucho de alta carga, capaz de fornecer uma taxa uniforme de aquecimento ao longo de seu comprimento. Considerando uma placa posicionada verticalmente, a resistência selecionada é montada em contato com sua base. As demais faces da placa são deixadas livres para sofrerem convecção natural. A exposição das faces da placa a este mecanismo de troca de calor tem o objetivo de produzir um gradiente de temperatura similar ao de uma aleta. Além disso, esse posicionamento permite a aquisição das imagens térmicas sobre uma das faces de maior área enquanto as medições por CDI são realizadas na face oposta, como ilustrado na figura 6.1. Isto é importante, pois cada uma destas técnicas de aquisição de dados depende de preparo específico da superfície a ser medida para garantia de sua precisão. O sistema de CDI requer que a superfície a ser medida possua um padrão com distribuição aleatória de pontos para assegurar a precisão dos algoritmos de correlação utilizados. Já para o sistema de aquisição das imagens térmicas é necessário que a superfície a ser medida seja o mais uniforme possível.

A figura 6.1 também exibe a montagem da resistência de cartucho em um canal usinado em um tijolo refratário. Esta montagem tem a função de, além de apoiar a resistência, concentrar o fluxo de calor conduzido na direção de contato com a placa, limitando-o nas demais, dada a característica isolante do tijolo. 


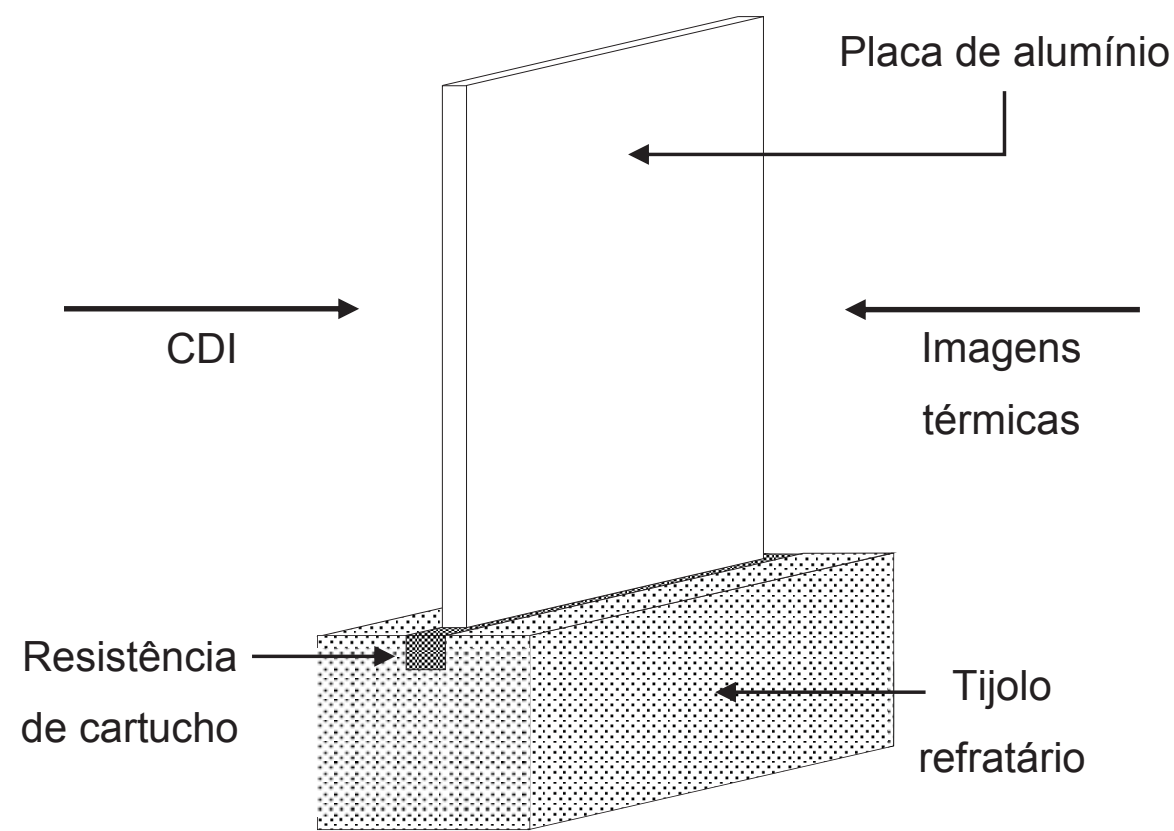

Figura 6.1 - Esquema da montagem da placa de alumínio permitindo a aquisição simultânea das imagens térmicas e das imagens necessárias para análise por $\mathrm{CDI}$.

\subsubsection{Materiais e equipamentos utilizados}

Segue uma listagem de todos os componentes e equipamentos utilizados na montagem e execução do procedimento experimental proposto:

- Corpo de prova retangular (140 x 102.6 x 9.6 mm) de alumínio ASTM 6351;

- Resistência de cartucho de alta carga $220 \mathrm{~V}$ com 3/8" de diâmetro;

- Tijolo refratário;

- 3 Lâmpadas incandescentes de 40w;

- Tarugo de alumínio perfil quadrado (10 x 10 mm);

- Tinta spray preto fosco;

- Tinta spray branco fosco;

- Termovisor FLUKE Ti 125;

- Sistema de correlação de imagens Dantec Q-400;

- Marcador de tinta permanente ponta fina (1.0mm). 


\subsubsection{Construção do sistema de aquecimento}

O sistema de aquecimento utilizado, como comentado consiste basicamente de uma resistência de cartucho de 450W montada em um canal usinado em um tijolo refratário, baseada na montagem utilizada em Oberg (2013) [46]. Diante do formato cilíndrico da resistência utilizada, foi necessária a fabricação de uma peça a ser posicionada entre a resistência e a base da placa a ser aquecida. Para acomodar a resistência cilíndrica de um lado e a base plana da placa do lado oposto, utilizou-se um tarugo de alumínio de perfil quadrado com comprimento de aresta $10 \mathrm{~mm}$. No lado em contato com a resistência, foi usinado um rebaixo semicircular com raio ligeiramente maior que o da resistência, como ilustrado na figura 6.2. O lado em contato com a placa foi mantido plano, sendo apenas necessárias eventuais pequenas correções de irregularidades resultante de seu processo de fabricação.

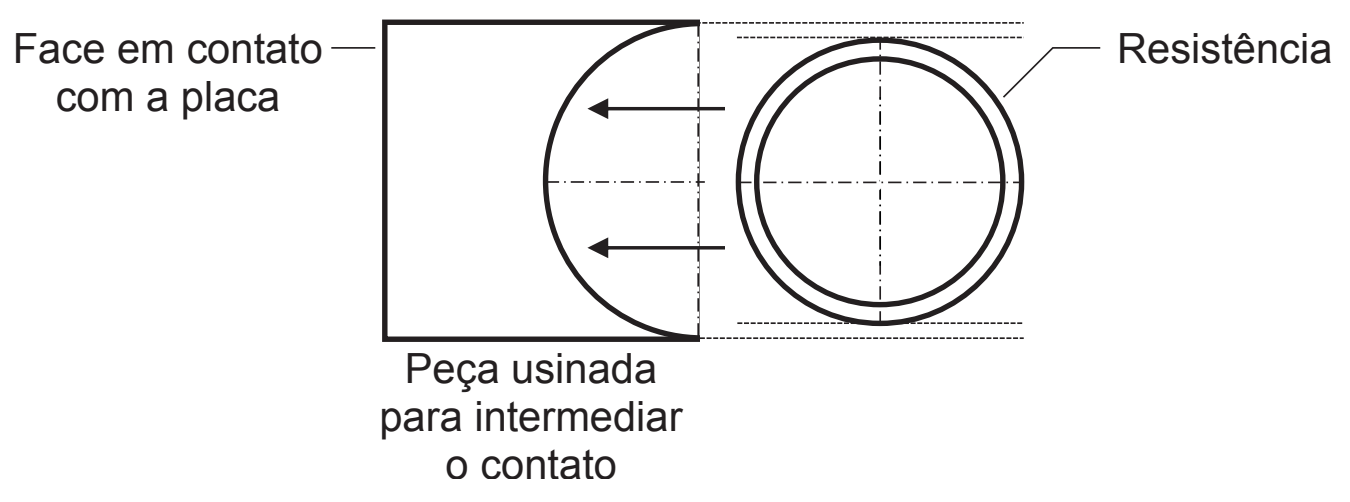

Figura 6.2 - Encaixe entre a peça usinada para intermediar o contato entre a base do corpo de prova e a resistência utilizada.

A folga entre a peça usinada para intermediar o contato entre a resistência e a própria resistência utilizada, evidenciada na figura 6.2, é preenchida com pasta térmica, que além de garantir a adesão entre os componentes, maximiza a condução de calor neste meio. A mesma pasta térmica é utilizada entre a base da placa e face plana da peça utilizada para garantir a condução uniforme de calor ao longo de todo seu comprimento.

A resistência de cartucho de alta carga selecionada é capaz de atingir temperaturas bastante elevadas caso conectada diretamente a uma alimentação 
220V. Entretanto, de acordo com o manual de operação da câmera térmica utilizada, o erro associado à leitura do campo de temperaturas aumenta para superfícies acima de $100^{\circ} \mathrm{C}$. Sendo assim, foi necessária a adoção de um circuito auxiliar para dissipar parte da potência que seria entregue a resistência e, consequentemente, reduzir a temperatura máxima alcançada em regime permanente. Neste sentido foi adicionado um circuito de dissipação composto por 3 lâmpadas incandescentes de 40W ligadas em paralelo ao circuito de alimentação da resistência, como mostra a figura 6.3. A utilização de lâmpadas incandescentes, diferentemente de um sistema de dissipação que utiliza resistências comuns, não requer a utilização de um sistema de arrefecimento para garantia da sua integridade. Desta maneira a construção do sistema elaborado se mantém relativamente simples.

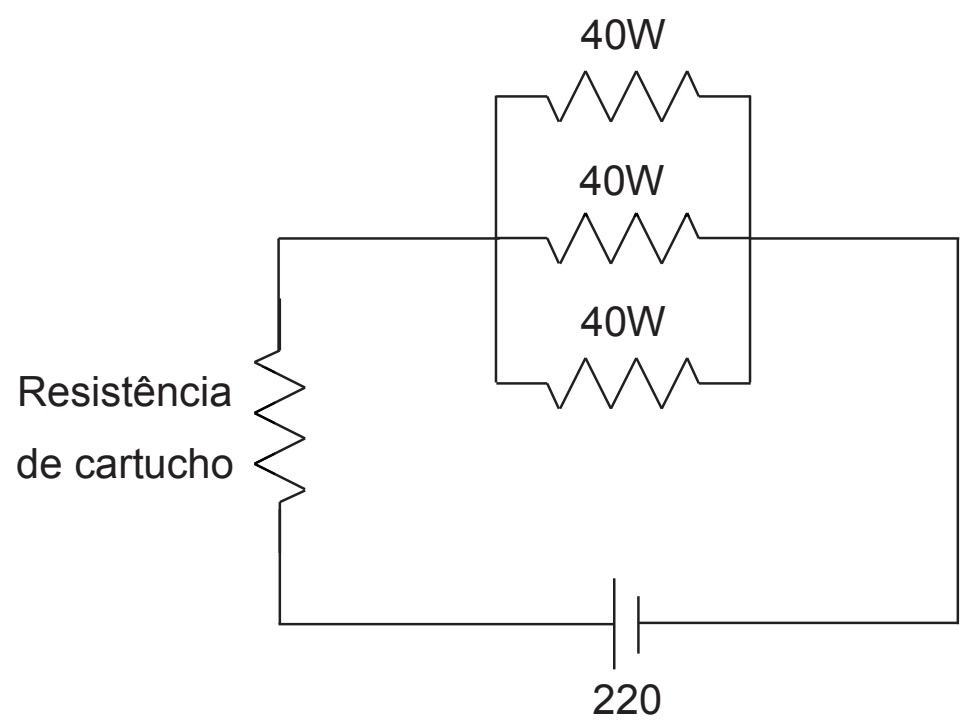

Figura 6.3 - Circuito de alimentação da resistência de cartucho.

\subsubsection{O corpo de prova}

Como comentado, as análises por CDI e por imagens térmicas tem requisitos específicos de preparo da superfície a ser medida. Dada a montagem esquematizada na figura 6.1, o corpo de prova sobre o qual serão realizadas as aquisições de dados deve ter uma de suas faces de maior área preparada para a análise de CDI, enquanto a face oposta deve ser preparada a aquisição das imagens térmicas. 
O ensaio por CDI requer que seja impresso sobre a superfície um padrão de pontos com distribuição aleatória. Antes de executar o processo de marcação, a superfície sobre a qual o padrão será impresso é pintada com uma fina camada de tinta spray branca fosca. Isto é realizado para aumentar o contraste do padrão de pontos a ser impresso, dado o impacto deste parâmetro para a precisão da análise ressaltada em Lecompte et al. (2006) [11], Pan et al. (2009) [10], Barranger et al. (2010) [39] e Crammond et al. (2013) [40]. Além disso, a fina camada de tinta branca também tem a função de eliminar o problema da elevada reflexibilidade do alumínio, que pode interferir nas leituras realizadas pelo sistema de CDI. Após o comentado pré-preparo da superfície, o padrão de pontos é marcado utilizando-se o equipamento de marcação CNC desenvolvido para este trabalho. Com base nos resultados apresentados em Lecompte et al. (2006) [11], o padrão marcado, gerado computacionalmente, conta com uma porcentagem de área marcada de cerca de $40 \%$ da superfície total, composto por uma distribuição de pontos com diâmetros de 0,6 \pm 0,1 mm. A figura 6.4 exibe uma foto tirada durante o procedimento de marcação da superfície do corpo de prova utilizado. padrão de superfície obtido ao final é exibido na figura 6.5 .

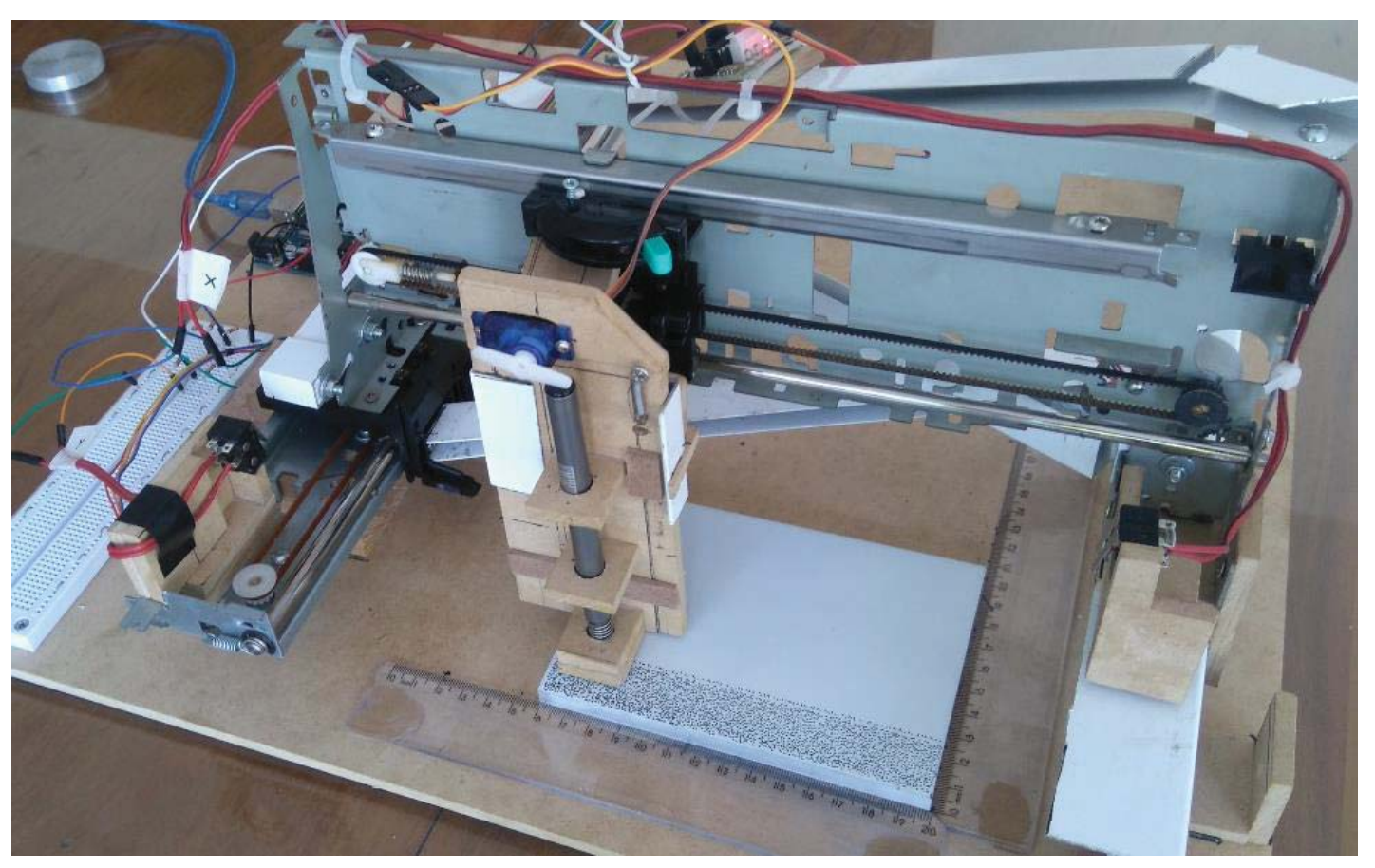

Figura 6.4 - Procedimento de marcação dos corpos de prova. 


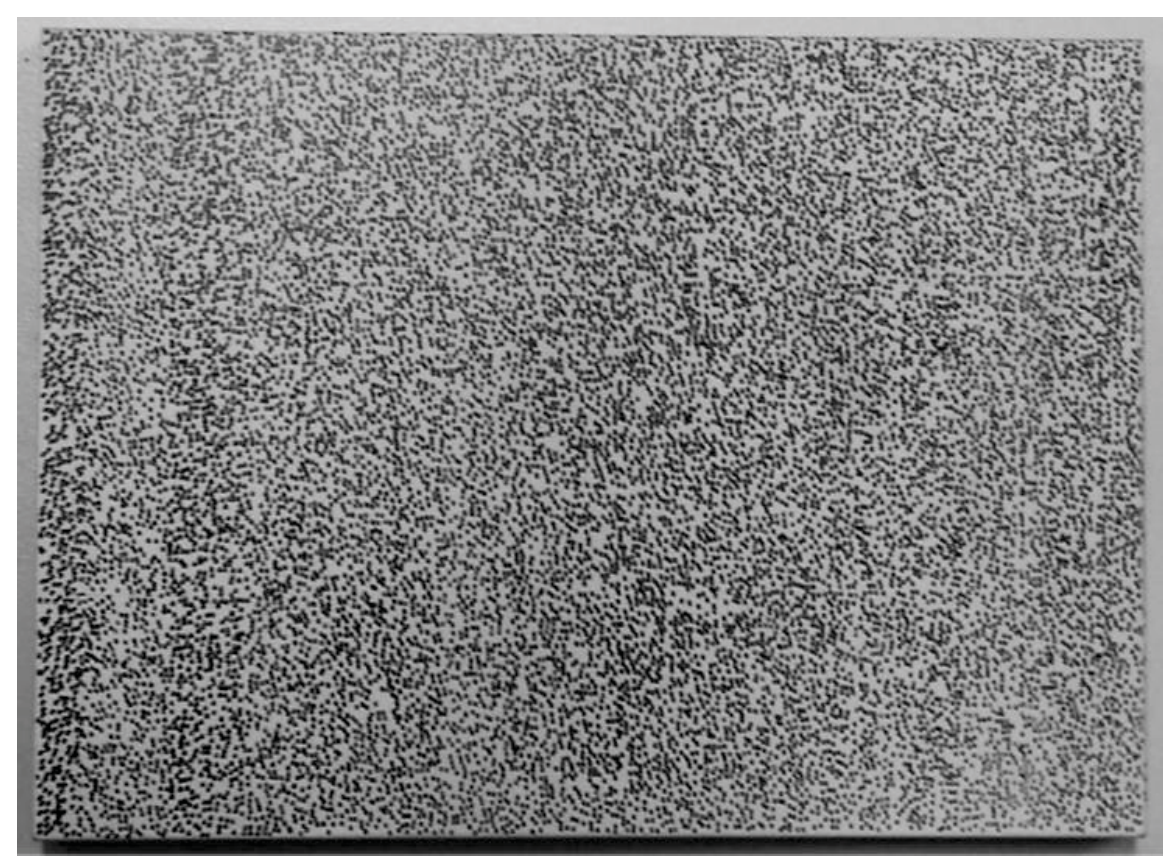

Figura 6.5 - Padrão de pontos resultante do processo de marcação.

Com base em Oberg (2013) [46] e Dondero et al. (2011) [45], a superfície oposta do corpo de prova, na qual serão tomadas as imagens térmicas, foi pintada com uma fina camada de tinta preta fosca. Esta pintura tem a função de maximizar e homogeneizar a emissividade infravermelha da superfície interpretada pelo software da câmera térmica utilizada, resultando em campos de temperaturas adquiridos mais precisos.

\subsubsection{Montagem do aparato experimental}

Discutidos todos os elementos da montagem experimental elaborada, a sua montagem final pode ser visualizada nas figuras 6.6, 6.7 e 6.8. A figura 6.6 exibe a montagem experimental sem o corpo de prova. Nesta imagem é possível ver, ao centro, o posicionamento no tijolo refratário do conjunto da resistência de cartucho e a peça usinada para intermediar seu contato com a base do corpo de prova. Nota-se também que o tijolo foi pintado de preto para reduzir a reflexão de luz nas superfícies do corpo de prova sobre as quais são realizadas as medições 
As imagens exibidas nas figuras 6.7 e 6.8 mostram a montagem elaborada dos pontos de vista da câmera térmicas e do sistema de CDI respectivamente. Nestas fotos destacam-se as superfícies a serem medidas por cada equipamento.

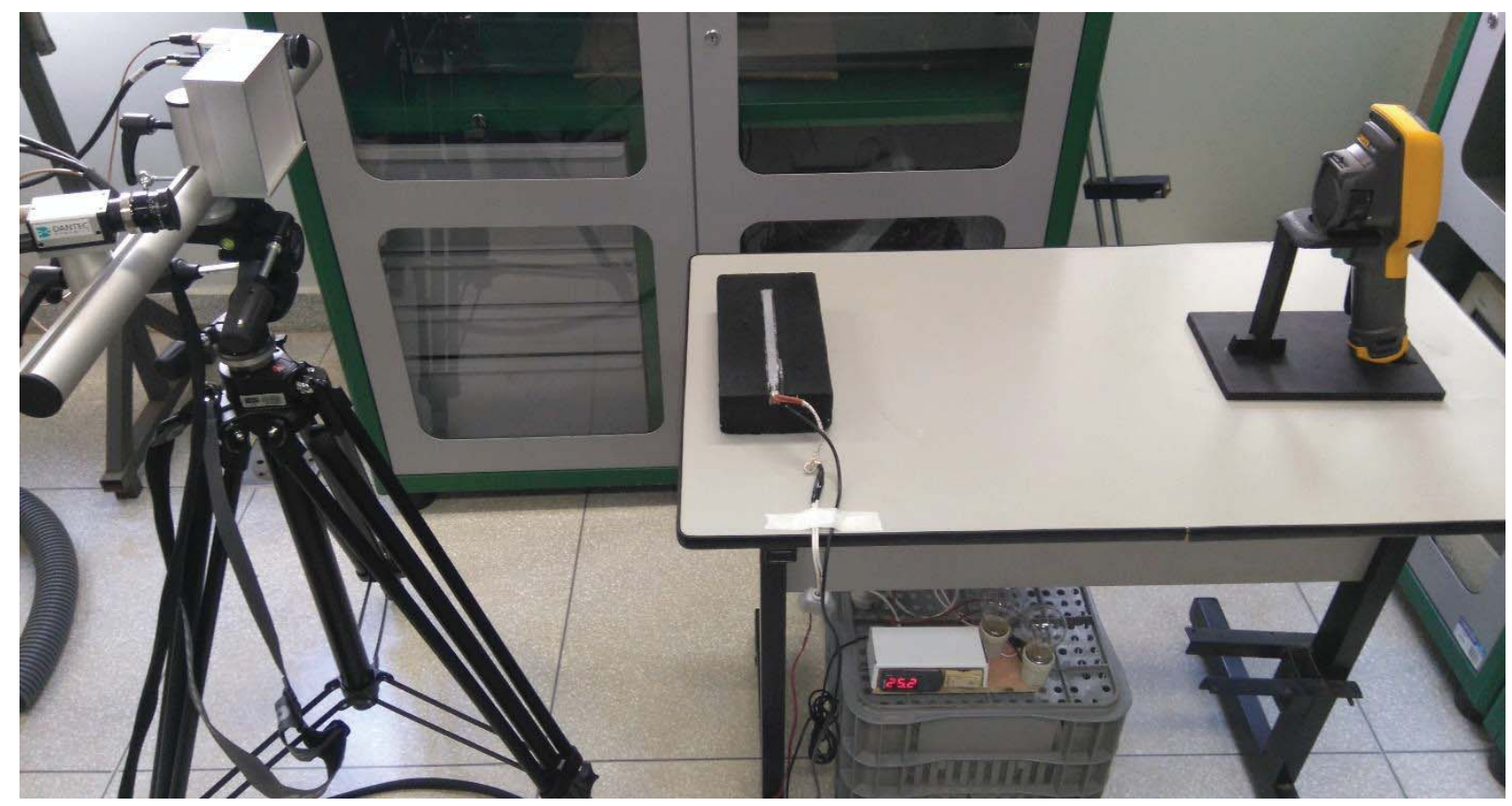

Figura 6.6 - Montagem experimental antes da colocação do corpo de prova

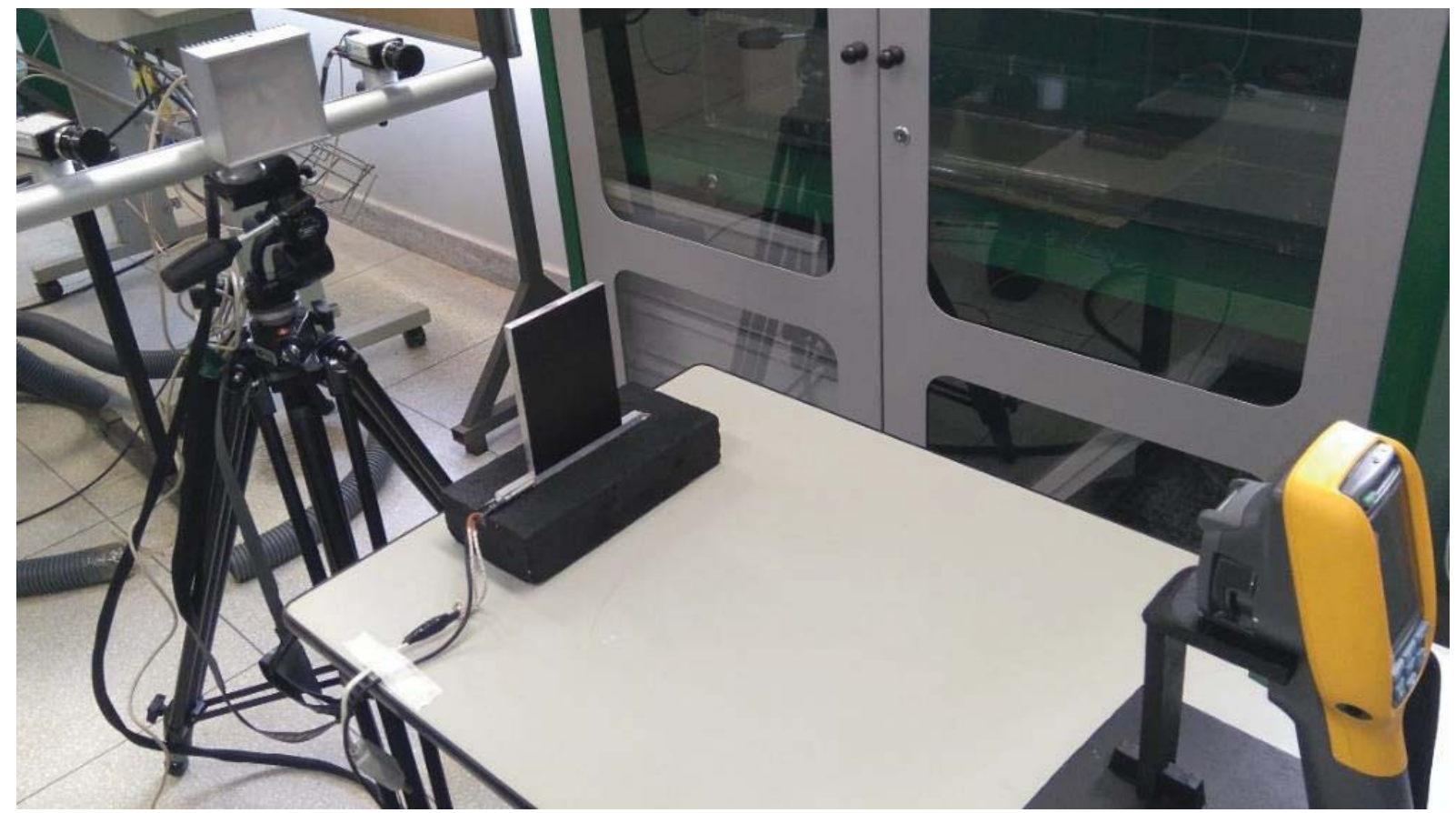

Figura 6.7 - Montagem experimental do ponto de vista da câmera térmica. 


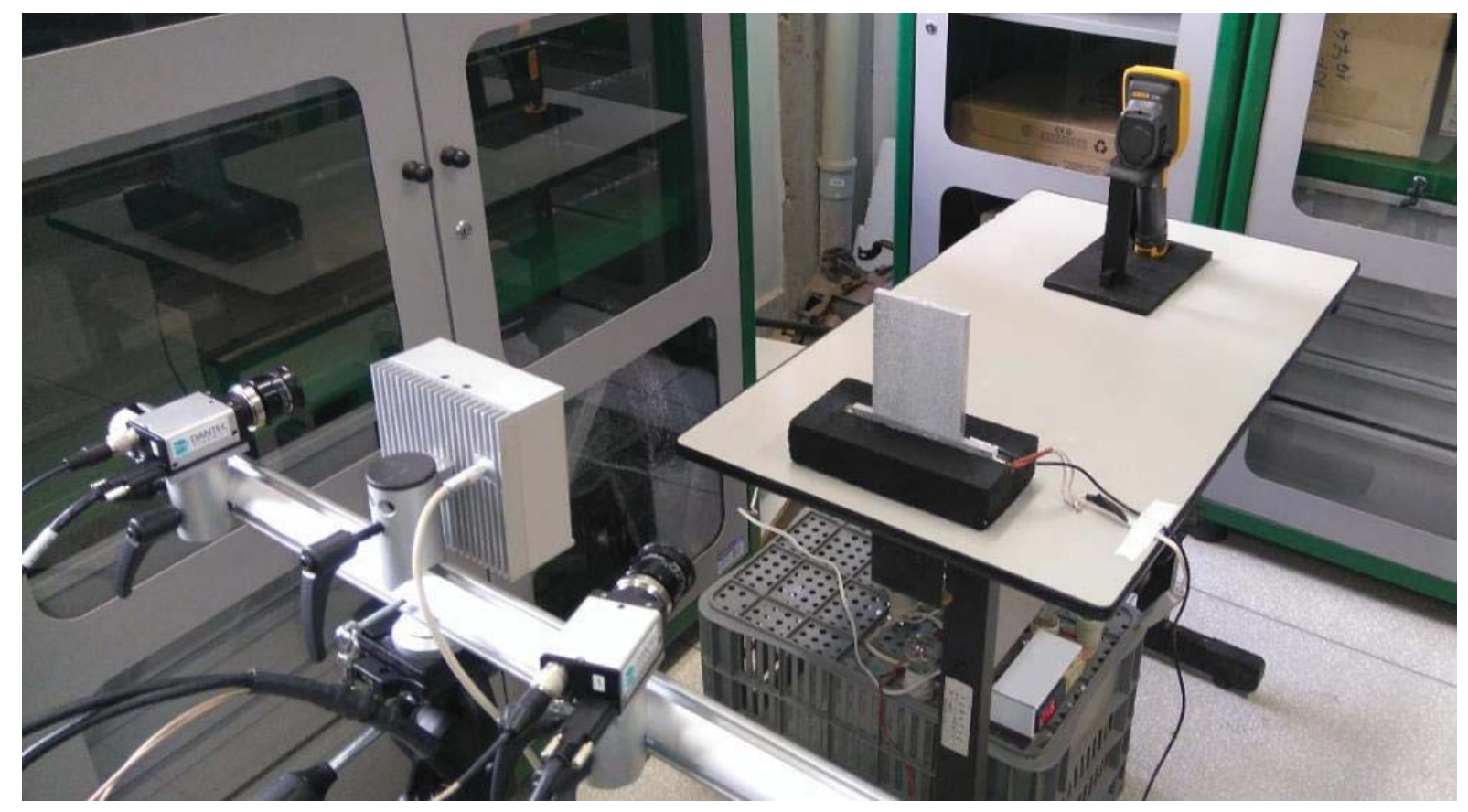

Figura 6.8 - Montagem experimental do ponto de vista do sistema de CDI.

\subsection{Procedimento Experimental}

O procedimento experimental adotado pode ser divido em três etapas principais: a etapa de aquisição de imagens de referência, a etapa de aquecimento e a etapa de aquisição em regime permanente. A primeira destas etapas, a de aquisição de imagens de referências, é realizada antes de qualquer aquecimento e tem por objetivo a aquisição das imagens que servirão de base para as análises térmica e de CDI. A imagem térmica de referência tem a função de fornecer a temperatura que o corpo de prova se encontra ao início do experimento. Além disso serve para verificar se o corpo de prova se encontra em condição isotérmica, ou seja, se a temperatura é constante ao longo de toda sua superfície. Esta condição será importante na etapa de verificação da metodologia numérica, facilitando a obtenção do campo de temperatura resultante do processo de aquecimento. Durante esta etapa também é obtida a imagem de referência a ser utilizada pelo sistema de CDI para o cálculo do campo de deslocamento. 
Terminada a etapa de aquisição de imagens de referência, o circuito da resistência de cartucho é acionado e tem início o lento processo de aquecimento do corpo de prova. O processo de aquecimento é acompanhado pelo visor da câmera térmica de maneira que seja possível detectar se a condição de regime permanente, na qual o sistema atinge um estado de temperatura estável, é atingida. A etapa de aquecimento tem duração de aproximadamente duas horas. Durante esta etapa é imprescindível que o ambiente no qual o experimento esteja montado seja livre de perturbações que possam afetar o mecanismo de convecção a que o corpo de prova é submetido.

Atingida a condição de regime permanente um novo conjunto de imagens é adquirido pela câmera térmica e pelo sistema de CDI, concluindo o procedimento experimental proposto.

\subsection{Resultados Experimentais e Análises}

\subsubsection{Imagens térmicas}

$\mathrm{Na}$ imagem térmica, adquirida antes do aquecimento, verificou-se uma condição isotérmica com o corpo de prova na temperatura ambiente de $28,8^{\circ} \mathrm{C}$. Já na imagem térmica adquirida na condição de regime permanente, exibida na figura 6.9, observa-se um gradiente quase linear na direção $x_{2}$. Enquanto isso, na direção $x_{1}$ é observado um comportamento quase simétrico, com gradientes mais acentuados nas regiões próximas às arestas laterais devido à convecção natural nas laterais do corpo de prova. A simetria observada indica um aquecimento quase homogêneo da base do corpo de prova, evidenciando o bom funcionamento da resistência de cartucho utilizada.

A condição isotérmica do corpo de prova no instante anterior ao aquecimento permite que o campo de temperaturas efetivamente resultante do aquecimento seja obtido por meio da subtração direta do valor da temperatura inicial, $\theta_{0}$, de todos os 
valores de temperaturas pontuais, $\theta_{\mathrm{ss}}\left(\mathrm{x}_{1}, \mathrm{x}_{2}\right)$, que compõem o campo de temperaturas em regime permanente. A equação (6.1) resume esta operação.

$$
\theta\left(\mathbf{x}_{1}, \mathbf{x}_{2}\right)=\theta_{\mathrm{ss}}\left(\mathbf{x}_{1}, \mathbf{x}_{2}\right)-\theta_{0}
$$

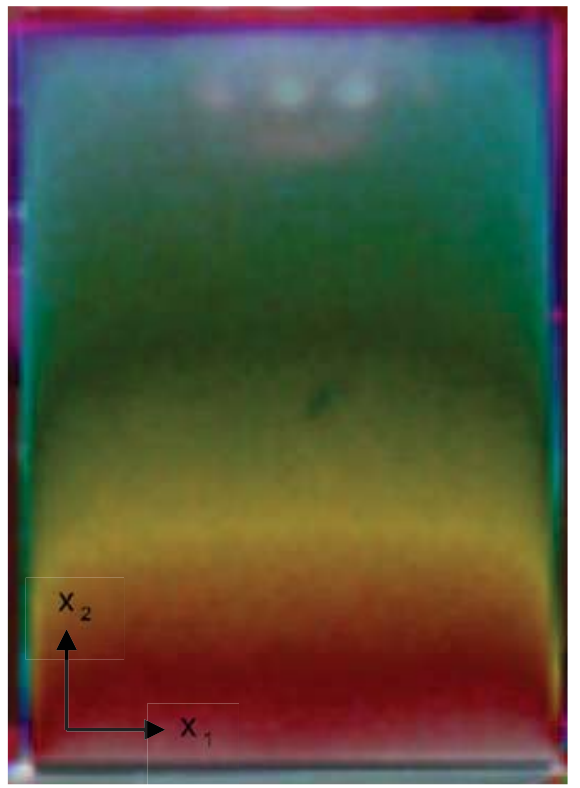

Figura 6.9 - Imagem térmica do campo de temperatura em regime permanente.

\subsubsection{Resultados da análise de CDI}

Em posse da imagem de referência e da imagem em regime permanente, o sistema de CDI é capaz de calcular o deslocamento resultante para um conjunto de pontos físicos distribuídos ao longo da superfície medida. A geração e posicionamento destes pontos físicos é realizada de maneira automática pelo próprio equipamento de CDI utilizado com base no padrão de pontos marcado sobre a superfície. A figura 6.10 exibe a disposição dos pontos físicos gerados no interior da placa pelo sistema de CDI. A partir desta figura é possível notar que os pontos físicos gerados apresentam uma distribuição relativamente homogênea, favorecendo o procedimento de interpolação para obtenção dos deslocamentos nas demais regiões da superfície. Este fato, em conjunto com a grande quantidade de pontos físicos observados indicam 
um bom desempenho das metodologias de geração e aplicação de padrões de superfície para análises por CDI desenvolvidas para este trabalho. Entretanto, notase também nesta imagem a ausência de pontos físicos na região mais próxima à base. Originalmente, no arquivo de saída fornecido pelo software de análise de CDI, fornecido em conjunto com o equipamento utilizado, contava com um conjunto maior de pontos físicos registrados. Os pontos não considerados na figura 6.10 não apresentavam significado físico real para a análise, possuindo coordenadas que extrapolavam os limites físicos da placa, ocupando regiões até mesmo em planos distantes do plano da placa. Este fenômeno foi percebido nos pontos mais próximos à região da base da placa, levando a sua exclusão. Uma hipótese que explica este fenômeno é, que mesmo pintado de preto fosco, ainda houve reflexão da iluminação do sistema de CDI na superfície do tijolo refratário, afetando as leituras nas regiões da placa mais próximas.

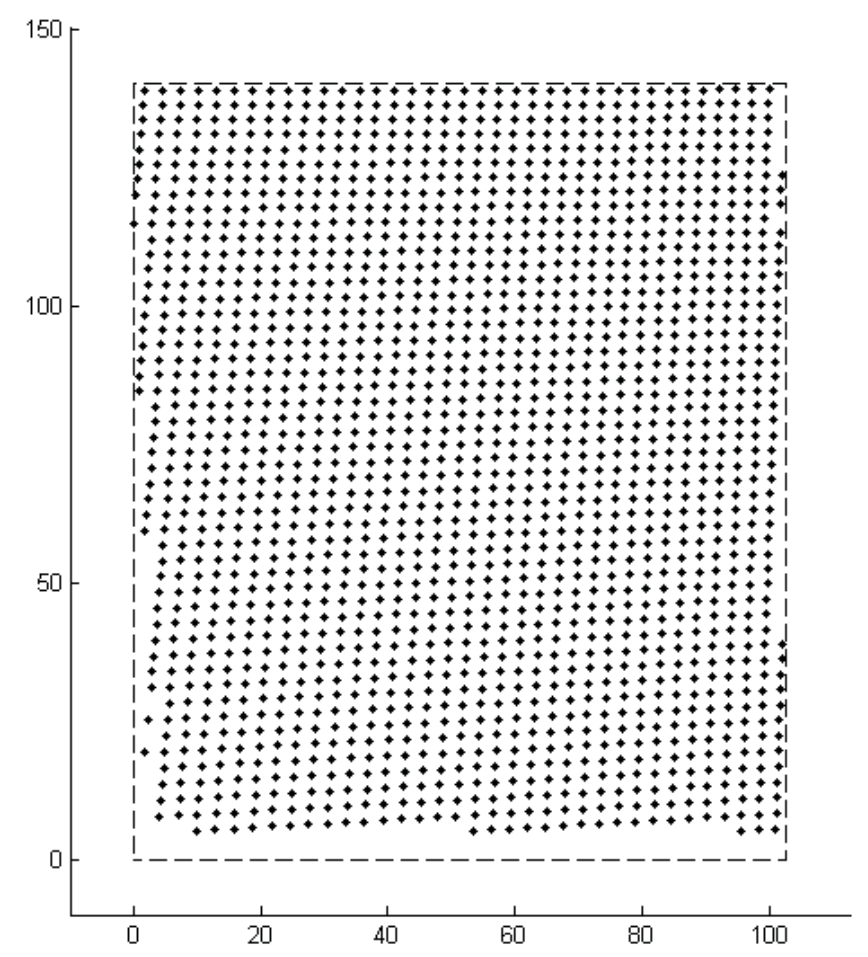

Figura 6.10 - Distribuição de pontos físicos gerados pelo sistema de CDI.

Juntamente com as coordenadas o sistema de correlação de imagens fornece, entre outros dados, o deslocamento calculado para cada ponto físico. Subtraindo-se a dilatação do conjunto composto pela resistência de cartucho e a peça usinada para 
intermediar o contato da base da placa com a resistência, a interpolação das componentes dos deslocamentos para o restante do domínio resulta nos campos de deslocamentos retratados nas figuras $6.11,6.12$ e 6.13 .

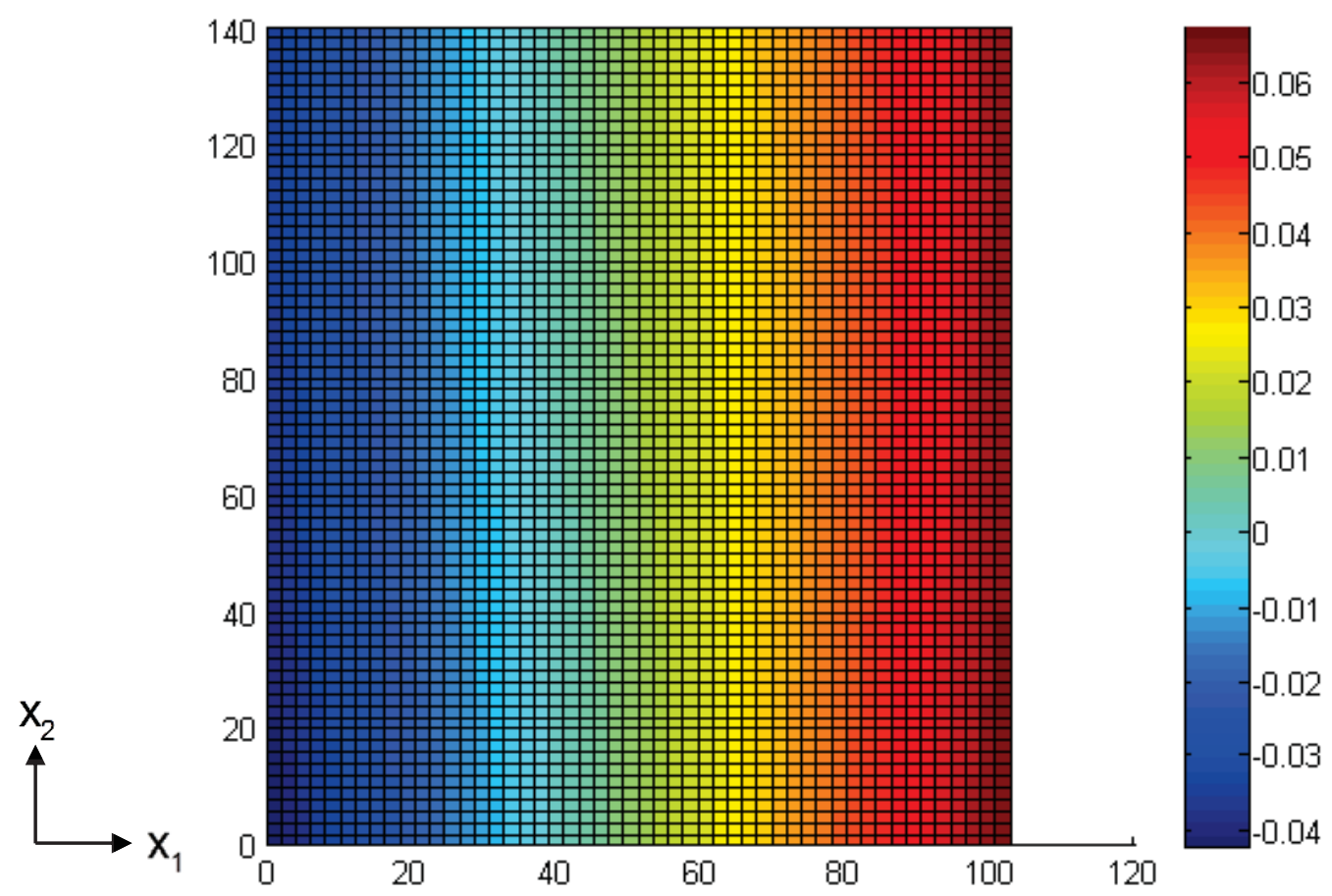

Figura 6.11 - Campo experimental de deslocamentos na direção $X_{1}$. Dimensões em mm.

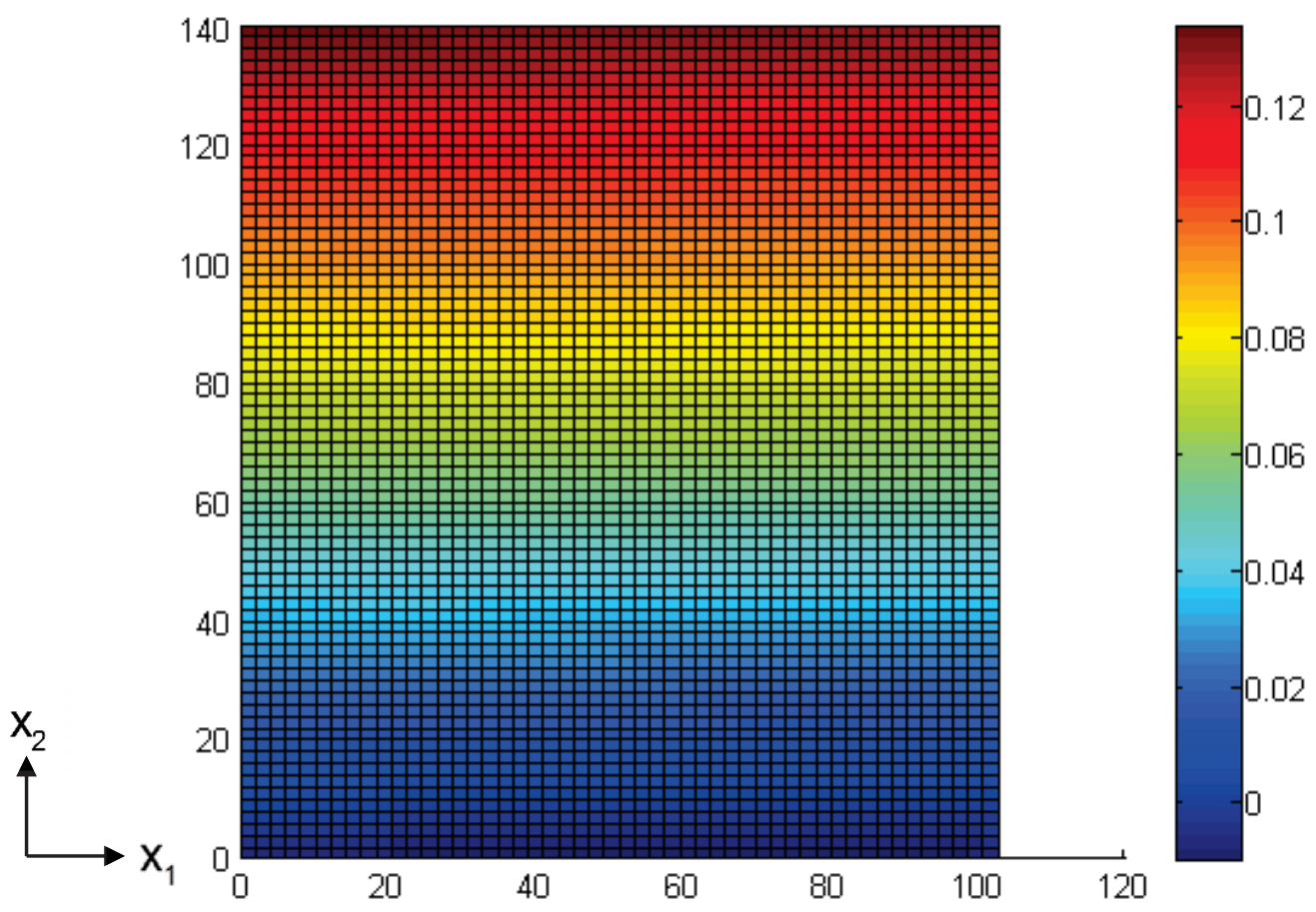

Figura 6.12 - Campo experimental de deslocamentos na direção $X_{2}$. Dimensões em mm. 


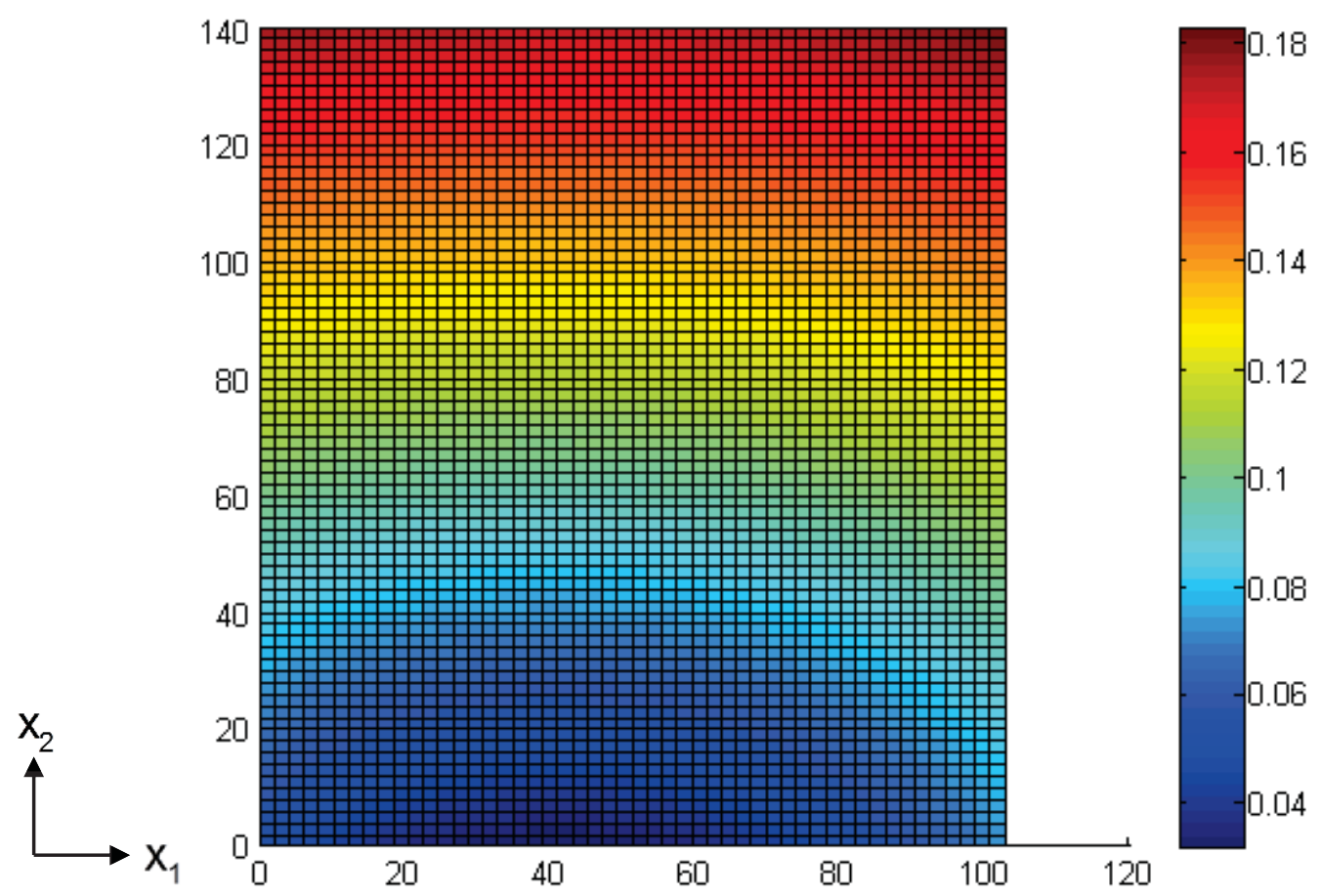

Figura 6.13 - Campo experimental de deslocamentos resultantes. Dimensões em mm.

O campo de deslocamentos resultante exibido na figura 6.13 é obtido de forma indireta com base na soma vetorial das componentes nas direções $x_{1}$ e $x_{2}$ obtidas experimentalmente.

Da análise das figuras 6.11 e 6.12 nota-se um comportamento quase linear dos campos das componentes dos deslocamentos tanto na direção $x_{1}$ quanto na direção $x_{2}$. Ainda da análise da figura 6.11 , nota-se a presença de um eixo quase vertical com deslocamento quase nulo na direção $x_{1}$ dividindo o campo em duas regiões: uma com deslocamentos apenas no sentido positivo de $x_{1}$ e outra com deslocamentos apenas no sentido negativo de $x_{1}$. A posição em que este eixo cruza com a aresta da base da peça age como um ponto de ancoragem do corpo de prova, permanecendo fixa durante todo o aquecimento. A determinação deste ponto é necessária para que a construção do modelo numérico a ser simulado utilizando o MEC para termoelasticidade retrate a condição visualizada experimentalmente. Neste sentido, parte-se de uma busca dos pontos físicos visando determinar os indivíduos cujo valor absoluto da componente do deslocamento na direção $x_{1}$ mais se aproximam de $0 . A$ aplicação de uma regressão linear ao conjunto de pontos encontrados resulta no eixo 
apresentado na figura 6.14. Nesta figura, os pontos circulados correspondem ao conjunto de pontos físicos utilizados na regressão realizada. Este procedimento resultou em um ponto de interceptação a aproximadamente $38 \mathrm{~mm}$ da aresta esquerda do corpo de prova.

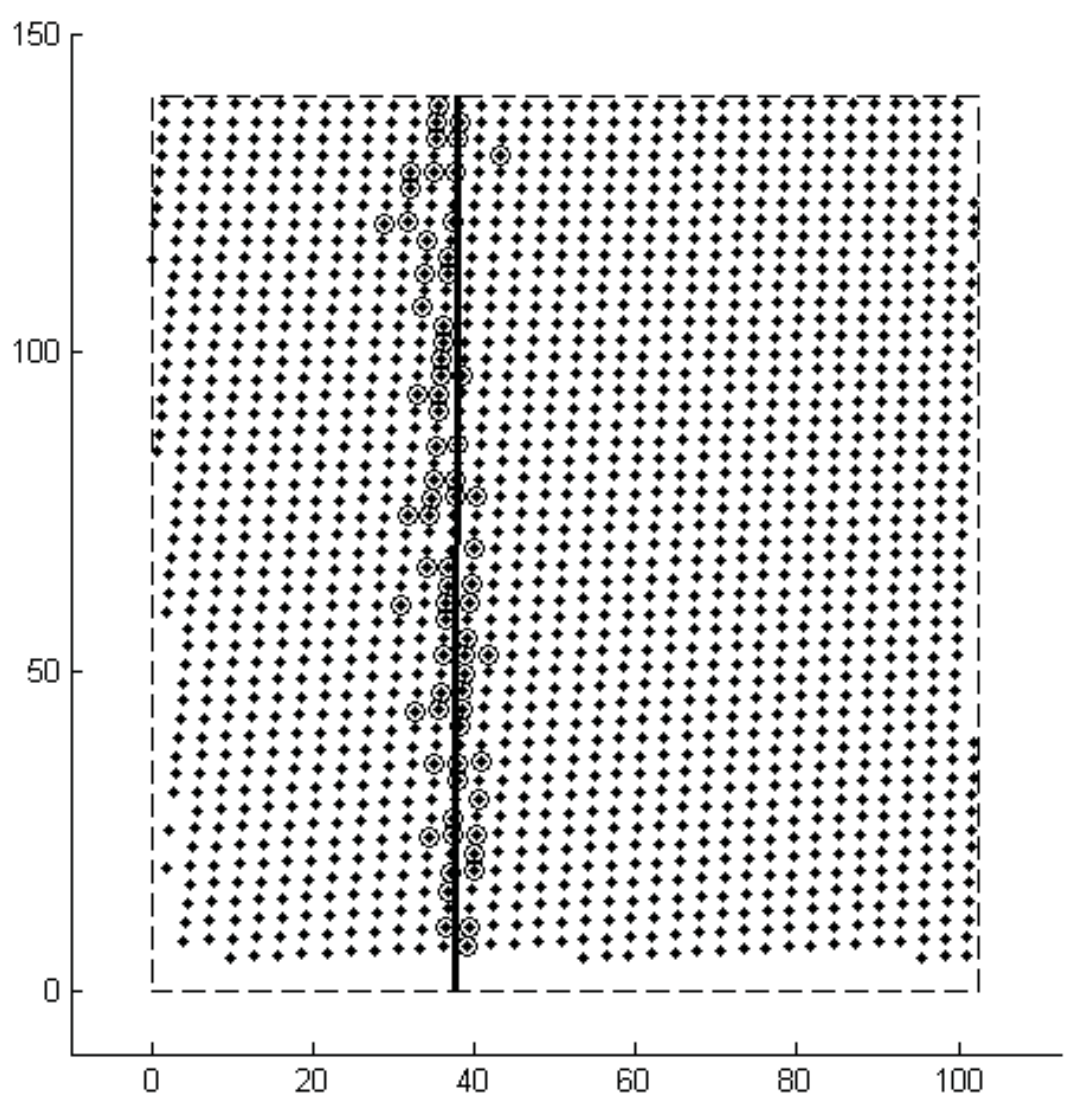

Figura 6.14 - Determinação do ponto de ancoragem do corpo de prova. 


\section{VERIFICAÇÃO DA METODOLOGIA NUMÉRICA}

Em posse dos dados experimentais acerca do campo de deslocamentos causado pelo aquecimento do corpo de prova, o passo seguinte deste trabalho consiste na reprodução numérica da condição observada experimentalmente. E por fim, avaliar desempenho da metodologia numérica utilizada por meio da comparação direta entre os resultados numéricos por ela proporcionados e os resultados experimentais obtidos na etapa anterior.

\subsection{O Modelo Numérico}

Para possibilitar a avaliação da performance da metodologia numérica, baseada na formulação bidimensional do MEC para problemas termoelásticos apresentada, o primeiro passo consiste na elaboração de um modelo capaz de reproduzir de maneira fiel a condição experimental observada. Sendo assim, com base nas observações experimentais discutidas no capítulo anterior foi elaborado o modelo apresentado na figura 7.1. Como é possível observar por esta figura, o modelo elaborado consiste basicamente de um contorno retangular que replica as dimensões do corpo de prova original, 140 x $102.6 \mathrm{~mm}$. Para simular o apoio da base do corpo de prova no equipamento de aquecimento, aplica-se a condição de contorno de restrição do deslocamento na direção $\mathrm{X}_{2}$ ao longo de toda a aresta inferior do modelo. Além disso, buscando a obtenção do mesmo comportamento observado experimentalmente para o deslocamento na direção $\mathrm{X}_{1}$, figura 6.11 , aplica-se também a essa aresta uma restrição pontual do deslocamento nesta direção. O posicionamento deste ponto com a restrição em ambas as direções a aproximadamente $38 \mathrm{~mm}$ da aresta da esquerda do modelo elaborado se dá em conformidade com os resultados da análise do ponto de ancoragem realizada no capítulo anterior. 


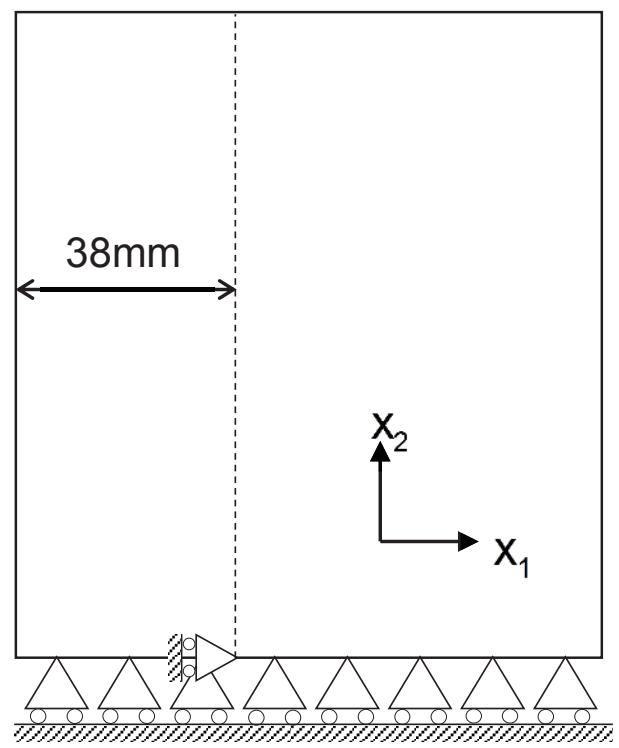

Figura 7.1 - Modelo elaborado para reprodução das condições observadas experimentalmente.

Estabelecidas as condições de contorno de restrição de deslocamentos realizou-se um breve teste de convergência de malha para determinação da discretização ideal do contorno a ser utilizada na análise via MEC. Desta análise, verificou-se que uma discretização em 15 elementos quadráticos descontínuos nas arestas maiores e 11 nas arestas menores é capaz de proporcionar um resultado estável mantendo todos os elementos com aproximadamente o mesmo tamanho. Além disso essa discretização permite o posicionamento de um nó físico próximo à posição de ancoragem exibida na figura 7.1 .

\subsection{A Função que Aproxima o Campo de Temperaturas}

Além do modelo elaborado, outro ponto chave para a análise é determinação da função do campo de temperatura causado pelo aquecimento do corpo de prova $\theta\left(x_{1}, x_{2}\right)$, definido de acordo com equação 6.1. A formulação de MEC para termoelasticidade obtida com base no MIR, demonstrada no capítulo 3, requer que o campo de temperaturas seja descrito na forma de uma função possibilitar a avaliação da integral no termo $F(Q)$, conforme a equação 3.19. O campo de temperaturas experimental obtido na imagem térmica adquirida em regime permanente, figura 6.9, é composto por um grande conjunto de medições pontuais de temperaturas. Desta 
forma é necessária a utilização de uma ferramenta de regressão polinomial para obtenção de um polinômio cuja superfície descrita aproxime bem os valores pontuais de temperatura provenientes da imagem térmica. A função "fit", própria do Matlab, é capaz de fornecer uma função polinomial que aproxima uma distribuição de valores pontuais com coordenadas definidas por uma função polinomial bidimensional com intervalo de confiança de $95 \%$. Para a realização do procedimento de regressão polinomial do campo de temperaturas foram considerados 874 pontos individuais dispostos sobre 19 linhas de aquisição horizontais e igualmente espaçadas.

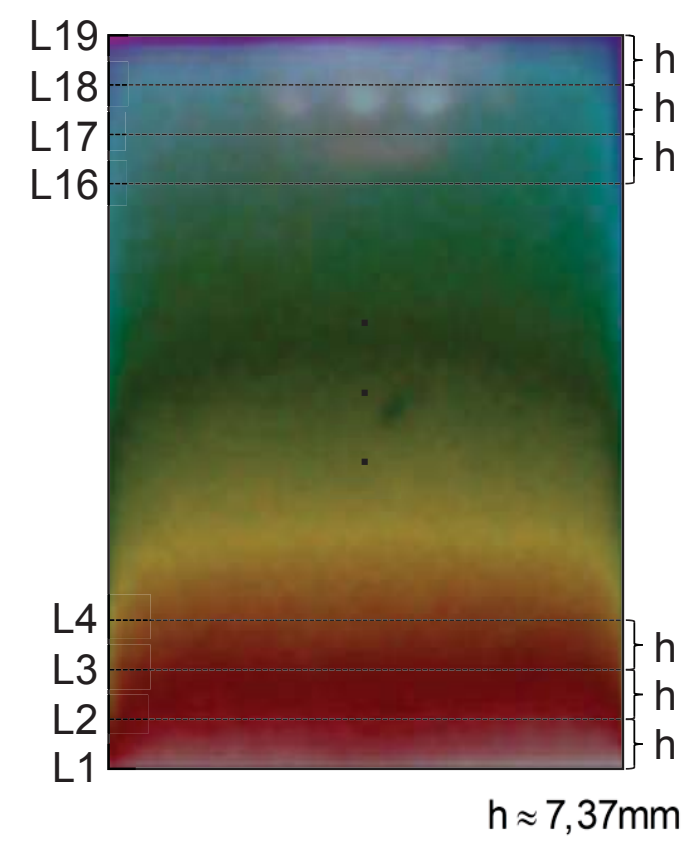

Figure 7.2 - Distribuição dos valores pontuais de temperatura utilizados para a regressão polinomial.

A função "fit" do Matlab é capaz de executar regressões polinomiais bidimensionais de ordens que vão desde bi lineares até mesmo bi quínticas. A fim de avaliar a influência da ordem do polinômio utilizado para aproximar o campo de temperatura em questão, foram realizadas três regressões para polinômios de ordens distintas: bi quadrático, bi cúbico e bi quártico. As figuras 7.3, 7.4 e 7.5 exibem as superfícies descritas pelos polinômios resultantes de cada procedimento de regressão. Os círculos azuis presentes nestas imagens correspondem aos valores experimentais utilizados como base para as regressões. 


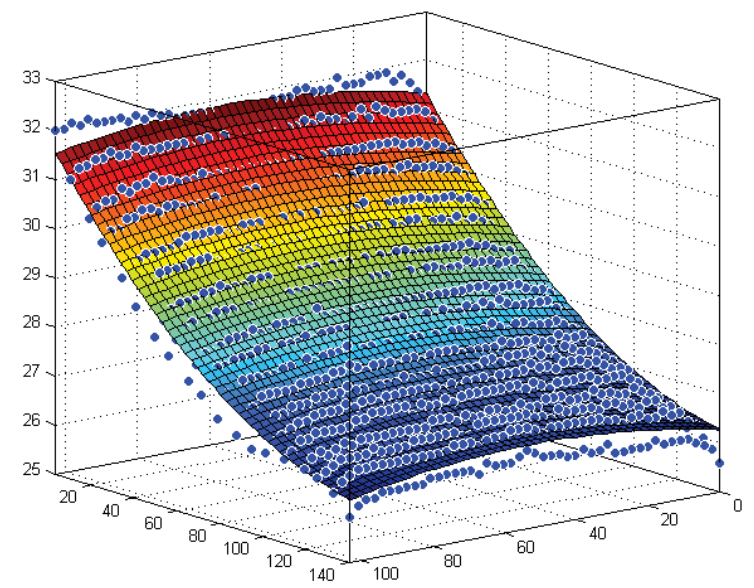

Figura 7.3 - Superfície descrita pelo polinômio bi quadrático resultante do procedimento de regressão.

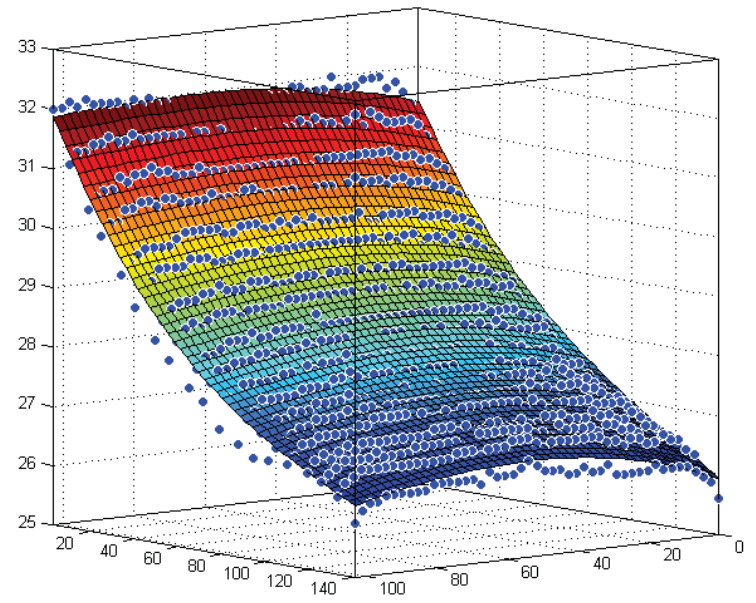

Figura 7.4 - Superfície descrita pelo polinômio bi cúbico resultante do procedimento de regressão.

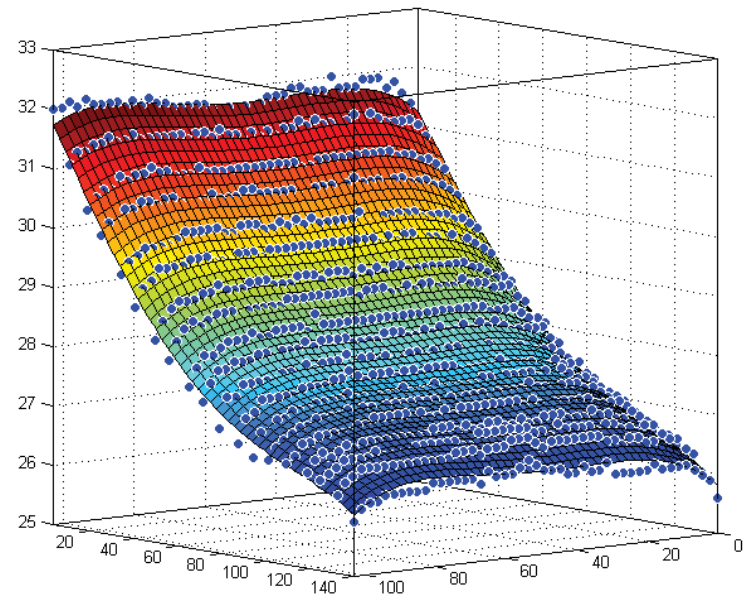

Figura 7.5 - Superfície descrita pelo polinômio bi quártico resultante do procedimento de regressão. 
Os polinômios bi quadrático, bi cúbico e bi quártico resultantes da função "fit" são dados conforme as equações (7.1), (7.2) e (7.3) respectivamente. Os coeficientes obtidos em cada uma das regressões são exibidos nas tabelas 7.1, 7.2 e 7.3.

$$
\begin{gathered}
P_{2}=A_{00}+A_{10} x_{1}+A_{01} x_{2}+A_{20} x_{1}^{2}+A_{11} x_{1} x_{2}+A_{02} x_{2}^{2} \\
P_{3}=P_{2}+A_{30} x_{1}^{3}+A_{21} x_{1}^{2} x_{2}+A_{12} x_{1} x_{2}^{2}+A_{03} x_{2}^{3} \\
P_{4}=P_{3}+A_{40} x_{1}^{4}+A_{31} x_{1}^{3} x_{2}+A_{22} x_{1}^{2} x_{2}^{2}+A_{13} x_{1} x_{2}^{3}+A_{04} x_{2}^{4}
\end{gathered}
$$

Tabela 7.1 - Coeficientes do polinômio: regressão bi quadrática. Intervalo de confiança: 95\%.

\begin{tabular}{|c|c|}
\hline Coeficiente & Valor obtido \\
\hline$A_{00}$ & 31.54 \\
\hline$A_{10}$ & 0.01873 \\
\hline$A_{01}$ & -0.06692 \\
\hline$A_{20}$ & -0.000163 \\
\hline$A_{11}$ & $-1.421 .10^{-5}$ \\
\hline$A_{02}$ & 0.0002092 \\
\hline
\end{tabular}

Tabela 7.2 - Coeficientes do polinômio: regressão bi cúbica. Intervalo de confiança: 95\%. Continua.

\begin{tabular}{|c|c|}
\hline Coeficiente & Valor obtido \\
\hline$A_{00}$ & 31,64 \\
\hline$A_{10}$ & 0,02049 \\
\hline$A_{01}$ & $-0,07807$ \\
\hline$A_{20}$ & $-0,0002216$ \\
\hline$A_{11}$ & $-4,223.10^{-5}$ \\
\hline$A_{02}$ & 0,0004369 \\
\hline$A_{30}$ & $6,749.10^{-7}$ \\
\hline
\end{tabular}


Tabela 7.2 - Coeficientes do polinômio: regressão bi cúbica. Intervalo de confiança: 95\%. Conclusão.

\begin{tabular}{|c|c|}
\hline$A_{21}$ & $-6,341 \cdot 10^{-7}$ \\
\hline$A_{12}$ & $6,517 \cdot 10^{-7}$ \\
\hline$A_{03}$ & $-1,219 \cdot 10^{-6}$ \\
\hline
\end{tabular}

Tabela 7.3 - Coeficientes do polinômio: regressão bi quártica. Intervalo de confiança: 95\%.

\begin{tabular}{|c|c|}
\hline Coeficiente & Valor obtido \\
\hline$A_{00}$ & 31,45 \\
\hline$A_{10}$ & 0,0555 \\
\hline$A_{01}$ & $-0,0677$ \\
\hline$A_{20}$ & $-0,002008$ \\
\hline$A_{11}$ & 0,0002451 \\
\hline$A_{02}$ & $-1,965.10^{-5}$ \\
\hline$A_{30}$ & $2,85.10^{-5}$ \\
\hline$A_{21}$ & $-2,818 \cdot 10^{-6}$ \\
\hline$A_{12}$ & $-1,698.10^{-6}$ \\
\hline$A_{03}$ & $4,215.10^{-6}$ \\
\hline$A_{40}$ & $-1,336 \cdot 10^{-7}$ \\
\hline$A_{31}$ & $-5,818.10^{-9}$ \\
\hline$A_{22}$ & $2,156 \cdot 10^{-8}$ \\
\hline$A_{13}$ & $6,42 \cdot 10^{-10}$ \\
\hline$A_{04}$ & $-1,915.10^{-8}$ \\
\hline & \\
\hline
\end{tabular}

Para realização da integração analítica, conforme a equação 3.19, é necessário convertê-los do sistema de coordenadas cartesianos, como fornecidos, para um sistema de coordenadas polar local. Este procedimento detalhado é apresentado nos apêndices ao final deste trabalho. 


\subsection{Resultados Numéricos X Experimentais}

Estabelecidos o modelo a ser analisado e todas as condições de contorno atuantes sobre ele, é realizada, por fim, a análise numérica utilizando o MEC com formulação para termoelasticidade baseada do MIR. Para uma melhor visualização da comparação entre os resultados numéricos e experimentais adotou-se uma estratégia na qual esta comparação é realizada sobre três linhas horizontais posicionadas conforme mostra a figura 7.6.

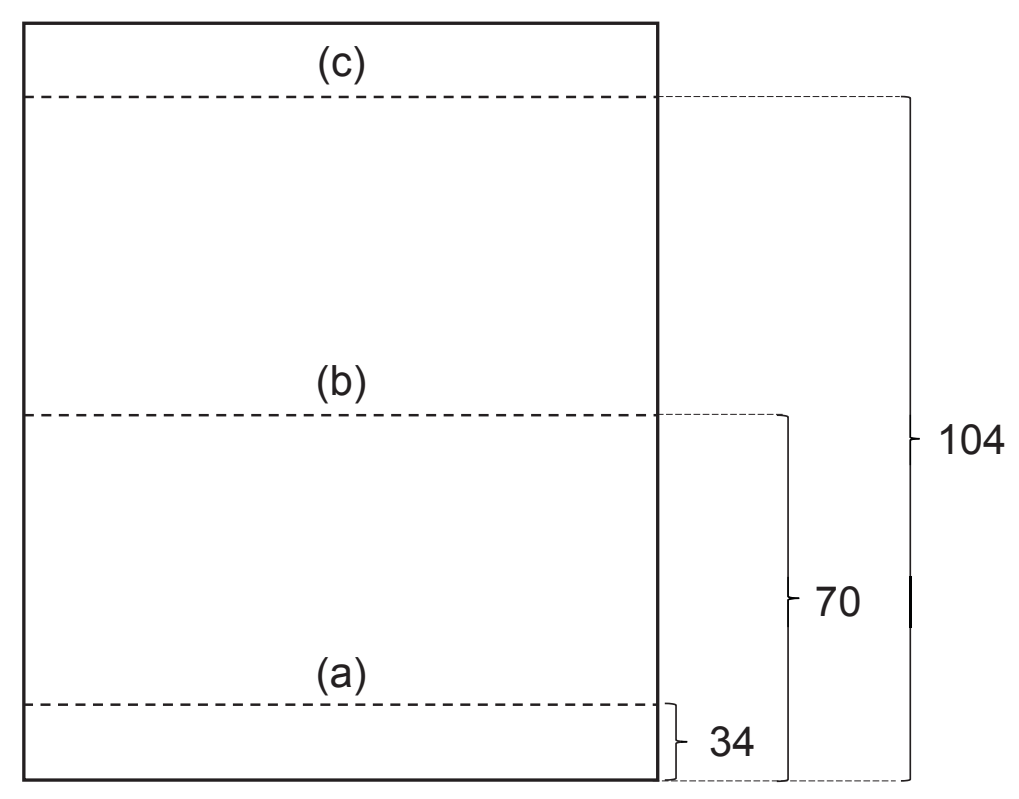

Figura 7.6 - Posicionamento das linhas para avaliação dos resultados numéricos. Dimensões em $\mathrm{mm}$.

Sobre essas linhas são realizadas comparações buscando a análise individual de cada componente dos deslocamentos e também os deslocamentos resultantes para cada tipo de polinômio utilizado para aproximar o campo de temperaturas causado pelo aquecimento. Desta forma, as figuras 7.7 e 7.8 exibem a comparação gráfica entre os resultados numéricos de deslocamento em cada direção para cada aproximação polinomial utilizada e o resultado experimental. Para uma avaliação quantitativa do desempenho das aproximações polinomiais utilizadas para representar o campo de temperaturas foram, também, realizadas análises de erro 
máximo e erro RMS. Os resultados dessas análises, organizado por gráfico utilizado para aproximar o campo de temperaturas são exibidos nas tabelas 7.4 e 7.5.

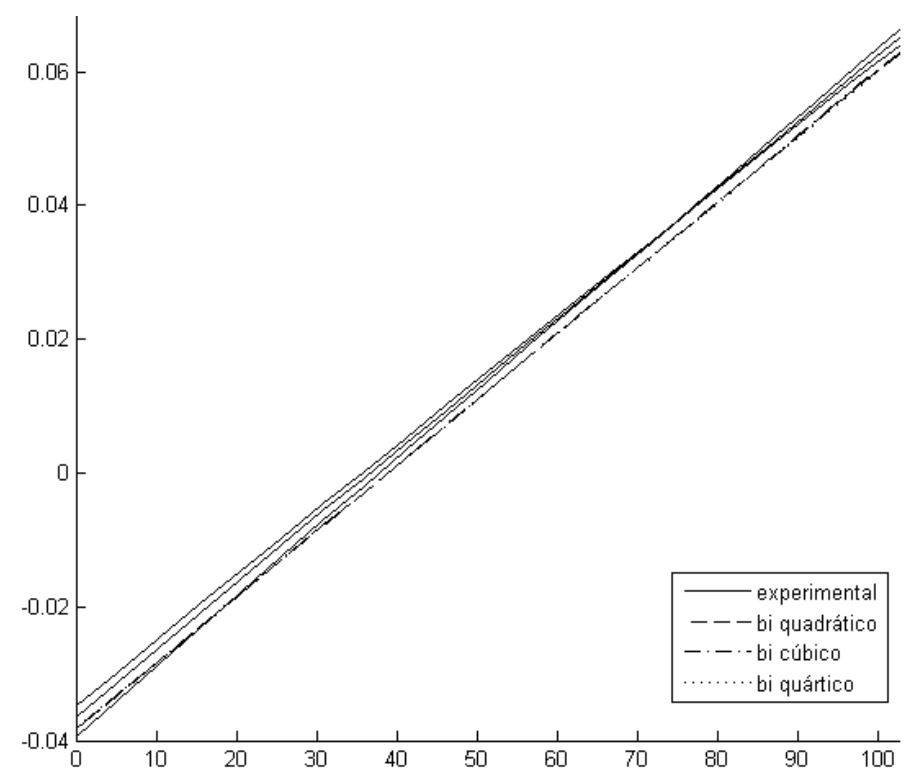

Figura 7.7 - Deslocamentos numéricos $\mathrm{x}$ experimentais na direção $\mathrm{X}_{1}$ sobre as 3 linhas horizontais traçadas na figura 7.6. Dimensões em $\mathrm{mm}$.

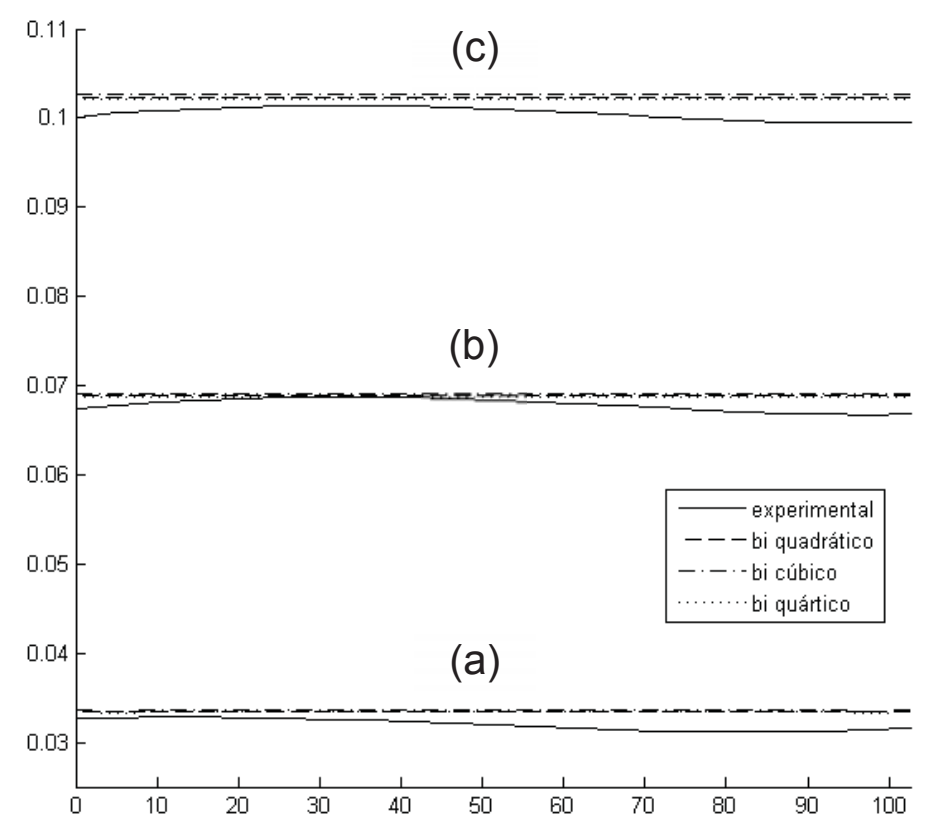

Figura 7.8 - Deslocamentos numéricos x experimentais na direção $X_{2}$ sobre as 3 linhas horizontais traçadas na figura 7.6. Dimensões em $\mathrm{mm}$. 
Tabela 7.4 - Erros máximos do deslocamento calculado na direção $\mathrm{X}_{1}$ em cada linha para cada tipo de aproximação polinomial utilizada para aproximar o campo de temperaturas.

\begin{tabular}{|c|c|c|c|}
\hline Linha & Bi quadrática & Bi cúbica & Bi quártica \\
\hline (a) & $0.0035 \mathrm{~mm}$ & $0.0033 \mathrm{~mm}$ & $0.0036 \mathrm{~mm}$ \\
\hline (b) & $0.0022 \mathrm{~mm}$ & $0.0022 \mathrm{~mm}$ & $0.0024 \mathrm{~mm}$ \\
\hline (c) & $0.0034 \mathrm{~mm}$ & $0.0036 \mathrm{~mm}$ & $0.0033 \mathrm{~mm}$ \\
\hline
\end{tabular}

Tabela 7.5 - Erros RMS do deslocamento calculado na direção $\mathrm{X}_{1}$ em cada linha para cada tipo de aproximação polinomial utilizada para aproximar o campo de temperaturas.

\begin{tabular}{|c|c|c|c|}
\hline Linha & Bi quadrática & Bi cúbica & Bi quártica \\
\hline (a) & $0.0019 \mathrm{~mm}$ & $0.0018 \mathrm{~mm}$ & $0.0020 \mathrm{~mm}$ \\
\hline (b) & $0.0021 \mathrm{~mm}$ & $0.0021 \mathrm{~mm}$ & $0.0022 \mathrm{~mm}$ \\
\hline (c) & $0.0027 \mathrm{~mm}$ & $0.0027 \mathrm{~mm}$ & $0.0028 \mathrm{~mm}$ \\
\hline
\end{tabular}

Tabela 7.6 - Erros máximos do deslocamento calculado na direção $X_{2}$ em cada linha para cada tipo de aproximação polinomial utilizada para aproximar o campo de temperaturas.

\begin{tabular}{|c|c|c|c|}
\hline Linha & Bi quadrática & Bi cúbica & Bi quártica \\
\hline (a) & $0.0023 \mathrm{~mm}$ & $0.0024 \mathrm{~mm}$ & $0.0022 \mathrm{~mm}$ \\
\hline (b) & $0.0021 \mathrm{~mm}$ & $0.0023 \mathrm{~mm}$ & $0.0019 \mathrm{~mm}$ \\
\hline (c) & $0.0029 \mathrm{~mm}$ & $0.0032 \mathrm{~mm}$ & $0.0026 \mathrm{~mm}$ \\
\hline
\end{tabular}

Tabela 7.7 - Erros RMS do deslocamento calculado na direção $X_{2}$ em cada linha para cada tipo de aproximação polinomial utilizada para aproximar o campo de temperaturas.

\begin{tabular}{|c|c|c|c|}
\hline Linha & Bi quadrática & Bi cúbica & Bi quártica \\
\hline (a) & $0.0016 \mathrm{~mm}$ & $0.0017 \mathrm{~mm}$ & $0.0015 \mathrm{~mm}$ \\
\hline (b) & $0.0012 \mathrm{~mm}$ & $0.0014 \mathrm{~mm}$ & $0.0011 \mathrm{~mm}$ \\
\hline (c) & $0.0019 \mathrm{~mm}$ & $0.0022 \mathrm{~mm}$ & $0.0017 \mathrm{~mm}$ \\
\hline
\end{tabular}

Em uma análise inicial das comparações gráficas dos deslocamentos numéricos e experimentais nota-se a proximidade dos resultados numéricos obtidos para os 3 tipos de aproximações polinomiais utilizadas. Essa quase colinearidade 
pode ser explicada pelo fato de que, apesar do polinômio bi quártico apresentar uma melhor aproximação do campo de temperaturas, o fenômeno de expansão térmica é pouco sensível a variações pequenas de temperaturas. A proximidade dos resultados numéricos é verificada também nas tabelas construídas para análise dos erros, que exibe valores bastante próximos tanto de erros máximos quanto de erros RMS.

Da comparação entre os valores de deslocamentos obtidos numericamente e os resultados experimentais, nota-se que, independente do polinômio utilizado para aproximar o campo de temperaturas resultante do aquecimento, os erros calculados mostraram-se inferiores a $0.005 \mathrm{~mm}$. Esta distância relativamente pequena entre os resultados numéricos e experimentais aponta para um desempenho satisfatório da metodologia numérica avaliada.

Além disso, nota-se desta mesma comparação que os resultados obtidos para a linha (b), localizada bem ao centro da peça possuem os menores erros em comparação às outras duas. Dois fenômenos podem ter relação com essa maior precisão: O fato de que os procedimentos de regressão linear empregados, tradicionalmente, apresentarem maior dificuldade para aproximar os valores próximos às margens que limitam fisicamente a distribuição de pontos de dados; $E$ a menor precisão das leituras da câmera térmica nas regiões próximas às arestas do corpo de prova, devido a possíveis interferências causadas pela iluminação ao fundo da imagem e/ou por efeitos reflexivos do ambiente. 


\section{CONCLUSÃO}

O presente trabalho teve como objetivo inicial a verificação experimental da metodologia numérica para análise de problemas termoelásticos em regime permanente baseada no MEC. O MEC tem como característica fundamental, e maior atrativo, a solução numérica restrita ao contorno do domínio em análise. Isto limita o procedimento de discretização, requerido para o cálculo da solução numérica, ao próprio contorno. Entretanto, como apresentado, o problema termoelástico adiciona naturalmente uma integral de domínio à formulação. Para preservar as vantagens da utilização do MEC utilizou-se o MIR como ferramenta de conversão desta integral de domínio em sua equivalente no contorno.

Estabelecida a formulação numérica a ser utilizada na simulação do fenômeno termoelástico, foi elaborado um procedimento experimental para sua verificação. Neste experimento um corpo de prova retangular, fabricado em alumínio ASTM 6351, tem a sua base aquecida de maneira uniforme até que atingida a condição de regime permanente seja atingida. Os campos de temperaturas resultantes do aquecimento são adquiridos por meio de imagens térmicas enquanto ao mesmo tempo que o consequente campo de deslocamentos é avaliado por meio de um sistema de CDI.

$A$ análise por CDI requer um preparo especial da superfície a ser medida que consiste na marcação de um padrão de pequenos pontos distribuídos de forma aleatória. Em vista da influência deste padrão na qualidade da análise de deslocamentos por CDI, foi desenvolvido um equipamento de marcação CNC exclusivamente para esta tarefa. Juntamente com este equipamento foi também desenvolvida uma rotina para geração computacional dos padrões a serem marcados pelo equipamento, permitindo o controle da quantidade de pontos e garantindo padrões com distribuição homogênea. A grande quantidade de pontos físicos observados nos resultados experimentais fornecidos pela análise por CDI, e a sua distribuição relativamente homogênea indicam que as estratégias elaboradas de geração e marcação dos padrões de pontos foram bem-sucedidas.

Realizado o experimento e adquiridos os dados necessários, o próximo passo para avaliação da metodologia numérica apresentada consistiu na elaboração de um modelo numérico capaz de reproduzir as condições observadas experimentalmente. O MIR, utilizado para conversão da integral responsável pelo efeito termoelástico na formulação do MEC empregada, requer que o campo de temperaturas seja dado na 
forma de uma função. Assim sendo, foi necessário aproximar a distribuição de temperaturas obtida a partir da imagem térmica do corpo de prova adquirida em regime permanente por uma função polinomial bidimensional. Foram testadas aproximações por polinômios de três ordens distintas: bi quadrática, bi cúbica e bi quártica.

Em primeiro lugar, a boa qualidade dos resultados proporcionados pela metodologia de análise experimental proposta, com a qual foi possível obter-se os campos de deslocamentos sobre a superfície assim como o campo de temperaturas atuante de forma simultânea, evidencia seu bom desempenho, cumprindo com um dos objetivos principais estipulados.

Apesar de o polinômio de ordem mais elevada descrever uma superfície mais próxima à distribuição de temperaturas observada na câmera térmica, todas as aproximações polinomiais utilizadas resultaram em valores de deslocamentos próximos. Esta proximidade de valores pode ser atribuída ao fato de que, para este caso, a utilização de um polinômio de ordem mais elevada para descrever a distribuição de temperaturas experimental provoca uma alteração muito pequena dos valores pontuais de temperatura quando comparado a uma aproximação polinomial uma ordem abaixo, por exemplo. Além disso o fenômeno de dilatação térmica também é pouco sensível a variações muito pequenas de temperatura.

Por fim, os deslocamentos resultantes das análises numéricas foram comparados aos valores obtidos experimentalmente. A proximidade entre os resultados numéricos e experimental é evidenciada pela análise de erros realizada. Desta resultou um erro máximo inferior a $0,005 \mathrm{~mm}$, isto é, inferior a $5 \%$ do deslocamento máximo observado, o que aponta para um desempenho satisfatório da metodologia numérica apresentada.

\subsection{Propostas de Continuidade}

Com base na metodologia numérica e experimental apresentada e no equipamento desenvolvido para marcação dos padrões de superfície, abrem-se diversas oportunidades de continuação deste trabalho. Para citar algumas possibilidades: 
- Extensão da análise para o caso transiente, visto que tanto a câmera térmica quanto o equipamento de CDI empregados possuem capacidade para aquisição contínua de dados.

- Análise de diferentes topologias, como uma placa com furos e/ou inclusões de diferentes materiais por exemplo;

- Avaliação da metodologia experimental-numérica apresentada como ferramenta de caracterização de propriedades termoelásticas efetivas de materiais.

- Estudo sobre a otimização da velocidade de marcação e aplicação de técnicas para avaliação da qualidade dos padrões de pontos marcados com o equipamento de marcação CNC desenvolvido e implementação de possíveis melhorias. 


\section{REFERÊNCIAS BIBLIOGRÁFICAS}

(1) Sládek V, Sládek J. Boundary integral equation in thermoelasticity, Part I: General analysis. Applied Mathematical Modelling. 1983 Aug; 7(4):241-253.

(2) Sládek V, Sládek J. Boundary integral equation in thermoelasticity, Part III: Uncoupled thermoelasticity. Applied Mathematical Modelling. 1984 Dec; 8(6):413418.

(3) Aliabadi MH. The Boundary Element Method, Volume 2, Applications in Solids and Structures. $1^{\text {a }}$ edition. Chichester (United Kingdom). Wiley; 2002.

(4) Gao XW. The radial integration method for evaluation of domain integrals with boundary-only discretization. Engineering Analysis with Boundary Elements. 2002; 26:905-916.

(5) Yang K, Gao XW. Radial integration BEM for transient heat conduction problems. Engineering Analysis with Boundary Elements. 2010 Jun; 34(6):557-563.

(6) Yang K, Gao XW, Liu YF. Using analytical expressions in radial integration BEM for variable heat conduction problems. Engineering Analysis with Boundary Elements. 2011 Oct; 35(10):1085-1089.

(7) Gao XW. Boundary element analysis in thermoelasticity with and without internal cells. International Journal for Numerical Methods in Engineering. 2003 Jun; 57(7):975-990.

(8) Silva ML, Ravichandran G. Combined thermoelastic stress analysis and digital image correlation with a single infrared camera. Journal of Strain Analysis for Engineering Design. 2011 Nov; 46(8):783-793.

(9) Bodelot L, Sabatier L, Charkaluk E, Dufrénoy P. Experimental setup for fully coupled kinematic and thermal measurements at the microstructure scale of an AISI 316L steel. Materials Science and Engineering A. 2009 Sep; 501:52-60. 
(10) Pan B, Qian Kemao, Xie H, Asundi A. On errors of digital image correlation due to speckle patterns. Proceedings of ICEM 2008: International Conference on Experimental Mechanics; 2008 Nov 8; Nanjing, China. SPIE; 2009.

(11) Lecompte D, Sol H, Vantomme J. Analysis of speckle patterns for deformation measurements by digital image correlation. Proceedings of SPIE vol. 6341, Speckle06, From Grains to Flowers; 2006 Sep 13; Nimmes, France.

(12) Lecompte D, Smits A, Bossuyt S, Sol H, Vantomme J, Van Hemelrijck D, Habraken AM. Quality assessment of speckle patterns for digital image correlation. Optics and Lasers in Engineering. 2006 Nov; 44(11): 1132-1145.

(13) Katsikadelis JT. Boundary elements: Theory and Applications. $1^{\text {a }}$ edition. Oxford (United Kingdom). Elsevier; 2002.

(14) Banerjee P, Butterfield R. Boundary elements method in engineering science. London (United Kingdom). Mcgraw-hill; 1981.

(15) Cheng AHD, Chen CS, Goldberg MA, Rashed YF. BEM for thermoelasticity and with body force - A revisit. Engineering Analysis with Boundary elements. 2001 Apr; 25(4): 377-387.

(16) Cruse TA. Boundary integral equation method for three-dimensional elastic fracture mechanics. AFOSR-TR-75-0813, ADA 011660, Pratt and Whitney Aircraft, Connecticut.

(17) Danson DJ. A boundary element formulation for problems in linear isotropic elasticity with body forces. In: Brebbia CA, editor. Boundary Element Methods. Berlin: Springer; 1981. 105-122.

(18) Nardini D, Brebbia, CA. A new approach for free vibration analysis using boundary elements. Applied Mathematical Modelling. 1983 Jun; 7(3):157-162. 
(19) Nowak AJ, Brebbia CA. The multiple-reciprocity method. A new approach for transforming B.E.M. domain integrals to the boundary. Engineering Analysis with Boundary Elements 1989 Sep; 6(3):164-167.

(20) Neves AC, Brebbia CA. The multiple reciprocity boundary element method in elasticity: a new approach for transforming domain integral to the boundary. International Journal for Numerical Methods in Engineering. 1991 Mar; 31(4):709-27.

(21) Neves AC, Brebbia CA. The multiple reciprocity method applied to thermal stress problems. International Journal for Numerical Methods in Engineering. 1992 Mar; 35(3):443-455.

(22) Gao XW. Boundary only integral equations in boundary element analysis. Proceedings of the International Conference on Boundary Element Techniques; 16-18 Jul, 2001, Rutgers University, NJ, USA.

(23) Brebbia, CA, Domingues J. Boundary Elements: An introductory course. $2^{\mathrm{a}}$ edition. Southampton (United Kingdom). WIT Press; 1996.

(24) Buroni FC. Modelagem e projeto computacional de materiais micro-porosos com distribuição aleatória utilizando uma formulação de elementos de contorno. [dissertação de mestrado]. Porto Alegre: Universidade Federal do Rio Grande do Sul.

(25) Peters WH, Ranson WF. Digital imaging techniques in experimental stress analysis. Optical Engineering. 1982 Jun; 21(3):427-431.

(26) Sutton MA, Wolters WJ, Peters WH, Ranson WF, McNeill SR. Determination of displacements using an improved digital correlation method. Image and Vision Computing. 1983 Aug; 1(3):133-139. 
(27) Chu TC, Ranson WF, Sutton MA, Peters WH. Applications of digital-imagecorrelation techniques to experimental mechanics. Experimental Mechanics. 1985 Sep; 25(3): 232-244

(28) Scherier H, Braasch JR, Sutton MA. Systematic errors in digital image caused by intensity interpolation. Optical Engineering. 2000 Nov; 39(11):2915-2921.

(29) Souza AMR, Xavier J, Vaz M,Morais JJL, Filipe VMJ. Measurement of displacement fields with sub-pixel accuracy by combining cross-correlation and optical flow. Revista da Associação Portuguesa de Análise de Tensões. 2012; 21:101-109.

(30) Zhang D, Zhang X, Cheng G. Compression strain measurement by digital speckle correlation. Experimental Mechanics. 1999 Mar; 39(1):62-65.

(31) Zhou P, Goodson KE. Subpixel displacement and deformation gradient using digital image/speckle correlation. Optical Engineering. 2001 Aug; 40(8):16131620.

(32) Bay BK. Texture correlation - a method for the measurement of detailed strain distributions within trabecular bone. Journal of Orthopaedic research. 1995 Mar; 13(2): 258-267.

(33) Chen DJ, Chiang FP, Tan YS, Don HS. Digital speckle-displacement measurement using a complex spectrum method. Applied Optics. 1993 Apr; 32(11):1839-1849.

(34) Gaudette GR, Todaro J, Krukenkamp IB, Chiang FP. Computer aided speckle interferometry: A technique for measuring deformation of the surface of the heart. Annals of Biomedical Engineering. 2001 Sep; 29(9): 775-780.

(35) Pan B, Qian Kemao, Xie H, Asundi A. Two dimensional digital image correlation for in-plane displacement and strain measurement: A review. Measurement Science and Technology. 2009 Apr; 20(6):1-17. 
(36) Gonzales RC, Woods RE. Digital Image Processing. $2^{a}$ edition. New Jersey (United States). Prentice Hall; 2002.

(37) Lecompte D, Bossuyt S, Cooreman S, Sol H, Vantomme J. Study and generation of optimal speckle patterns for DIC. Proceedings of SEM Annual Conference \& Exposition on Experimental and Applied Mechanics; 2007 Feb 19-22; Orlando, United States.

(38) Gu G. A comparative study of random speckle pattern simulation in digital correlation. Optik - International Journal for Light and Electron Optics. 2015 Dec; 126(23): 3713-3716.

(39) Barranger Y, Doumalin P. Dupré JC, Germaneau A. Digital image correlation accuracy: Influence of kind of speckle and recording setup. EPJ web of conferences Volume 6 - ICEM 14 - 14th International Conference on Experimental Mechanics; 2010 Jul 4-9; Poitiers, France.

(40) Crammond G, Boyd SW, Dulieu-Barton JM. Speckle pattern assessment for digital image correlation. Optics and Lasers in Engineering. 2013 Dec; 51(12): 1368-1378.

(41) Ghorbani R, Matta F, Sutton MA. Full-field deformation measurement and crack mapping on confined masonry walls using digital image correlation. Experimental Mechanics. 2015 Jan; 55(1):227-243.

(42) Mazzoleni P, Zappa E, Matta F, Sutton MA. Thermo-mechanical toner transfer for high quality digital image correlation speckle patterns. Optics and Lasers in Engineering. 2015 Dec; 75: 72-80.

(43) Pan B, Huimin X, Wang Z, Qian K, Wang Z. Study on the subset size selection in digital image correlation for speckle patterns. Optics Express. 2008 May; 16(10):7037-7048. 
(44) Sato M. Modelagem de Problemas da Mecânica da Fratura e Propagação de Trincas [dissertação de mestrado]. Campinas: Universidade Estadual de Campinas, Departamento de Mecânica Computacional; 2009.

(45) Dondero A, Cisilino AP, Carella JM, Tomba JP. Effective thermal conductivity of functionally graded random micro-heterogeneous materials using representative volume element and BEM. Intenational Journal of Heat and Mass Transfer. 2011 Aug; 54(17-18): 3874-3881.

(46) Oberg M. Análise numérica via MEC e experimental via imagens térmicas para predição da condutividade térmica efetiva [trabalho de conclusão de curso]. Brasília: Universidade de Brasília, Curso de engenharia mecânica, Departamento de Engenharia Mecânica; 2013.

(47) Gao XW, Davies TG. Boundary element programming in mechanics. Cambridge. Cambridge University Press; 2002.

(48) Dominguez J. Boundary Elements in Dynamics. Computational Mechanics Publications, Elsevier Applied Sciences; 1993.

(49) Zhang ZF, Kang YL, Wang HW, Qin QH, Qiu Y, Li XQ. A novel coarse-fine scheme for digital correlation method. Measurement. 2006 Oct; 39(8): 710-718.

(50) McRoberts M. Arduino Básico. 2a edição. São Paulo. Novatec; 2015. 


\section{APÊNDICE A - DESENHO ESQUEMÁTICO DO CIRCUITO COMPLETO DO EQUIPAMENTO DE MARCAÇÃO CNC DESENVOLVIDO}

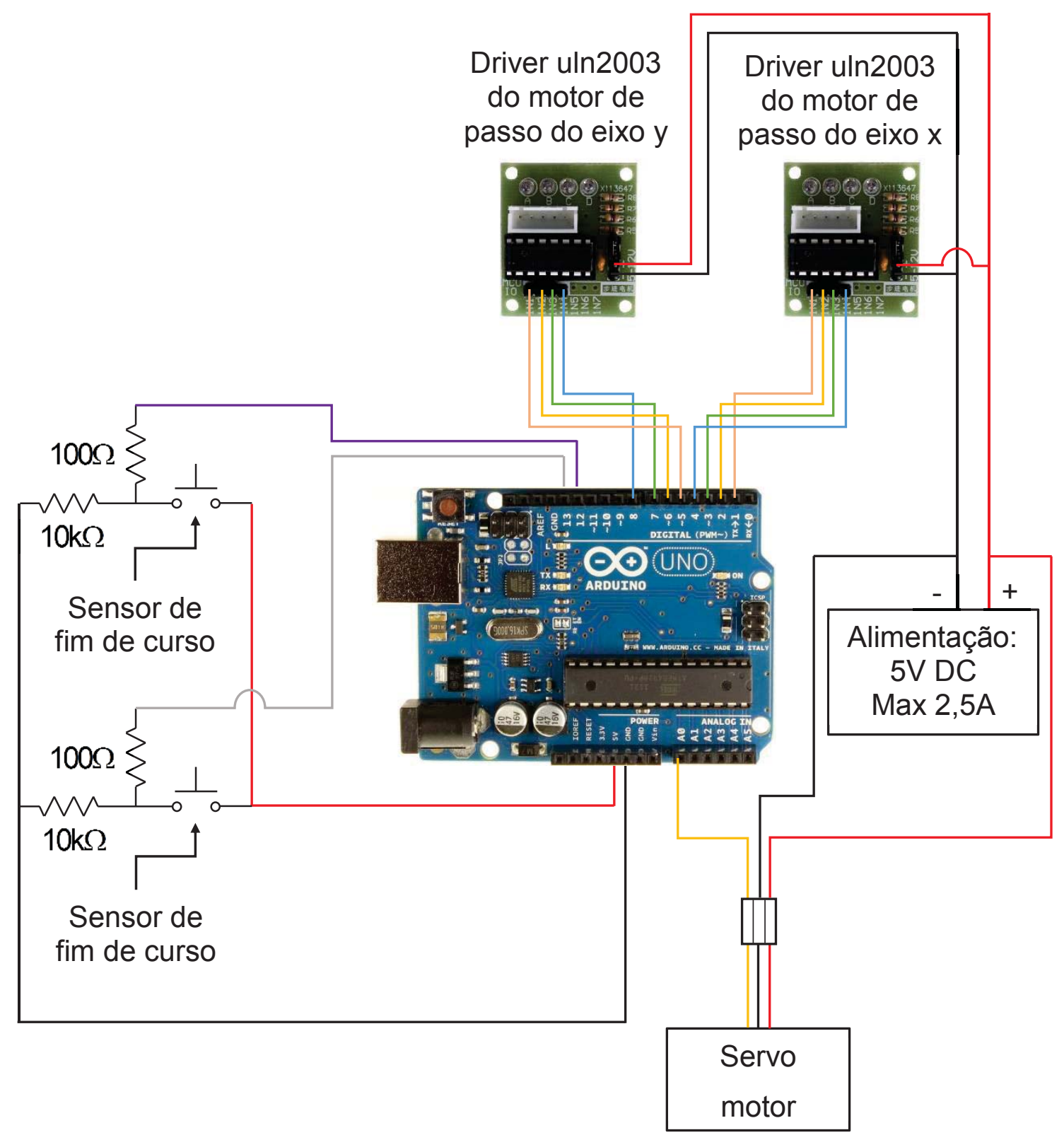

Observação: Por segurança, tanto no desenho esquemático deste circuito quanto na sua execução, adotou-se o padrão no qual fios vermelhos sempre são utilizados para para conexões com o positivo da alimentação e fios da cor preta para conexões com o negativo/terra. 


\section{APÊNDICE B - CÓDIGO PRINCIPAL DE GERAÇÃO DOS PADRÕES DE PONTOS (MATLAB)}

Observação: Este código e o código em python para envio de dados ao Arduino devem ser colocados juntos em uma mesma pasta. Isto possibilita que este código atualize diretamente a informações no código em python sempre que um novo padrão de pontos for gerado.

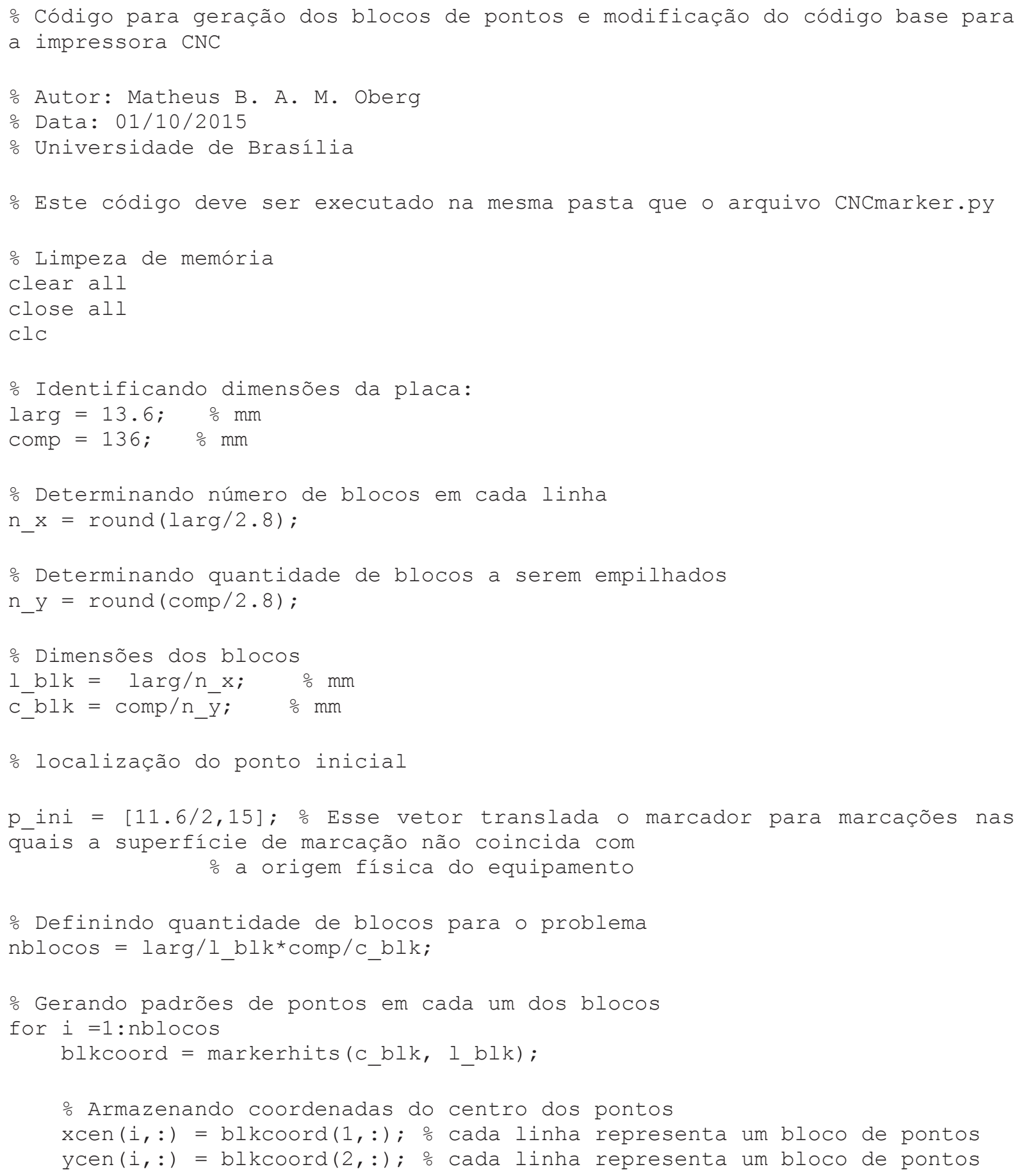




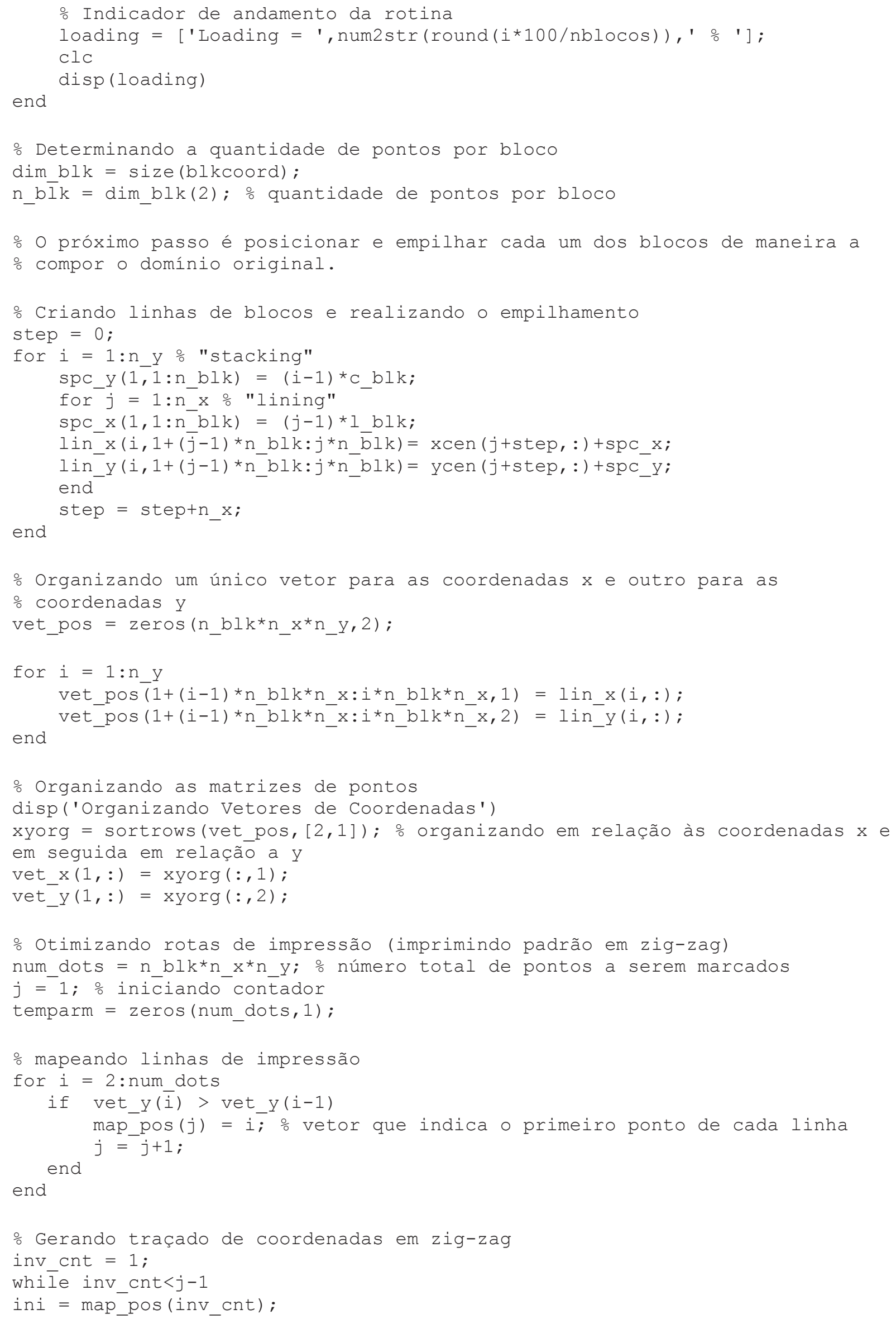




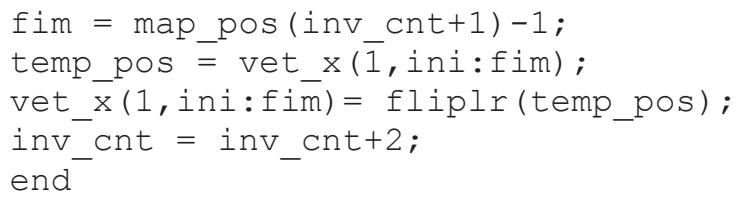




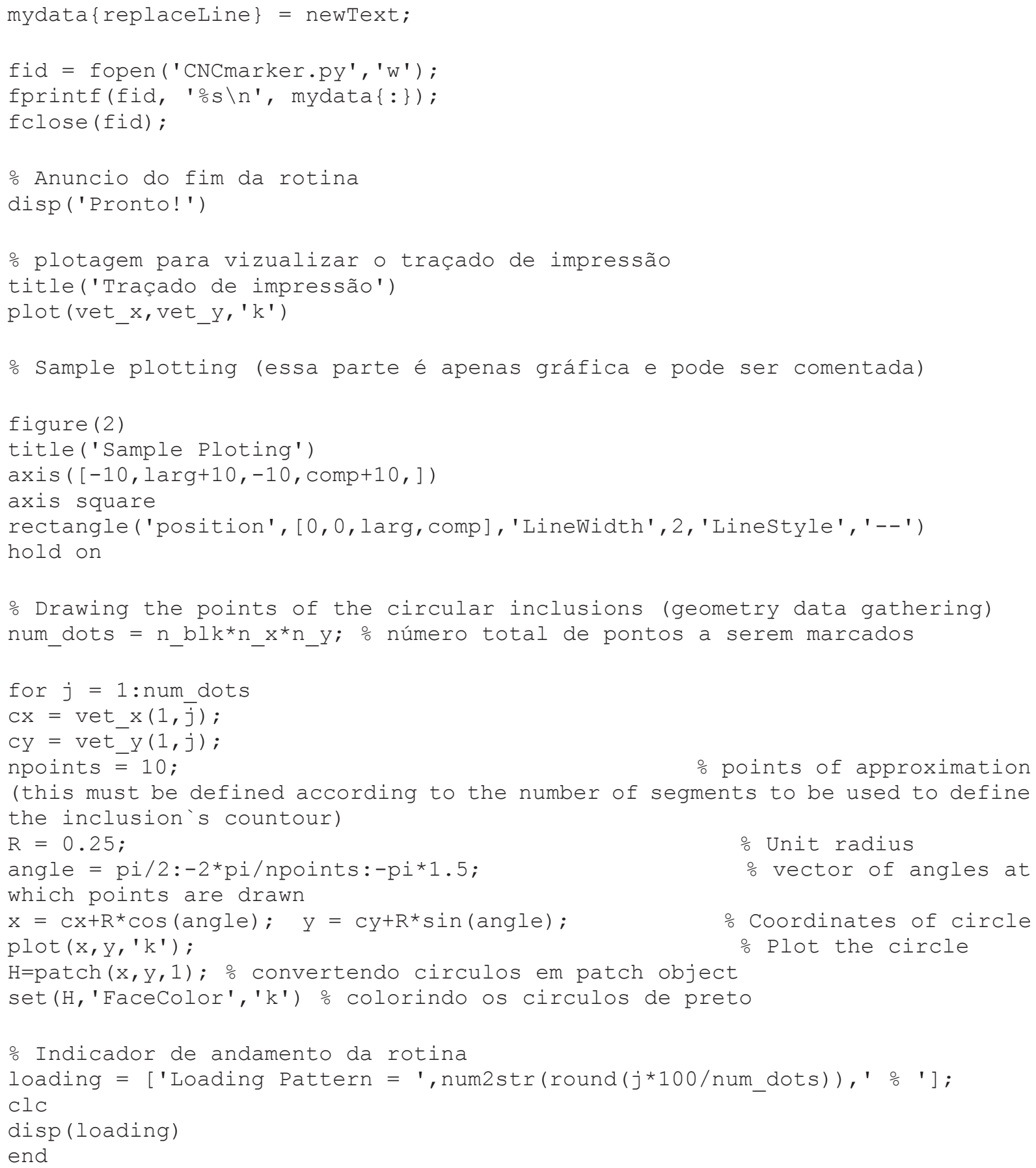




\section{APÊNDICE C - FUNÇÃO PARA GERAÇÃO E POSICIONAMENTO DOS PONTOS GERADOS (MATLAB)}

Observação: Esta função faz parte do código principal apresentado no apêndice B e, portanto, devem estar na mesma pasta para possibilitar sua execução.

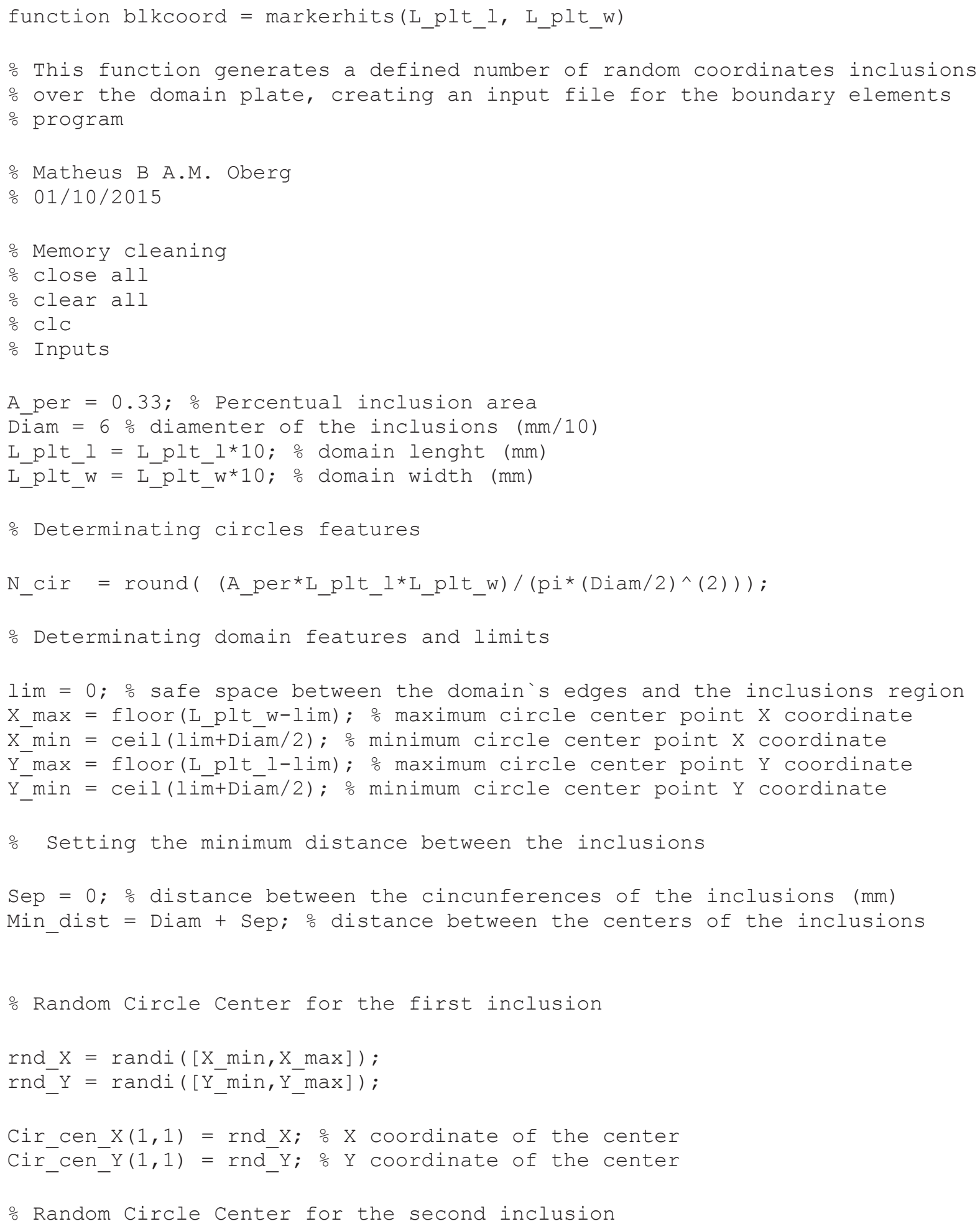




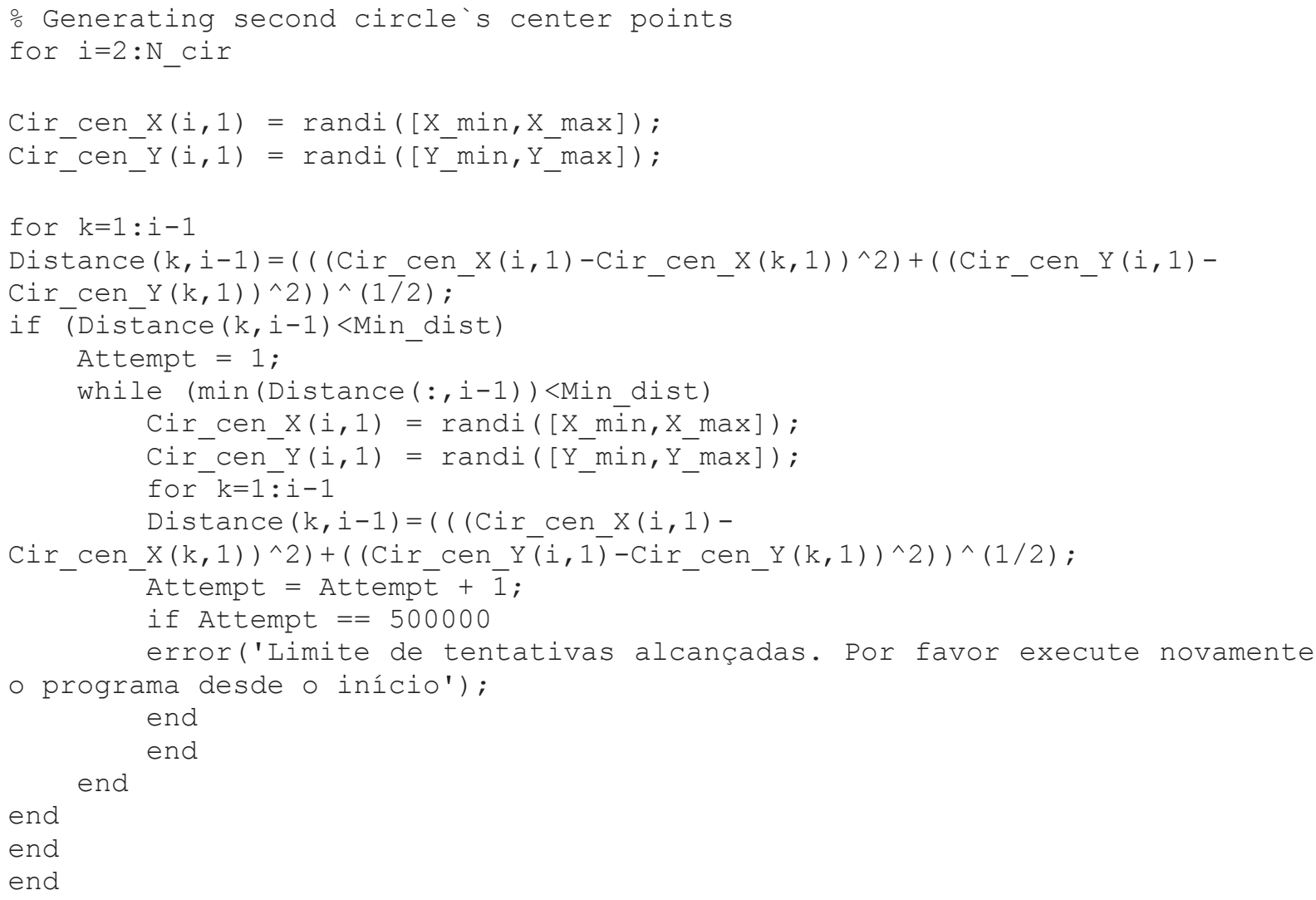




\title{
APÊNDICE D - CÓDIGO PARA CONTROLE DA MARCAÇÃO DO PADRÃO DE PONTOS (PYTHON)
}

\author{
\# CNCmarker.py \\ \# Código para controle da marcadora de pontos CNC \\ \# Autor: Matheus B. A. M. Oberg \\ \# Brasília, 05 de outubro de 2015
}

\# Código feito utilizando Python 3.5 Windows x86 e Pyserial-2.7.win32_py3.exe

\# Este código deve ser executado em conjunto com um arduino

\# carregado com o arquivo CNCmarker_python.ino.

import serial

import time

data = ' 0 ' \# iniciando variável data

ret $=0$ \# iniciando variável ret

$\mathrm{i}=0$ \# iniciando contador $\mathrm{i}$

\# As duas linhas de código a seguir carregam as informações a serem passadas ao \# Arduino e são escritas diretamente pelo código de geração de padrões de pontos \# apresentado no apêndice $B$.

vetx $=[]$

vety $=[]$

dim_vet = len(vetx) \# determinando a quantidade de pontos

\# Estabelecendo comunicação serial

\# estabelecendo comunicação via porta serial 'COM3'

\# Baudrate $=115200$ e limite para timeout $=30 \mathrm{~s}$

arduino $=$ serial.Serial $($ 'COM3', 115200, timeout=30)

\# Dando tempo para que a comunicação seja estabelecida corretamente time.sleep(2)

ready = arduino.read(100) \# lendo resposta inicial do Arduino \# imprime mensagem para indicar que a comunicação está estabelecida 


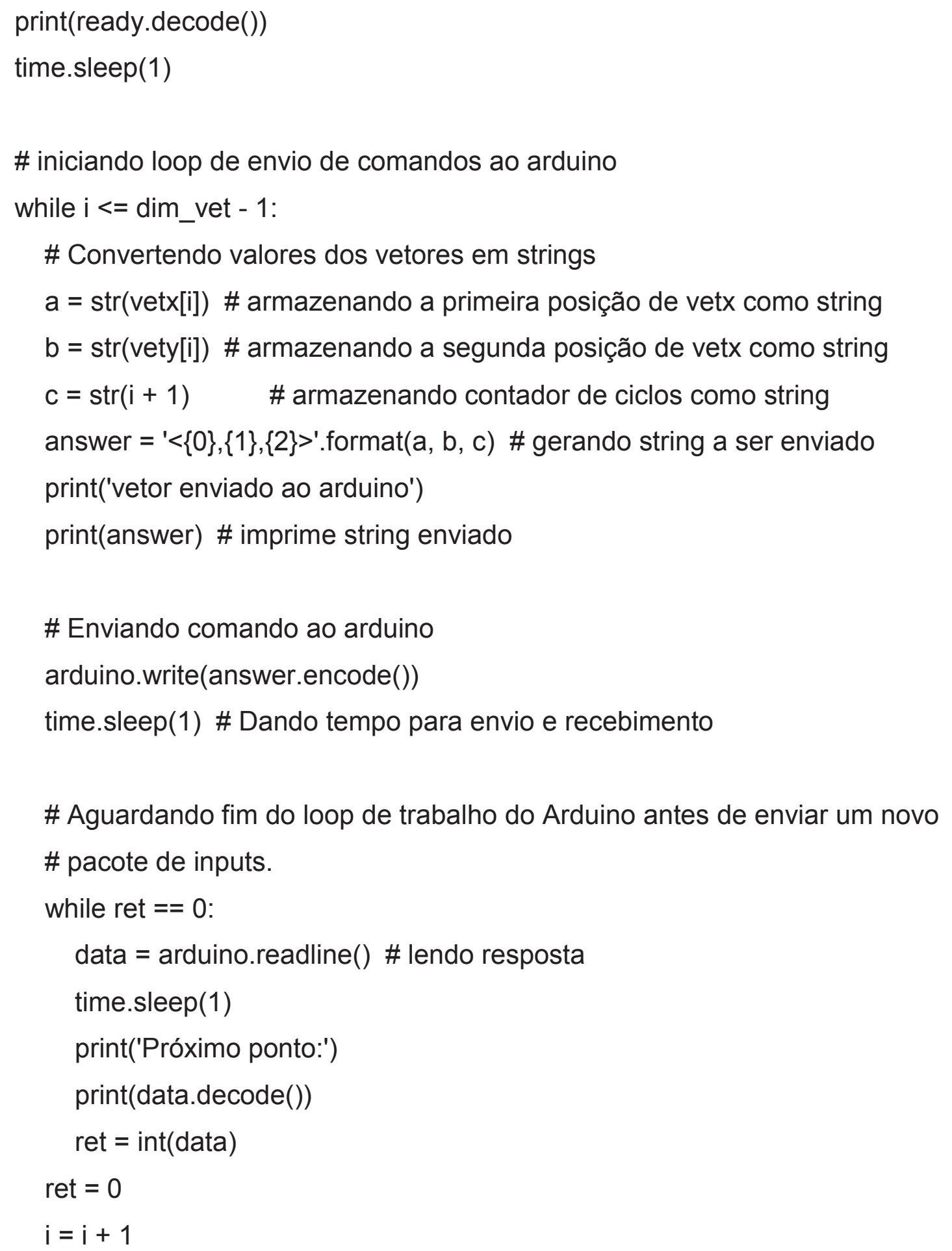




\section{APÊNDICE E - CÓDIGO DE MARCAÇÃO DO EQUIPAMENTO DE MARCAÇÃO CNC DESENVOLVIDO (ARDUINO)}

// CNCmarker_python.ino

// Código para controle da marcadora de pontos CNC para preparação de corpos de prova para análises com DIC

// Autor: Matheus B. A. M. Oberg

// Brasília, 05 de outubro de 2015

// Este código deve ser executado em conjunto com o arquivo CNCmarker.py que controla seu funcionamento

\#include <AccelStepper.h>

\#include $<$ Servo.h>

\#define HALFSTEP 8

// Motor pin definitions

\#define motorPin1 2 // IN1 on the ULN2003 driver 1

\#define motorPin2 3 // IN2 on the ULN2003 driver 1

\#define motorPin3 4 // IN3 on the ULN2003 driver 1

\#define motorPin4 5 // IN4 on the ULN2003 driver 1

// Motor pin definitions 2

\#define motorPin5 $6 \quad$ // IN1 on the ULN2003 driver 2

\#define motorPin6 7 // IN2 on the ULN2003 driver 2

\#define motorPin7 8 // IN3 on the ULN2003 driver 2

\#define motorPin8 9 // IN4 on the ULN2003 driver 2

// Inicializando com pin sequence IN1-IN3-IN2-IN4 para utilizar a biblioteca AccelStepper com 28BYJ-48

AccelStepper eixox(HALFSTEP, motorPin1, motorPin3,motorPin2, motorPin4); // stepper que controla o movimento no eixo $x$

AccelStepper eixoy(HALFSTEP, motorPin5,motorPin7,motorPin6,motorPin8); // stepper que controla o movimento no eixo y 
// Declarando servo controlador do marcador permanente int pin_servo $=14$; // pin analogico int curso_marker; // variavel de curso do servo Servo servo_marker; // Servo NomeDoServo

// Declarando sensores de fim de passo int end $\mathrm{x}=12$; / pino do botao do eixo $\mathrm{x}$ int val_x; // sinal recebido pelo botão do eixo $x$ int endy = 13; // pino do botao do eixo $y$ int val_y; // sinal recebido pelo botão do eixo y

// Definindo variaveis relativas ao recebimento e interpretação de dados seriais char inData[50]; // buffer dos dados transmitidos via serial char* valPosition; // variável do tipo ponteiro utilizada para armazenar o "parsing" do input serial

char delims[ = ","; // delimitador utilizado para separar o dado serial int interm[3] $=\{0,0,0\} ; / /$ vetor que armazena input serial já separado int vetx; // input serial resultante para o motor de passo do eixo $\mathrm{x}$ int vety; // input serial resultante para o motor de passo do eixo $y$ int num; // input serial com a numeração do pacote enviado int $\mathrm{i}=0$; // iniciando variavel contadora byte index; // índice dos pacotes de bytes \#define SOP ' $<$ ' // indica o início de um pacote de dados \#define EOP ' $>$ ' // indica o fim do pacote de dados bool started = false; // avaliador da leitura do pacote bool ended = false; // avaliador da leitura do pacote

int check $=1$; // iniciando um contador int loopcount =1; // iniciando contador de loops de execução

// controle do estado dos motores (movendo/parado) boolean moving_x = true; boolean moving_y = true; 
void $\operatorname{setup}()\{$

// iniciando sensores fim de curso e botão start

pinMode(endx, INPUT);

pinMode(endy,INPUT);

// iniciando servo motor

servo_marker.attach(pin_servo);

// parâmetros do stepper que controla o movimentos dos motores de passo eixox.setMaxSpeed(1000.0); // velocidade máxima do stepper eixox.setAcceleration(300.0); // aceleração padrão do stepper eixox.setSpeed(-900); // velocidade utilizada para setup inicial

eixoy.setMaxSpeed(1000.0);

eixoy.setAcceleration(300.0);

eixoy.setSpeed(-900);

// resetando eixo $x$

while (val_x!= HIGH)\{

val_x = digitalRead(endx);

eixox.runSpeed();

\}

eixox.stop(); // comando para parada imediata

// o valor abaixo define o ponto inicial do eixo $x$

eixox.move(600); // afastando o carro do sensor de fim de curso

eixox.runToPosition();

// resetando posição do eixo y

while (val_y != HIGH)\{

val_y = digitalRead(endy);

eixoy.runSpeed();

\}

eixoy.stop(); // comando para parada imediata

// o valor abaixo define o ponto inicial do eixo y 
eixoy.move(520); // afastando o carro do sensor de fim de curso eixoy.runToPosition();

// Iniciando servo do marcador

// condição inicial: marcador recuado

curso_marker $=75$;

servo_marker.write(curso_marker);

// Avisa ao pc que o arduino está pronto

Serial.begin(115200); // abrindo comunicação serial delay(2500);

memset(inData, '10', 50); // preparando variavel inData que armazena os dados recebidos

Serial.println("<Arduino pronto>");

delay (1000);

delay $(0)$;

\}

void $\operatorname{loop}()\{$

// garantindo que o pacote seja lido pro inteiro

// salvando dados recebidos via seria no buffer

while (Serial.available ()$>0)\{$

char inChar = Serial.read();

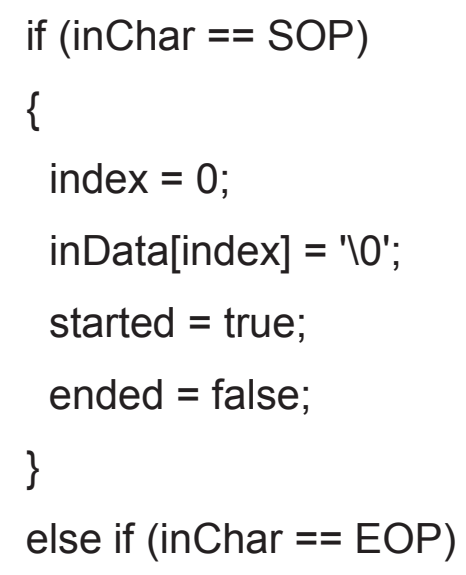




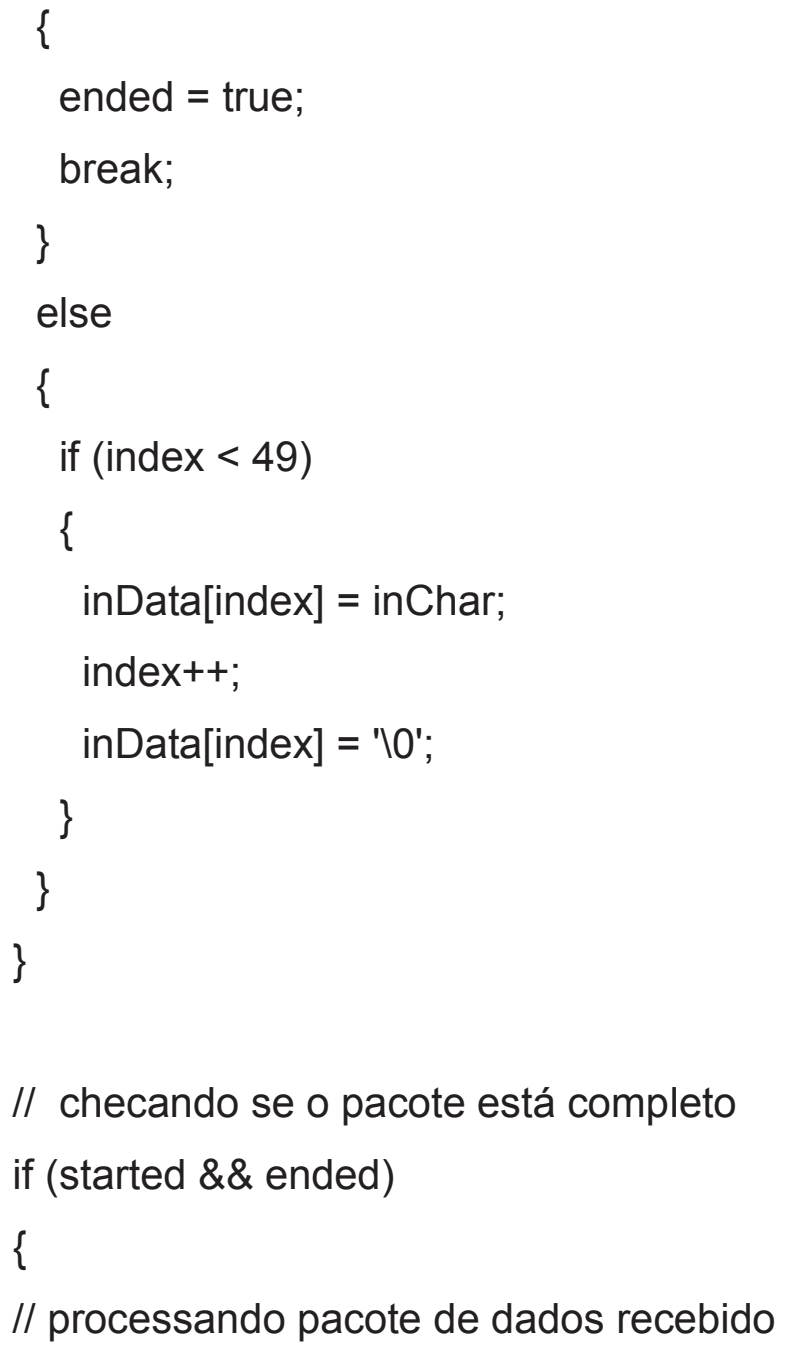




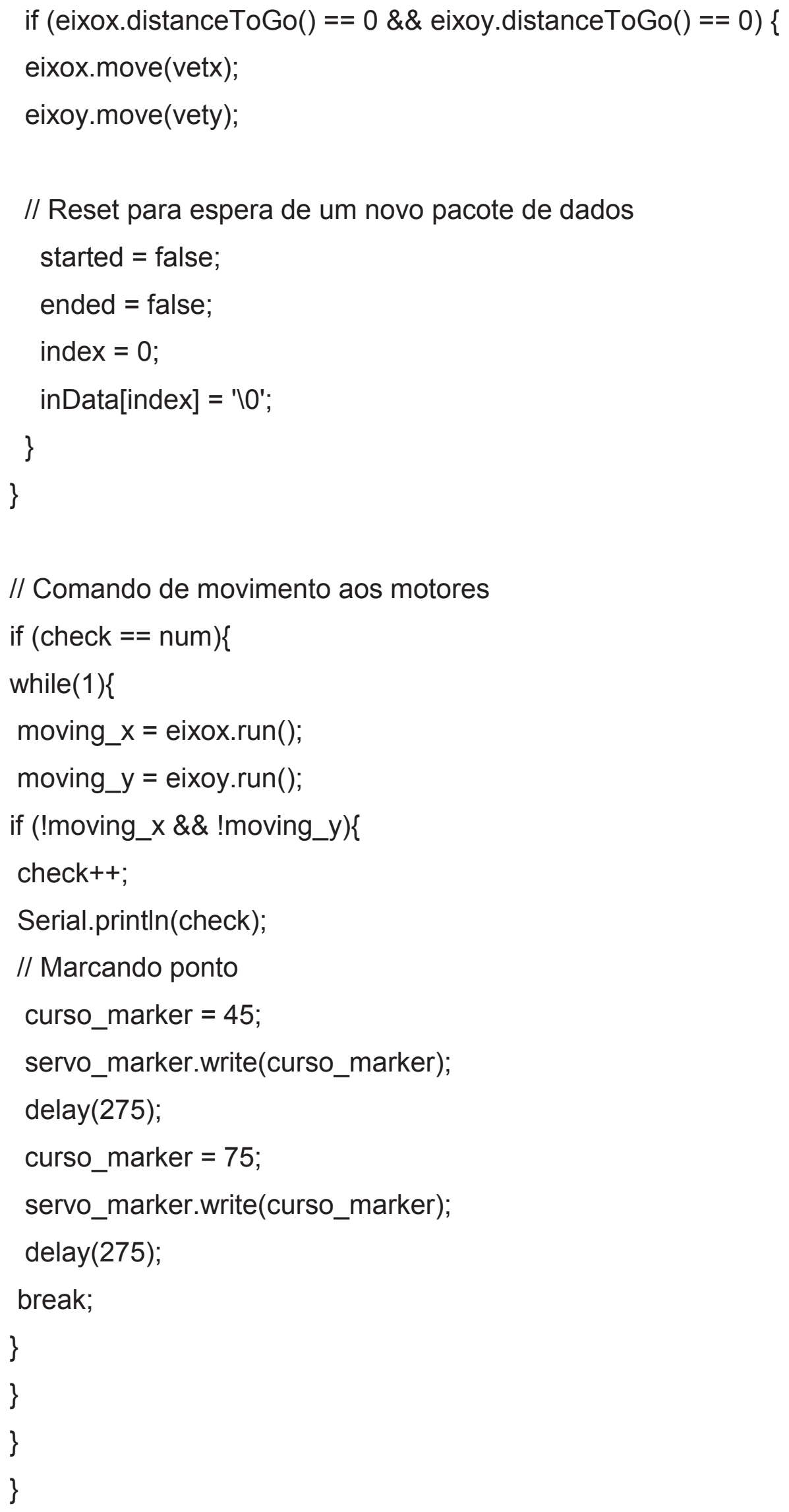




\section{APÊNDICE F - CONVERSÃO DE EQUAÇÕES POLINOMIAIS BIDIMENSIONAIS DO SISTEMA CARTESIANO PARA O SISTEMA POLAR LOCAL}

Neste trabalho foram utilizados polinômios bidimensionais de ordens bi quadrática, bi cúbica e bi quártica. A ferramenta de regressão utilizada, própria do MATLAB, fornece funções polinomiais, de ordem selecionável, cuja superfície descrita aproxima o campo descrito por uma distribuição de valores pontuais. Para utilização destas funções no MIR, é necessário converter o polinômio, obtido inicialmente no sistema de coordenadas cartesiano $\left[\mathrm{X}_{1}, \mathrm{X}_{2}\right]$, para um sistema de coordenadas local $\left[x^{p}, r\right]$, definido pela posição do ponto fonte, $x^{p}$, e distância entre o ponto fonte e o

ponto campo, r. Esta conversão permite a avaliação analítica da equação (3.19), aumentando a eficiência computacional do método proposto.

O procedimento de conversão é regido pelas relações exibidas nas equações (3.29) a (3.31), apresentadas em Gao (2002) [4] e Gao (2003) [7] e repetidas a seguir:

$$
\begin{gathered}
x_{i}=x_{i}^{p}+r_{i} \\
r_{i}=r_{, i} \cdot r \\
x_{i}=x_{i}^{p}+r_{, j} \cdot r
\end{gathered}
$$

Os polinômios bi quadrático $\left(P_{2}\right)$, bi cúbico $\left(P_{3}\right)$ e bi quárticos $\left(P_{3}\right)$ fornecidos pela ferramenta de regressão utilizada são do tipo:

$$
\begin{gathered}
P_{2}=A_{00}+A_{10} x_{1}+A_{01} x_{2}+A_{20} x_{1}^{2}+A_{11} x_{1} x_{2}+A_{02} x_{2}^{2} \\
P_{3}=P_{2}+A_{30} x_{1}^{3}+A_{21} x_{1}^{2} x_{2}+A_{12} x_{1} x_{2}^{2}+A_{03} x_{2}^{3} \\
P_{4}=P_{3}+A_{40} x_{1}^{4}+A_{31} x_{1}^{3} x_{2}+A_{22} x_{1}^{2} x_{2}^{2}+A_{13} x_{1} x_{2}^{3}+A_{04} x_{2}^{4}
\end{gathered}
$$


Substituindo-se a expressão apresentada na equação (3.31) na equação (7.1)

$$
\mathrm{P}_{2}=\mathrm{B}_{0}^{2}+\mathrm{B}_{1}^{2} \mathrm{r}+\mathrm{B}_{2}^{2} \mathrm{r}^{2}
$$

Com:

$$
\begin{gathered}
B_{0}^{2}=A_{00}+A_{10} x_{1}^{p}+A_{20}\left(x_{1}^{p}\right)^{2}+A_{01} x_{2}^{p}+A_{02}\left(x_{2}^{p}\right)^{2} \\
B_{1}^{2}=r_{, x_{1}}\left(A_{10}+2 A_{20} x_{1}^{p}\right)+r_{, x_{2}}\left(A_{10}+2 A_{20} x_{1}^{p}\right)+A_{11}\left(r_{, x_{1}} x_{2}^{p}+r_{, x_{2}} x_{1}^{p}\right) \\
B_{2}^{2}=r_{, x_{1}}^{2} A_{20}+r_{, x_{2}}^{2} A_{02}+r_{, x_{1}, x_{2}} A_{11}
\end{gathered}
$$

Repetindo este procedimento para a equação (7.2):

$$
P_{3}=B_{0}^{3}+B_{1}^{3} r+B_{2}^{3} r^{2}+B_{3}^{3} r^{3}
$$

No qual:

$$
\begin{gathered}
B_{0}^{3}=A_{00}+A_{10} x_{1}^{p}+A_{20}\left(x_{1}^{p}\right)^{2}+A_{30}\left(x_{1}^{p}\right)^{3}+A_{01} x_{2}^{p}+A_{02}\left(x_{2}^{p}\right)^{2}+\ldots \\
\ldots+A_{03}\left(x_{2}^{p}\right)^{3}+x_{1}^{p} x_{2}^{p}\left(A_{21} x_{1}^{p}+A_{12} x_{2}^{p}\right) \\
B_{1}^{3}=r_{, x_{1}}\left(A_{10}+2 A_{20} x_{1}^{p}+3 A_{30}\left(x_{1}^{p}\right)^{2}\right)+r_{, x_{2}}\left(A_{10}+2 A_{20} x_{1}^{p}+3 A_{03}\left(x_{2}^{p}\right)^{2}\right)+\ldots \\
\ldots+A_{12}\left(x_{2}^{p}\right)^{2} r_{, x_{1}}+A_{21}\left(x_{1}^{p}\right)^{2} r_{, x_{2}}+A_{11}\left(r_{x_{1}} x_{2}^{p}+r_{, x_{2}} x_{1}^{p}\right) \\
B_{2}^{3}=r_{, x_{1}}^{2}\left(A_{20}+3 A_{30} x_{1}^{p}\right)+r_{, x_{2}}^{2}\left(A_{02}+3 A_{03} x_{2}^{p}\right)+\ldots \\
\ldots+2 r_{, x_{1}, x_{2}} r_{21}\left(A_{21} x_{1}^{p}+A_{12} x_{2}^{p}\right)+A_{12} x_{1}^{p} r_{, x_{2}}+A_{21} x_{2}^{p} r_{x_{1}}+A_{11} r_{, x_{1}} r_{x_{2}} \\
B_{3}^{3}=A_{03} r_{, x_{2}}^{3}+A_{30} r_{, x_{1}}^{3}+r_{x_{1}} r_{x_{2}}\left(A_{21} r_{x_{1}}+A_{21} r_{x_{2}}\right)
\end{gathered}
$$

Por fim, para o polinômio bi quártico da equação (7.3): 


$$
P_{4}=P_{3}+B_{0}^{4}+B_{1}^{4} r+B_{2}^{4} r^{2}+B_{3}^{4} r^{3}+B_{4}^{4} r^{4}
$$

\section{Para:}

$$
\begin{aligned}
& B_{0}^{4}=A_{40}\left(x_{1}^{p}\right)^{4}+A_{04}\left(x_{2}^{p}\right)^{4}+A_{31}\left(x_{1}^{p}\right)^{3} x_{2}^{p}+A_{13}\left(x_{2}^{p}\right)^{3} x_{1}^{p}+A_{22}\left(x_{1}^{p}\right)^{2}\left(x_{2}^{p}\right)^{2} \\
& B_{1}^{4}=4\left[A_{40}\left(x_{1}^{p}\right)^{4} r_{, x_{1}}+A_{04}\left(x_{2}^{p}\right)^{4} r_{, x_{2}}\right]+A_{31}\left[3\left(x_{1}^{p}\right)^{2} x_{2}^{p} r_{x_{1}}+\left(x_{1}^{p}\right)^{3} r_{, x_{2}}\right]+\ldots \\
& \ldots+A_{13}\left[3\left(x_{2}^{p}\right)^{2} x_{1}^{p} r_{, x_{2}}+\left(x_{2}^{p}\right)^{3} r_{, x_{1}}\right]+A_{22}\left[2 r_{, x_{2}}\left(x_{1}^{p}\right)^{2} x_{2}^{p}+2 r_{, x_{1}}\left(x_{2}^{p}\right)^{2} x_{1}^{p}\right] \\
& B_{2}^{4}=6\left[A_{40}\left(x_{1}^{p}\right)^{2} r_{, x_{1}}^{2}+A_{04}\left(x_{2}^{p}\right)^{2} r_{, x_{2}}^{2}\right]+A_{31}\left[3\left(x_{1}^{p}\right)^{2} r_{, x_{1}} r_{x_{2}}+3 x_{1}^{p} x_{2}^{p} r_{, x_{1}}^{2}\right]+\ldots \\
& \ldots+A_{13}\left[3\left(x_{2}^{p}\right)^{2} r_{, x_{1}, x_{2}} r_{2}+3 x_{1}^{p} x_{2}^{p} r_{, x_{2}}^{2}\right]+A_{22}\left[\left(x_{1}^{p}\right)^{2} r_{, x_{2}}^{2}+4 x_{1}^{p} x_{2}^{p} r_{, x_{1}, x_{2}} r_{2}+\left(x_{2}^{p}\right)^{2} r_{, x_{1}}^{2}\right] \\
& B_{3}^{4}=4\left(A_{40} x_{1}^{p} r_{, x_{1}}^{3}+A_{04} x_{2}^{p} r_{, x_{2}}^{3}\right)+A_{31}\left[3\left(x_{1}^{p}\right)^{2} r_{, x_{1}} r_{x_{2}}+x_{2}^{p} r_{, x_{1}}^{3}\right]+\ldots \\
& +A_{13}\left[3\left(x_{2}^{p}\right)^{2} r_{, x_{1}} r_{x_{2}}+x_{1}^{p} r_{, x_{2}}^{3}\right]+A_{22}\left[2 x_{1}^{p} r_{, x_{1}} r_{, x_{2}}^{2}+2 x_{2}^{p} r_{, x_{2}} r_{, x_{1}}^{2}\right] \\
& B_{4}^{4}=A_{40} r_{, x_{1}}^{4}+A_{04} r_{, x_{2}}^{4}+A_{31} r_{, x_{1}}^{3} r_{x_{2}}+A_{13} r_{, x_{2}}^{3}, r_{,}+A_{2}{ }_{22} r_{, x_{1}}^{2} r_{, x_{2}}^{2}
\end{aligned}
$$

